\title{
ADOPTION OF DIGITAL TECHNOLOGY IN THE NEW ZEALAND MOTION PICTURE INDUSTRY
}

\author{
by \\ Rachel Gwendoline McInnes
}

A thesis submitted to Victoria University of Wellington in partial fulfilment of the requirements for the degree of Master of Management Studies in Technology.

July 1997 


\section{ACKNOWLEDGEMENTS}

I would first like to thank the organisations that participated in this study; their honest responses were appreciated. Thanks also to the many industry members who helped with advice and resources.

Thanks to my supervisors Bob Cavana and Dai Gilbertson for their advice and support. Also thanks Ruud Frambach, Russell Campbell, Pete Smith, and the staff at Statistics New Zealand, for their specialist knowledge.

A special thanks to Blair, Bronwyn, Michelle and the Clan McInnes for continued moral support (and cooked dinners) which I have learnt never to underestimate.

I would like to acknowledge the convenors of the Sarah Anne Rhodes Fellowship for their much appreciated recognition and financial support.

Last but not least, a huge thanks to my army of proof readers. 


\begin{abstract}
This research applies Frambach's integrated model of the adoption and diffusion of innovations to the adoption of digital technology in the New Zealand motion picture industry. Previous models concerning innovation adoption have typically focused on adopter side variables. The model employed here integrates supply-side variables with the adopter-side variables focused on in traditional research. This research extends Frambach's model to consider the time and extent of adoption. The model is tested through a mail-out survey. Tests of associations between dependent and independent variables are carried out through four measures of association in a bivariate fashion. The results show that supply-side and adopter-side variables are both important influencers of the extent of adoption of digital technology in the motion picture industry. However supply-side factors do not appear to be important determinants of the time of adoption of digital technology in this industry.
\end{abstract}




\section{IMPORTANT DISCLAIMER}

1. Victoria University of Wellington and its Council, its members, staff, employees, students and agents undertake no duty of care in contract, tort, or otherwise, to users (whether direct or indirect) of this "Adoption of Digital Technology in the New Zealand Motion Picture Industry", and make no warranties of representations of any kind whatsoever in relation to any of its contents.

2. "Adoption of Digital Technology in the New Zealand Motion Picture Industry" is only made available on the basis that all users of it, whether direct or indirect, must take appropriate legal or other expert advice in relation to their own circumstances and must rely solely on their own judgement and such legal or other expert advice.

3. Under no circumstances will Victoria University of Wellington and its Council, its members, staff, employees, students and agents be liable in any way whatsoever, whether in contract, tort (including negligence) for breach of statutory or regulatory duty (to the fullest extent permissible by law), or otherwise to any user (whether direct or indirect) of this "Adoption of Digital Technology in the New Zealand Motion Picture Industry" for any loss or damage whatsoever arising directly or indirectly as a result of the use in any way of this "Adoption of Digital Technology in the New Zealand Motion Picture Industry".

4. Each exclusion in the clauses of this disclaimer and each protection given by it is to be construed as a separate exclusion applying and surviving even if for any reason any of the exclusions or protections are held inapplicable in any circumstance. 
1. INTRODUCTION ............................................................................................................................................. 1

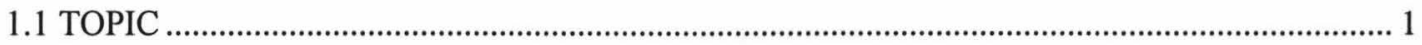

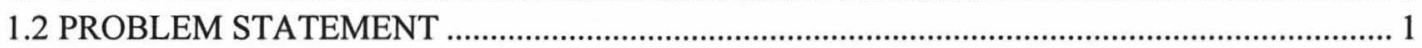

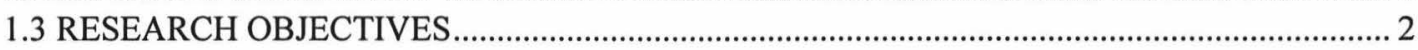

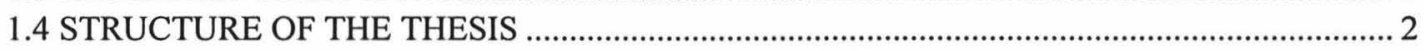

2. BACKGROUND TO THE INDUSTRY AND THE TECHNOLOGY ......................................... 4

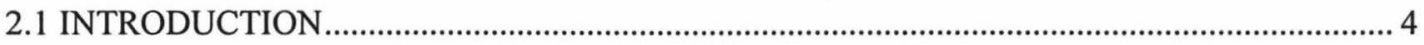

2.2 NEW ZEALAND MOTION PICTURE INDUSTRY ................................................................... 4

2.2.1 Introduction

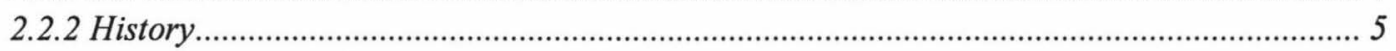

2.2.3 Organisations in the Industry and Their Roles ................................................................... 6

2.2.4 Previous Studies of the NZ Motion Picture Industry........................................................... 10

2.3 MOTION PICTURE INDUSTRY TECHNOLOGIES ............................................................. 16

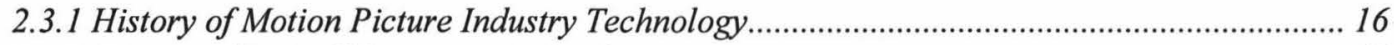

2.3.2 History of Digital/Computer Technology ........................................................................ 17

2.3.3 Digital Technology in the Motion Picture Industry ........................................................ 19

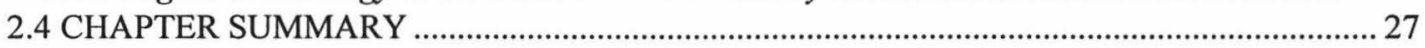

3. METHODOLOGICAL FRAMEWORK ................................................................................. 28

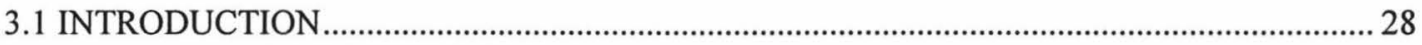

3.2 REVIEW OF ADOPTION AND DIFFUSION LITERATURE ................................................. 28

3.2.1 Concepts and Ideas in Adoption and Diffusion Literature ................................................ 29

3.2.2 Variance Versus Process Research ............................................................................... 41

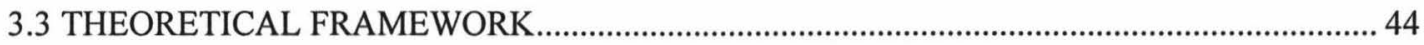

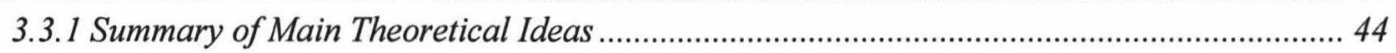

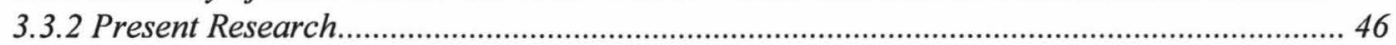

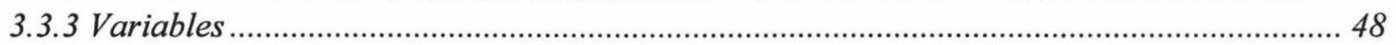

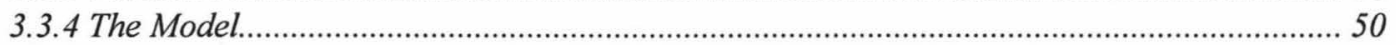

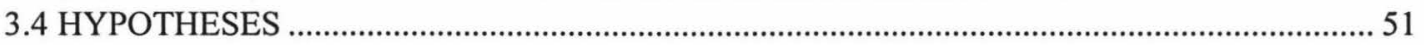

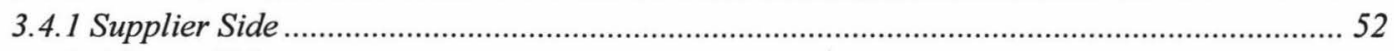

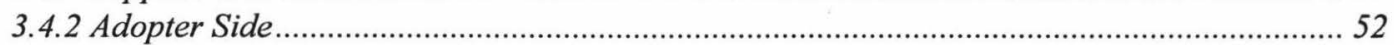

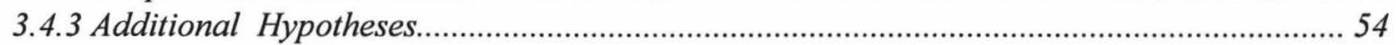

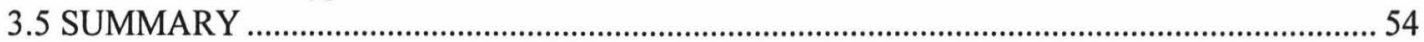

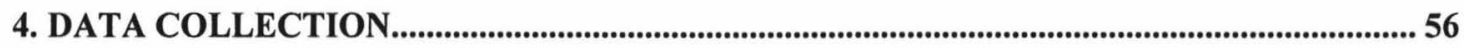

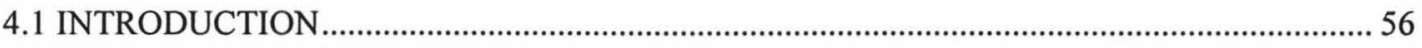

4.2 EXPLORATORY/QUALITATIVE RESEARCH ………………………………................... 56

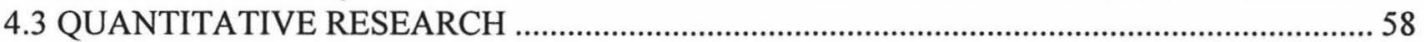

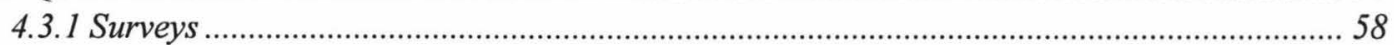

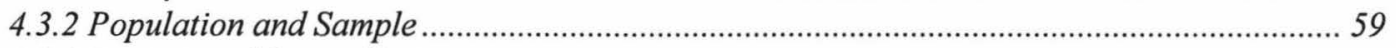

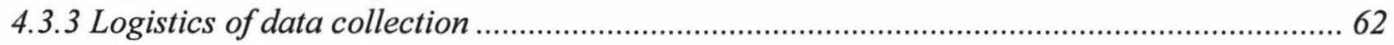

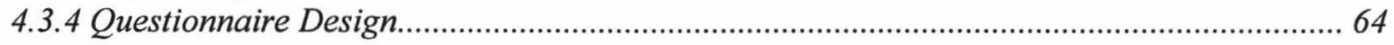

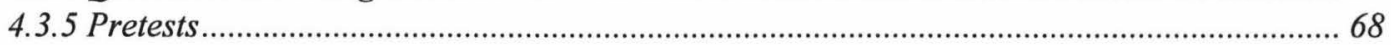

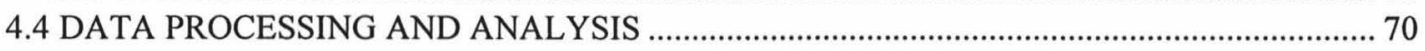

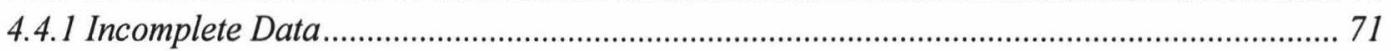

4.4.2 Coding/Analysis Packages .................................................................................................. 71

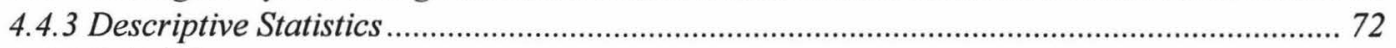

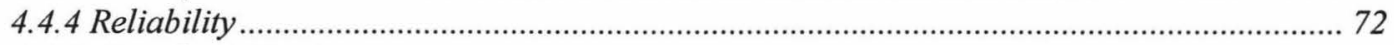

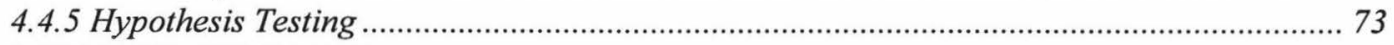

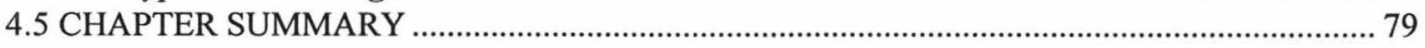

5. RESULTS - DESCRIPTIVE STATISTICS ............................................................................... 81

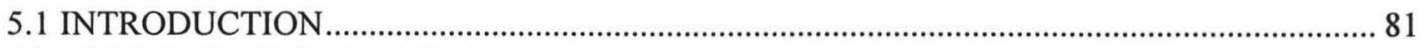

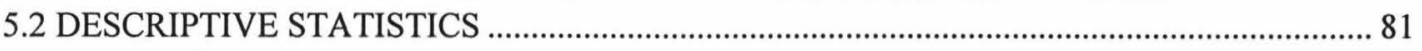

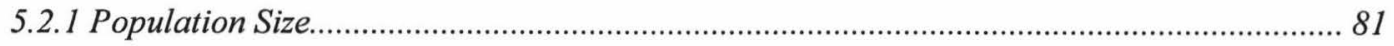

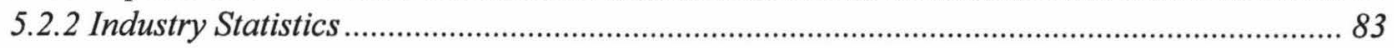




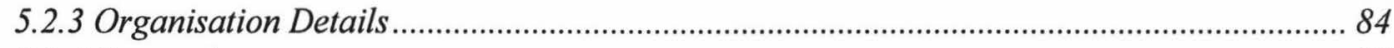

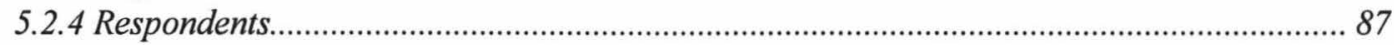

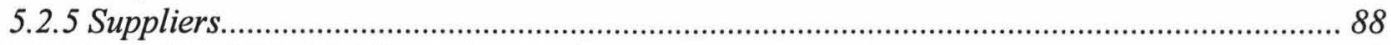

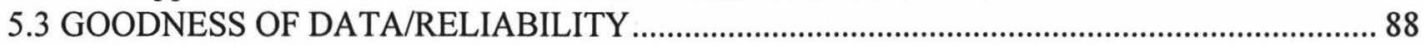

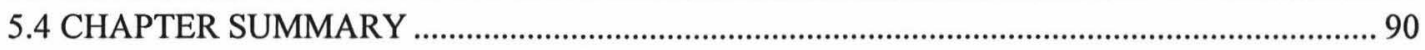

6. RESULTS - HYPOTHESES TESTING ............................................................................. 92

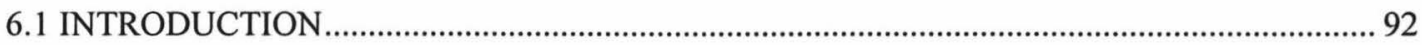

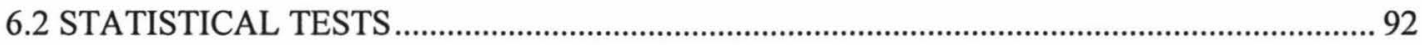

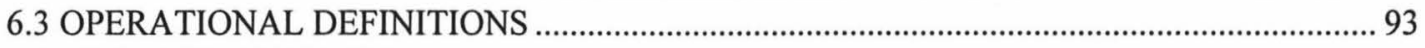

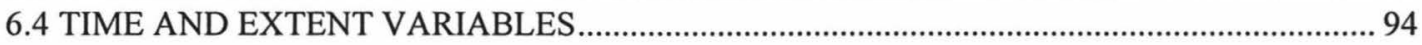

6.4.1 Extent Elements................................................................................................................. 95

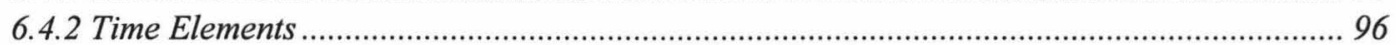

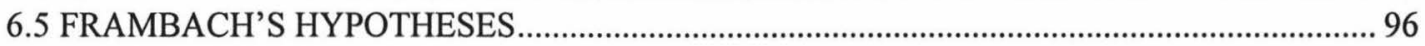

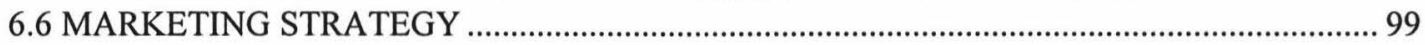

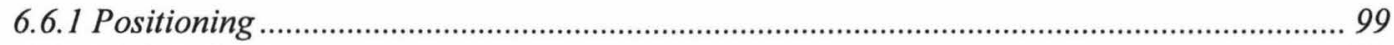

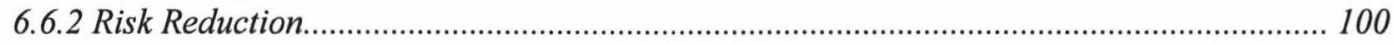

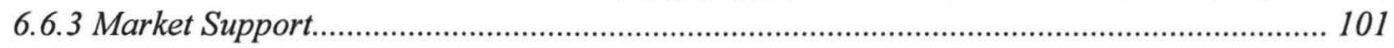

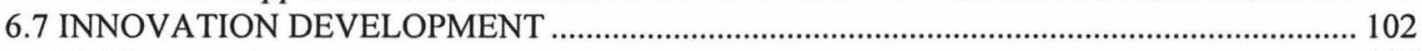

6.7.1 Perceived Customisation ...................................................................................................... 102

6.8 PERCEIVED INNOVATION CHARACTERISTICS........................................................... 103

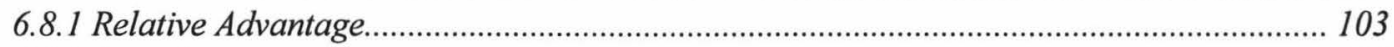

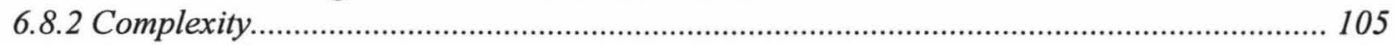

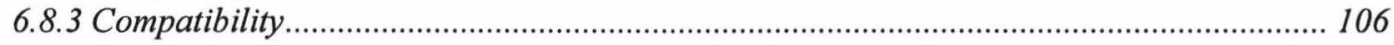

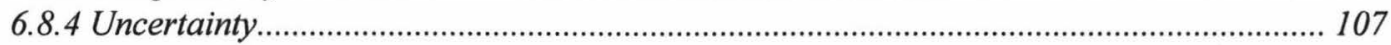

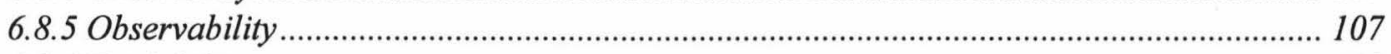

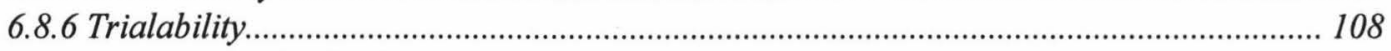

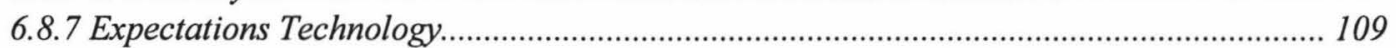

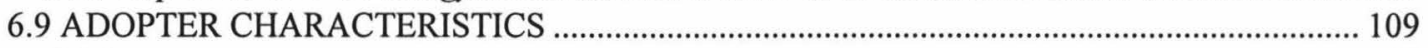

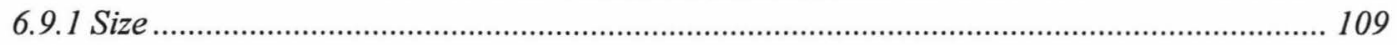

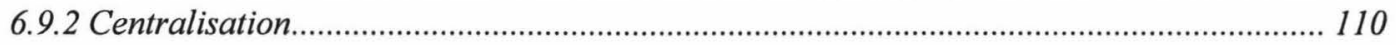

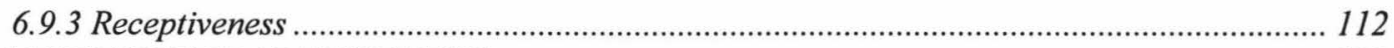

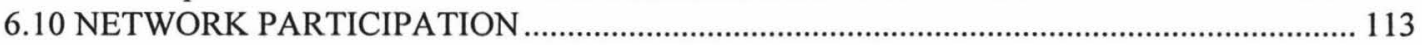

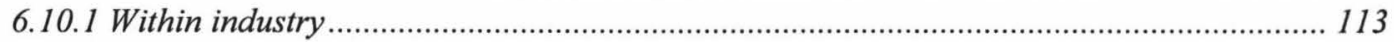

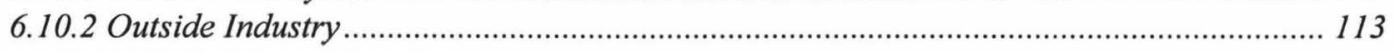

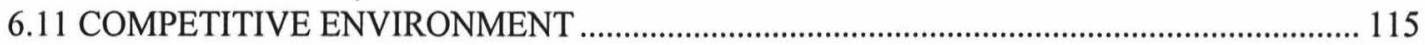

6.11.1 Intensity of Competition ............................................................................................... 115

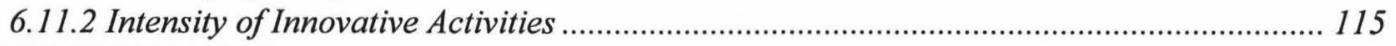

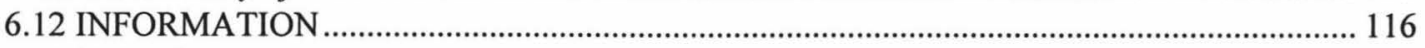

6.12.1 Information processing .................................................................................................. 116

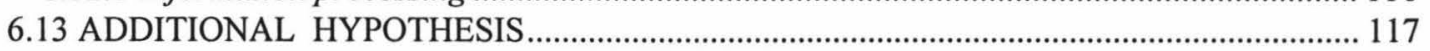

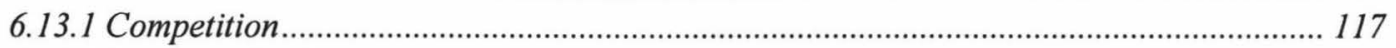

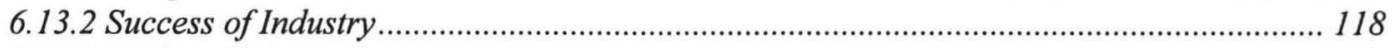

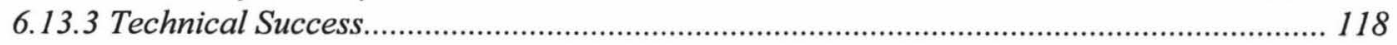

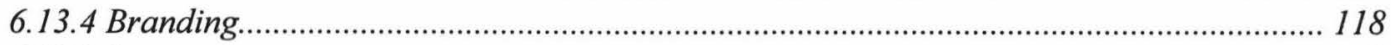

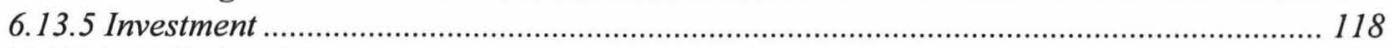

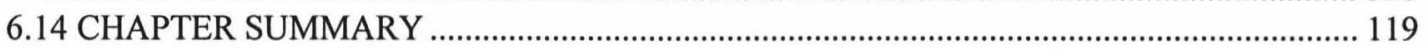

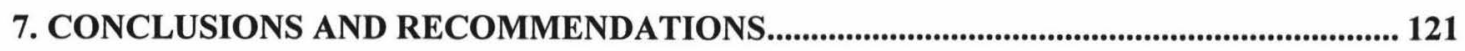

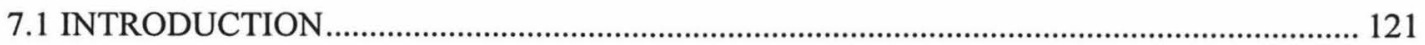

7.2 MODELS OF THE TIME AND EXTENT OF ADOPTION OF DIGITAL TECHNOLOGY . 121

7.3 LIMITATIONS OF THE RESEARCH.................................................................................... 128

7.4 SUMMARY OF RESEARCH............................................................................................ 128

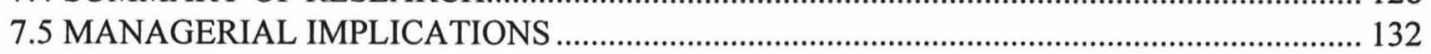

7.6 RECOMMENDATIONS FOR FUTURE RESEARCH....................................................... 133

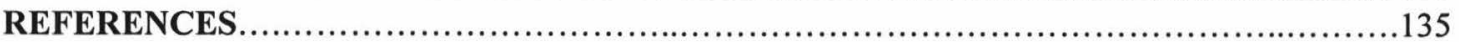




\title{
APPENDICES
}

\author{
Appendix A: Form Letter \\ Appendix B: Project in Brief \\ Appendix C: Fax response sheet \\ Appendix D: Pilot letter \\ Appendix E: Consent Form \\ Appendix F: Expert Letter \\ Appendix G: Survey cover letter \\ Appendix H: Survey Instrument \\ Appendix I: Descriptive Statistics 1 \\ Appendix J: Descriptive Statistics 2 \\ Appendix K: Spending on Digital Technology \\ Appendix L: Statistical Analysis \\ Appendix M: Expected Signs
}

\section{FIGURES}

Figure 1: NZ Motion Picture Industry structure .......................................................................... 5

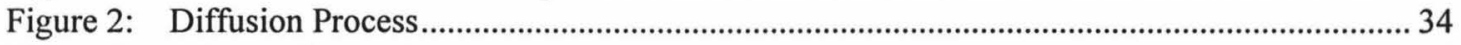

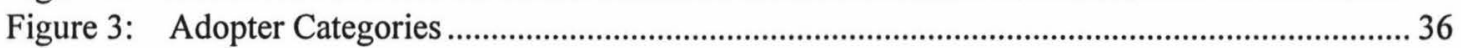

Figure 4: Integrated Framework of Organisational Innovation Diffusion ........................................ 45

Figure 5: Adoption and Diffusion in NZ motion picture industry ..................................................... 47

Figure 6: Integrated Model of Adoption of Digital Technology in the Motion Picture Industry........ 51

Figure 7: Which of the following adjectives would you use to describe your industry? ...................83

Figure 8: What is the main purpose or mission of your organisation? .......................................... 85

Figure 9: What main tasks does your organisation do in the area of editing and special effects? ...... 85

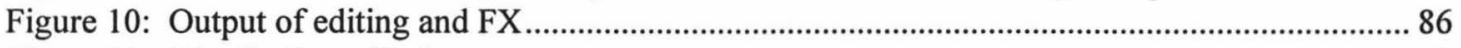

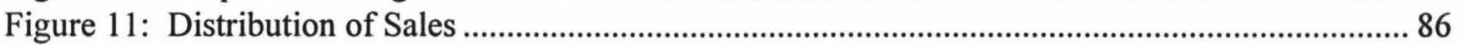

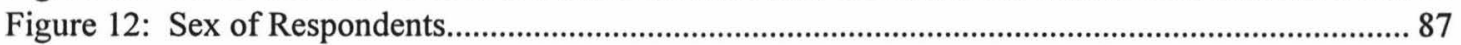

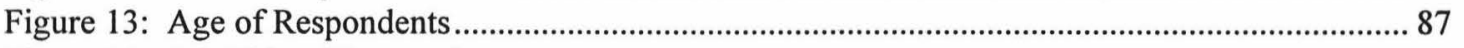

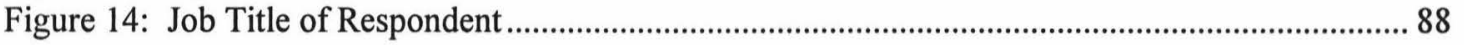

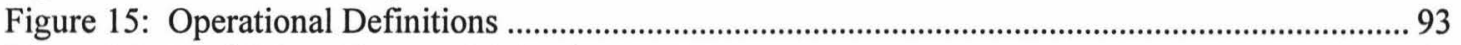

Figure 16: Model One: Extent of Adoption Model .................................................................... 125

Figure 17: Model Two: Time of Adoption Model ....................................................................... 126

Figure 18: Integrated Model of Adoption of Digital Technology in the Motion Picture Industry...... 127

\section{TABLES}

Table 1: Key Organisations in the NZ Motion Picture Industry ..................................................... 7

Table 2: History of Digital Technology in the Motion Picture Industry .......................................... 20

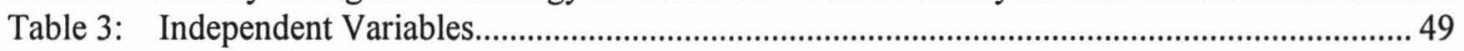

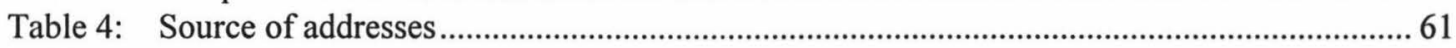

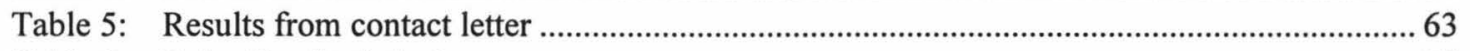

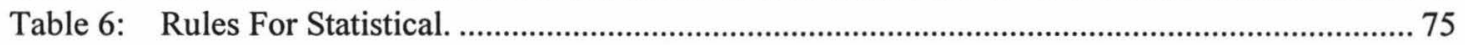

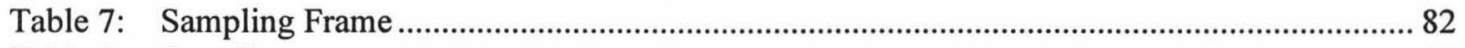

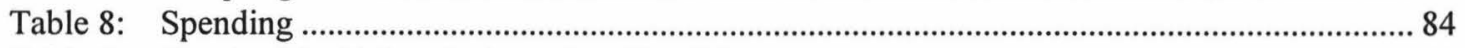

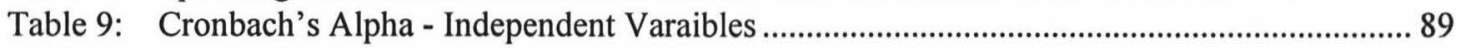

Table 10: Cronbachs alpha - Dependent Varaibles ........................................................................... 89

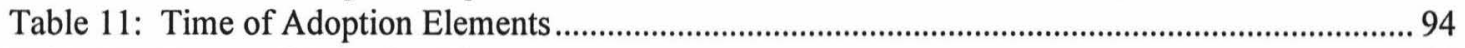

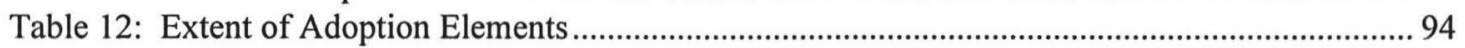


Table 13: Correlation Coefficients - Extent Variables P-values .................................................... 95

Table 14: Correlation Coefficients - Time Variables P-values ........................................................ 96

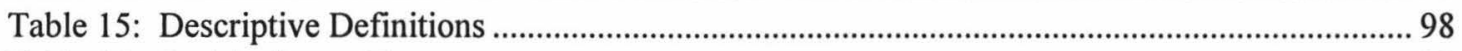

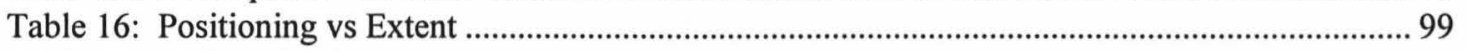

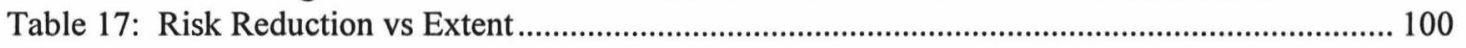

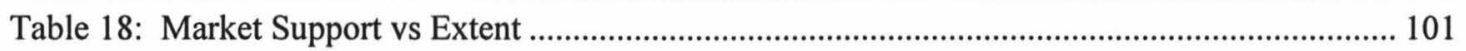

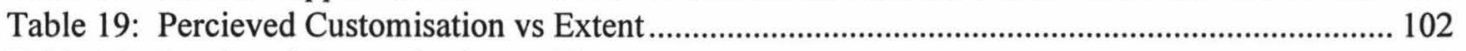

Table 20: Percieved Customisation vs Time ............................................................................... 103

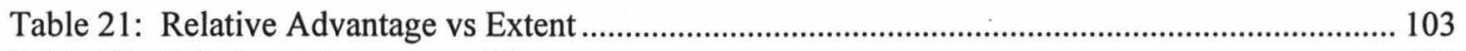

Table 22: Relative Advantage vs Time ....................................................................................... 104

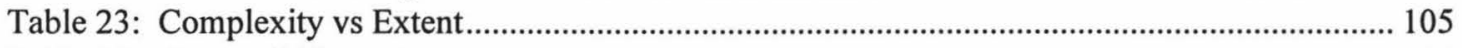

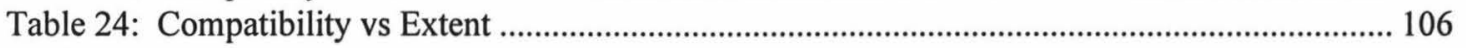

Table 25: Compatibility vs Time ................................................................................................. 106

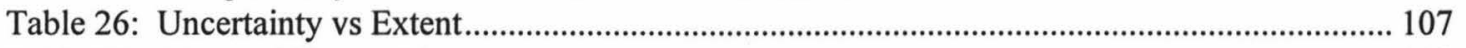

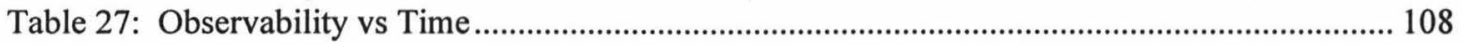

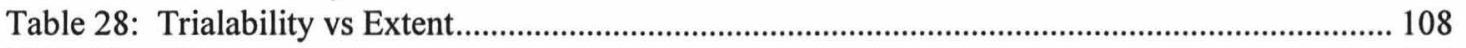

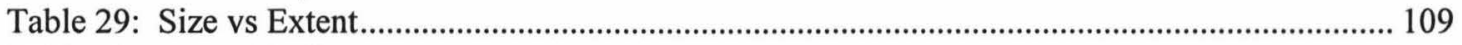

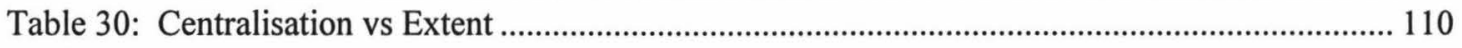

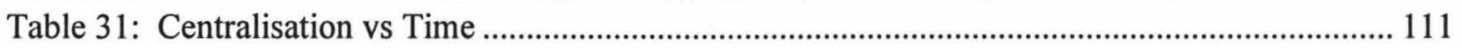

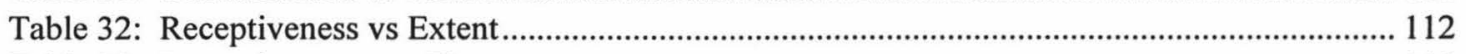

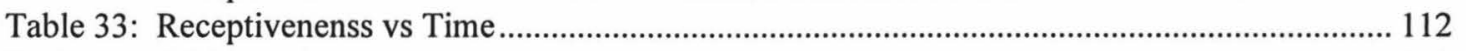

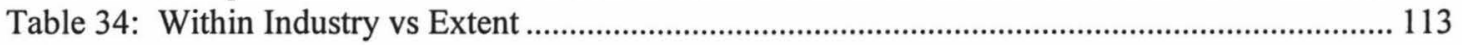

Table 35: Outside Industry vs Extent ....................................................................................... 113

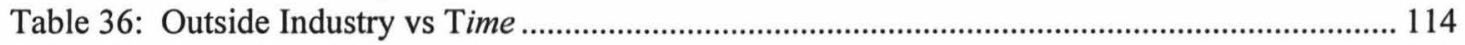

Table 37: Intensity of Competition vs Extent …........................................................................ 115

Table 38: Intensity of Innovative activities vs Extent ............................................................... 115

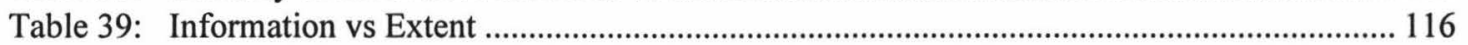

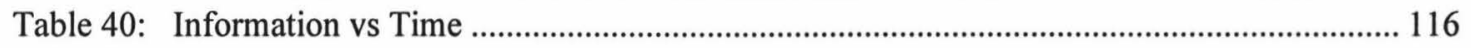

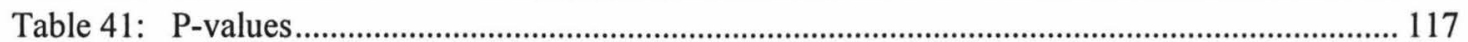

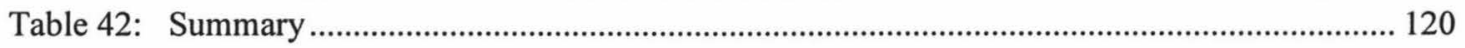




\section{INTRODUCTION}

\subsection{TOPIC}

This research aims to identify the characteristics affecting the time and extent of adoption of digital technology for the use in editing and special effects in the New Zealand(NZ) motion picture industry.

\subsection{PROBLEM STATEMENT}

The NZ motion picture industry is growing rapidly, for example foreign exchange earnings increased from $\$ 44$ million to $\$ 86$ million between 1994 and 1995 (Tradenz, 1995). It is only in the last decade that any substantial research has been carried out on the industry, of which none has considered the adoption of innovations. The motion picture industry, like many others, has been drastically affected by the information technology revolution. Technology in this industry is changing both the way jobs are done and the job roles that exist. Firms in the NZ motion picture industry must understand the many issues surrounding the adoption and diffusion of new technological innovations, if they are to achieve and maintain competitive advantage here and overseas.

The concept of the 'diffusion of innovations' has been the basis for effectively researching high-tech markets (Metcalfe, 1988). However diffusion theory in general, and diffusion research in marketing in particular, has traditionally taken an adopterside perspective, ignoring the influence of the supplier of the innovation. Frambach (1993) integrates supply-side and adopter-side perspectives to produce an integrated model of organisational adoption and diffusion of innovations. Frambach et al (1996) empirically tests this model in the context of the adoption of a service innovation in the Netherlands. The results of their research supported the premise that supply-side factors are important determinants of innovation adoption. Frambach et al (1996) 
suggest that future research considers "aspects like the time of adoption, the extent of adoption, and non-adoption of innovations". This thesis considers supply-side and adopter-side variables and their relationship to the time and extent of adoption of digital technology in the NZ motion picture industry.

Hence the objectives of this thesis are twofold:

- To understand adoption of digital technology for the use in editing and special effects in the NZ motion picture industry;

- To contribute to the theory and findings on innovation adoption through extending Frambach et al's (1996) work on the adoption of innovations in the business-tobusiness setting, the key extension being the consideration of time and extent variables.

\subsection{RESEARCH OBJECTIVES}

The fundamental questions this thesis seeks to answer are:

1. How should the time and extent of adoption be measured?

2. What characteristics of the adopter, supplier or motion picture industry encourage some organisations to uptake digital technologies faster or slower than others?

3. What characteristics of the adopter, supplier or motion picture industry encourage some organisations to uptake digital technology to a larger extent than others?

4. What are the demographics of the NZ motion picture industry?

\subsection{STRUCTURE OF THE THESIS}

Chapter Two considers the literature in two key areas: firstly the history, demographics, and key players involved in the NZ motion picture industry; secondly, the technology itself. The technology literature review is broken into three topics: the history of motion picture industry technology; the history of digital technology; and digital technology within the motion picture industry. 
Chapter Three considers the methodological framework for this thesis. This chapter considers some of the philosophical stand points in the adoption and diffusion literature, in particular the work of Rogers and Frambach. This is drawn together to produce the theoretical framework for this thesis. Lastly in this chapter the hypotheses to be tested are spelled out clearly.

Chapter Four covers data collection and analysis procedures. Firstly this chapter considers the preliminary exploratory research. Next the details of the population, sampling, logistics and data collection for the quantitative research are discussed. The second half of Chapter Four explains some of the theory and concepts behind the methods and procedures used in the statistical analysis

Chapters Five and Six present the results. Results are broken into descriptive statistics, reliability of data and hypothesis testing. Results are presented through text and various graphical means. Chapter Seven presents models of the time and extent of adoption of digital technology in the NZ motion picture industry. This final chapter also covers: limitations of the research; a summary of the findings; the managerial implications; and recommendations for future research. 


\section{BACKGROUND TO THE}

\section{INDUSTRY AND THE TECHNOLOGY}

\subsection{INTRODUCTION}

This research considers the adoption of digital technology for the use in editing and special effects in the $\mathrm{NZ}$ motion picture industry. There is no literature corresponding precisely to this topic. There are, however, two background areas important to the topic, namely the NZ motion picture industry and motion picture industry technologies. These two topics are discussed in some depth in this chapter. Furthermore, the extensive literature on the adoption and diffusion of innovations is central to this thesis. This literature is discussed separately in Chapter Three (methodological framework).

\subsection{NEW ZEALAND MOTION PICTURE INDUSTRY}

\subsubsection{Introduction}

The term motion picture is used to cover film, television and video. This broadly encompasses documentaries, series, feature films, short films, sponsored films and commercials. The industry can be roughly broken down into production, distribution and exhibition. However it is not this simple, as some companies such as Television NZ (TVNZ) carry out tasks in all three of these areas. Furthermore production itself can involve different companies at different stages of production, making categorisation difficult. Stephens (1984) diagrammatically represented the NZ motion picture industry in the manner shown in Figure 1.

Since its beginnings 100 years ago the NZ motion picture industry has moved through several phases of both prosperity and inaction. The recent success of NZ films such 
as The Piano, Once Were Warriors and Heavenly Creatures has enhanced the profile of the NZ industry and contributed to growth in foreign exchange earnings.

\section{Figure 1. NZ Motion Picture Industry structure}

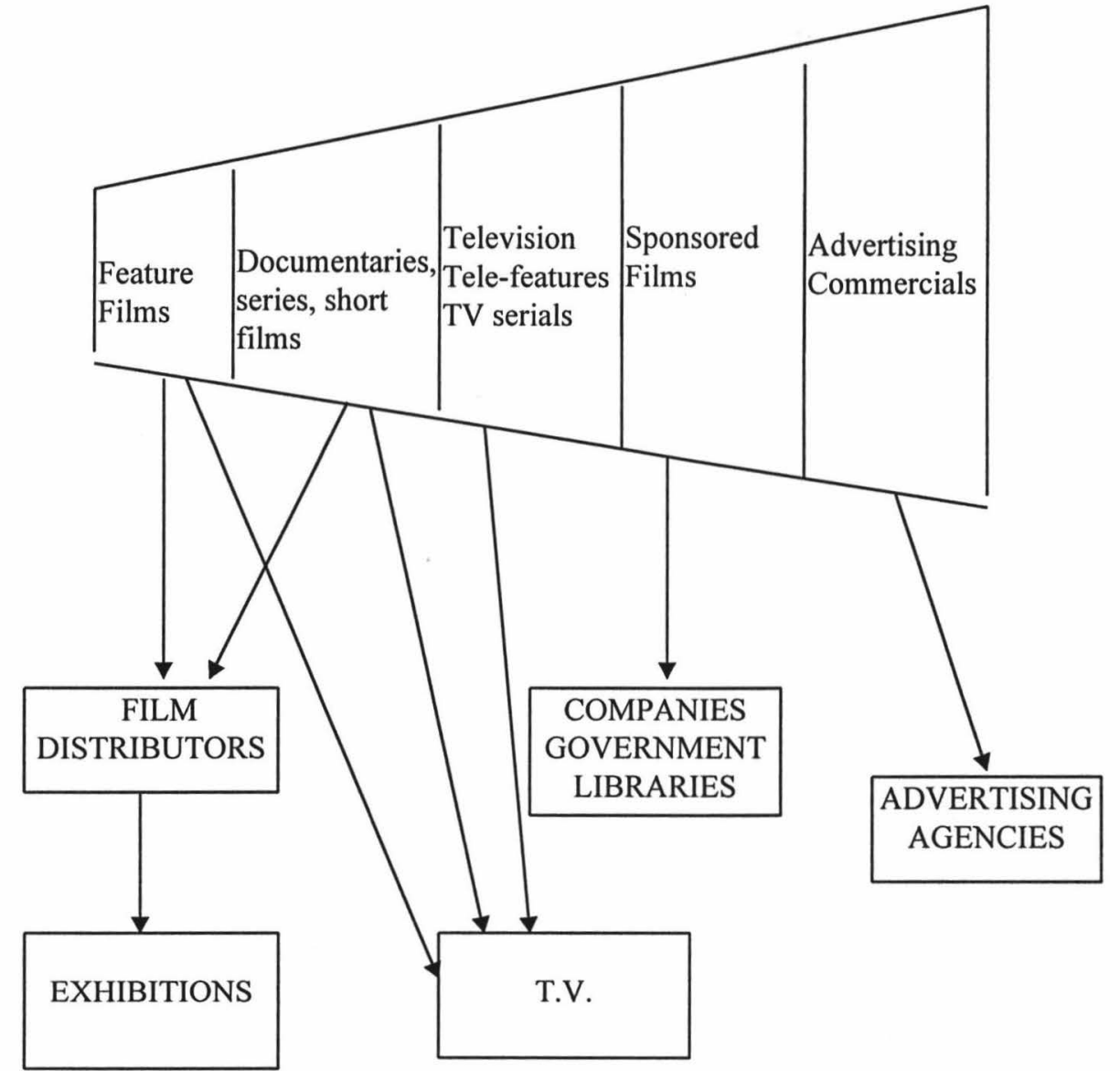

\section{Source: Adapted from Stephens, 1984, p32}

The following takes a brief look at the history which created the NZ industry as it stands today. Next, the key contemporary organisations and their roles will be considered. The latter part of the chapter considers the history of motion picture industry technologies, the history of digital technology and the marriage of the two.

\subsubsection{History}

New Zealand's first motion picture screening was on 13th October 1896 at the Opera House in Auckland. Local production began soon after in 1898 (Singley, 1990). The first full length feature film shot in NZ was Hinemoa, which was produced in 1914. Eight feature films were shot in NZ in the 1920s. These films had a combination of local and imported talent and funding (Statistics NZ, 1996). The only continuity 
within film production was in short films. These included scenics, industrials and beauty contests. 1929 saw the introduction of sound with the first 'talkie' being shown by New Zealander Edwin Coubray in late 1929. It was not until 1935 that the first talkie feature appeared. Between 1940 and 1970 only three NZ feature films were produced (Sowry, 1980). A tax break and the creation of the Film Commission in 1977 caused a revival of features in the early 1980s.

The first official transmission of television (TV) was on 1st June 1960. The transmission was in Auckland and lasted two hours on two nights per week. However this was extended to five nights a week in October. In 1961 there were 4,808 licensed TV sets. By 1979 95\% of NZ households had TV. Colour TV arrived in 1973 and a second channel in 1976 (Boyd-Bell, 1985). Today NZ has four national free-to-air channels and a rapid introduction of local free-to-air channels and pay TV.

\subsubsection{Organisations in the Industry and Their Roles}

Traditionally broadcasting services were provided by the government. In 1989 a new broadcast policy regime was established. The policy aimed to improve economic efficiency within the industry while ensuring social standards continued to be met. This was to be achieved by introducing a more flexible and competitive market for broadcasting services.

Today there are a number of organisations both public and private which play key roles in the NZ motion picture industry. These are listed in Table 1 and expanded upon in the following sections. 
Table 1. Key Organisations in the NZ Motion Picture Industry

\begin{tabular}{|ll|}
\hline Organisation & Ownership \\
\hline The Broadcasting Commission & Public \\
Broadcasting Standards Authority & Public \\
Te Mangai Paho & Public \\
Television New Zealand & SOE \\
TV3 Network Services Limited & Private \\
Sky Television & Private \\
Regional, Local and Cable Television Services & Various \\
Film Commission & Public \\
NZ Film Archive & Charitable Trust \\
\hline
\end{tabular}

\subsubsection{The Broadcasting Commission}

The Broadcasting Commission (NZ On Air) was established through the Broadcasting Act 1989. The Commission's role is to "promote cultural and social objectives in broadcasting" (Statistics NZ, 1996:237). NZ On Air fulfils these objectives by providing funds from the Public Broadcasting $\mathrm{Fee}^{1}$ for: broadcasting, production, and archiving of programmes.

The increase in TV channels, radio stations and computer technologies such as the internet are all rapidly adding to the wide range of foreign information and culture available to New Zealanders. Chairman of NZ On Air, David Beatson, feels it is more important now than ever that New Zealanders maintain access to quality, home-grown programmes (NZ On Air, 1995/6:2).

\subsubsection{Broadcasting Standards Authority}

The Broadcasting Standards Authority "is an independent body established to enforce and oversee the standards and objectives specified by the Broadcasting Act 1989" (Statistics NZ, 1996:238).

\footnotetext{
${ }^{1}$ The Public Broadcasting Fee is currently set at $\$ 110$ dollars per annum, for all households with a television set.
} 


\subsubsection{Te Mangai Paho}

The Broadcasting Amendment Act 1993 established Te Mangai Paho which has assumed primary responsibility for allocation of public funding for Maori broadcasting.

\subsubsection{Television New Zealand - TVNZ}

"TV is a risky business. The enormous prices asked for sporting rights and the looming changes in technology demonstrate that."

(Chris Anderson, Chief Executive, TVNZ, 1995, p4)

TVNZ has two channels and a number of subsidiaries and other broadcasting interests. TVNZ is an State Owned Enterprise (SOE) which seeks to be commercially successful while fostering NZ culture and identity.

Despite the fact that competition is tougher now than ever before, TVNZ continues to do well, reporting a strong financial performance in 1995. Turnover was up $9.2 \%$ from 1994 to NZ\$427.5 million (TVNZ, 1995:3). TVNZ's main revenue source is advertising. However revenue is also generated from distributing programmes internationally, the most successful of which are TVNZ Natural History's Wild South and children's drama programmes (Statistics NZ, 1996).

TVNZ's success can be attributed to their very high market share. All the 50 most watched programmes in 1995 were on TV ONE or TV2. Twenty nine of these were locally made. In fact, 14 of the top 20 were local programmes (Statistics NZ, 1996: 239).

Chris Anderson believes the main long term trend affecting TVNZ is the integration of broadcasting, computers and telecommunications. However he feels wireless will remain an important delivery system for TV. An increasing trend in NZ and worldwide is cable TV. TVNZ chairman N Geary comments that cable TV is unlikely to have a long term impact on the free-to-air market because: 
"Their [cable television operators] investment and operating costs are likely to be too high relative to potential income. Consumer appeal is highly doubtful, given the quality of TVNZ's free-to-air channels."

(N Geary, TVNZ, 1995:3).

\subsubsection{TV3 Network Services Limited}

TV3 Network Services Limited is privately owned and has been on air since 1989. It aims primarily at viewers aged 18-49. TV3's first dividend was announced in early 1995. Shareholders are a Canadian firm CanWest Global Communications Corporation (20\%, shareholdings), Westpac Bank (48\%, shareholdings) and TV3 Network Holdings Limited (32\%, shareholdings). (Statistics NZ, 1996).

\subsubsection{SKY Television}

SKY Television was NZ's first entry into pay television. SKY began broadcasting in May 1990. SKY provides movies, sports, news, non-fiction entertainment and dramas on five scrambled UHF channels. Subscribers are the main source of revenue. This enables SKY to keep commercial time down. SKY presently has approximately 220,000 subscribers. However, they have the potential to reach 850,000 homes (Statistics NZ, 1996).

\subsubsection{Other television services}

Regional, local and cable television have become a feature in the NZ television industry recently. Horizon Pacific Television which is wholly owned by TVNZ started regional broadcasting from four stations in May 1995, and later purchased the existing regional station Canterbury Television. Around $50 \%$ of programming for Horizon Pacific comes from BBC. All stations have their own local news and current affairs team (Statistics NZ, 1996).

Local stations Geyserland TV and ITV provide tourist information to hotels, motels and the like. NZ's first commercial cable television began in 1993 on the Kapiti 
coast. Cable is also being trialled in areas in Wellington where wireless broadcasting is difficult due to the topography (Statistics NZ, 1996).

\subsubsection{Film Commission}

The Film Commission's mission is to "sustain a vibrant, innovative and culturallyrelevant film industry in New Zealand" (Statistics NZ, 1996:258). The Commission's functions, powers and duties are defined by the NZ Film Commission Act 1978. The Commission receives funding from the Lottery Grants Board and offers financial support for development and production of film projects.

\subsubsection{NZ Film Archive}

The NZ Film Archive is a charitable trust obtaining money from lotteries, the Commission, NZ On Air, sponsorship and commercial activity. The Film Archive was established in 1981 to acquire, preserve and make available a collection of film and television materials (Statistics NZ, 1996).

\subsubsection{Previous Studies of the NZ Motion Picture Industry}

Historically there has been little research aimed at obtaining a greater understanding of the NZ motion picture industry. The following sections outline the key studies carried out over the last two decades.

\subsubsection{Economic appraisal}

Stephens (1984) carried out an economic appraisal of the NZ motion picture industry. The appraisal highlighted the importance of government funding to attracting private investment and that the government should provide more funds through The Film Commission as well as tax incentives.

\subsubsection{NZ television}

The TVNZ planning department (1990) produced a report titled "New Zealand and the International Television Industry", which highlights the revolution that is occurring world wide in television. Virtually all governments throughout the world have controlled television strictly since its emergence. Recent trends towards 
deregulation and the emergence of new technologies have changed the television industry world-wide. The industry is becoming more global and the number of channels is increasing dramatically. These trends are demonstrated in NZ through part foreign ownership of TV3 and the increase in local and pay TV. These new broadcasters are taking audiences from state owned broadcasters.

It is in this highly competitive international environment that NZ TV must survive and prosper. There are few barriers to entering the NZ television market. Concern is that as more competitors come into the NZ market, NZ programmes will become uneconomical and NZ TV will lose its unique identity.

\subsubsection{Tradenz}

In the 1990's Tradenz carried out several initiatives to aid the motion picture industry. Tradenz's mission is: "To foster the development and expansion of NZ's foreign exchange earnings" (Tradenz, 1995:1). These initiatives will be considered in the subsequent sections.

Tradenz (1990) carried out a study entitled "The US Market for New Zealand Film, Television and Commercial Production Services". The study revealed the US film and TV industry, excluding production of commercials, earned US \$15 billion in 1990. Nearly $40 \%$ of US films involved some offshore production. Also production is moving from the larger firms to independent production companies, which tend to be more mobile. The US Motion Picture Association sees low cost alternatives expanding. These factors offer the potential for NZ to increase foreign exchange earnings.

\subsubsection{Strategic audit of the industry.}

Miles and Fuller (1993) of Tradenz carried out a strategic audit of the NZ motion picture industry. This was the first major study to try and obtain information on the structure, dynamics, capabilities and offshore prospects of the NZ motion picture 
industry. An industry directory, The Databook ${ }^{2}$, was used to supply a comprehensive list of producers. The response rate was $27 \%$, which is seen as comparatively high for this industry. Furthermore two of the largest organisations, TVNZ and TV3, did not respond.

Total industry size was estimated at NZ\$300 million. That is all domestic and foreign production carried out in NZ. Commercials and television are by far the biggest sectors. Features, short films and non-broadcast video are substantially smaller.

Most organisations in the NZ motion picture industry appear to be small. All respondents had an average of less than six full time employees per company, of which $52 \%$ of the companies had under two employees. The companies are, for the most part, relatively young, with $50 \%$ of companies having been in business five years or less.

A large $98 \%$ of respondents were from privately owned NZ companies. Eighty five percent of respondents had two shareholders or less. Ninety one percent of respondents had only NZ shareholders. The largest proportion of companies' assets are comprised of video facilities and equipment. This industry is a major contributor to associate industries. For example, over four million dollars was spent on accommodation and catering in the 1991/92 financial year.

A high proportion (85\%) of firms were attempting to attract overseas work, mostly in America or Australia. Companies are reactive as opposed to proactive in their attempts to secure overseas work. The majority of companies, in fact, did not have either domestic or international business or marketing plans. The overseas work was mainly obtained through word of mouth and personal contacts. The largest problems in dealing with overseas companies were seen as the isolation of $\mathrm{NZ}$ and the volatility of overseas work. A further problem was the lack of quality information available on $\mathrm{NZ}$ for overseas companies. Many respondents stated that what is needed is generic

\footnotetext{
${ }^{2}$ The Databook is published by Onfilm Magazine and is updated biannually. It lists organisations and individuals in or relating to the NZ motion picture industry.
} 
marketing of NZ crews and facilities, promoting the diversity of locations, competitive costs, flexibility, quality and reverse seasonality.

Respondents were asked to list the key factors limiting their ability to maximise their capacity during the year. Finance was seen as the key feature limiting capacity. Surprisingly $35 \%$ said there were no factors limiting their ability to maximise their capacity. This is interesting given that summer is a very busy period and that $72 \%$ of companies work less than $50 \%$ of the year. A small number of respondents felt limited by their failure to market themselves internationally.

The two critical issues restricting companies from attracting overseas work were: firstly lack of both domestic and international finance; secondly lack of marketing skills was seen as a critical issue by $45 \%$ of respondents.

A SWOT ${ }^{3}$ analysis of the industry was conducted. The SWOT analysis showed industry strengths to be lower production costs, locations, and non-unionised crews. Key industry weaknesses were shortage of finance, people and equipment, and NZ's isolation.

The main opportunities for the NZ industry are TV commercials and co-productions with overseas firms. The key industry threat is the rapid expansion of the industry which could push up prices and reduce the quality. Other threats include the lack of marketing and the strengthening of the NZ dollar.

The NZ motion picture industry is similar in size to the NZ wine industry. However the wine industry has a higher profile and greater prestige. The potential to expand the motion picture industry much further exists. The industry and supporting organisations need to look at a number of important strategic issues. These are obtaining finance, marketing themselves overseas and attracting winter work.

\footnotetext{
${ }^{3}$ A SWOT analysis considers the strengths, weaknesses, opportunities and threats of an organisation and/or industry.
} 


\subsubsection{Project Blue Sky}

Tradenz launched Project Blue Sky (PBS) in 1993, to run to 1997. PBS is a Tradenz backed industry group (or Joint Action Group) aiming to improve the export earnings and production environment of the motion picture industry.

PBS has carried out two major surveys of film and television production activity and foreign exchange earnings. The first calculated 1993/94 foreign exchange earnings at NZ\$43.5 million ${ }^{4}$. The second calculated 1994/95 earnings at NZ\$86 million ${ }^{4}$. The majority of funding is domestic. However offshore funding increased from NZ\$44 million in 1993/94 to NZ\$69 million in 1994/95. On the other hand domestic funding dropped one million dollars over the same period to $\$ 106$ million. The most significant sources of domestic funding ${ }^{5}$ have remained static or declined slightly (Colmar Brunton, 1996).

PBS found the NZ motion picture industry to be buoyant and working close to capacity. The growth in the industry appears to be attributable to increased foreign investment.

The project concentrated on further integration with Australia under CER, establishing a facility for producers to bank distribution guarantees, holding master classes on sales and marketing and running short courses for industry staff.

\subsubsection{Other Tradenz initiatives}

As well as the projects discussed, in the 1993/94 report "Stretching for Growth", Tradenz highlighted the activities the motion picture industry would need to address in order to grow. These were facilitating a co-ordinated planning process and setting up a marketing programme. The progress of these issues was mapped in the 1994/5 "Stretching for Growth" report. An area that was seen as needing attention was ensuring the availability of facilities and equipment. Progress in training and increasing equity investment was seen as strong.

\footnotetext{
${ }^{4}$ These figures are excluding TV commercials and in-house production of news, sport and current affairs.

${ }^{5}$ Funding usually comes from NZ ON Air, The Film Commission, Creative NZ and Broadcasters.
} 
Tradenz has also participated in a working party which has recently established a Film New Zealand Office. This office supplies information for local and international enquiries as well as generic marketing material promoting film production in NZ.

\subsubsection{Report by FaEM}

In May 1996 the Film and Electronic Media Industry Training Organisation (FaEM ITO) carried out a survey to scope the size and structure of the FaEM industry. A 25\% response rate was received. The FaEM industry includes film and television, radio, animation, and multimedia.

"Quantifying exact employment figures applicable to the film, television, and radio industries proves a constant challenge for researchers. The diverse nature of the industry and high number of transient part-time independent contractual workers adds to the challenge." (FaEM, 1996:8). In film production for example an independent operator may work on several productions in one year, hence being counted more than once.

Consistent with Tradenz's study (Miles \& Fuller, 1993), FaEM ITO’s results showed most organisations to have less than 10 staff. The FaEM report also showed that smaller organisations are more likely to have part-timers and staff on contract than larger ones.

Most film and television companies do not have a training policy or run a training programme. Across the FaEM industry there is a near non-existent use of unit standards of the National Qualifications Framework. Animation companies do tend to have training policies and programmes and use industry standards. The most urgent training need identified by all sectors was in the use of computers (both basic and creative). The need was most critical in the animation sector. All replies for animation identified the need for training in 2-D and 3-D computer generated animation. 


\subsection{MOTION PICTURE INDUSTRY TECHNOLOGIES}

This thesis focuses on what has been a relatively recent introduction to motion picture industry technology, that is, digital technology. In particular it looks at the application of digital technology in the area of editing and special effects. Digital technology was introduced into the motion picture industry only in the 1970s; however the history of digital technology precedes this event. Hence the subsequent sections are separated into three topics: the history of digital technology; the history of technology in the motion picture industry; and finally digital technology in the motion picture industry.

\subsubsection{History of Motion Picture Industry Technology}

The invention of photography logically had to precede that of the cinema. In 1826 Joseph Nicéphore Niépce fixed an image on a pewter plate with a compound of silver. Around the same time European scientists were working intensively on the science of optics. This understanding was responsible for the invention of many popular toys, for example the Phenakistiscope ${ }^{6}$ and the Zoetrope ${ }^{7}$ (Wyer, 1989).

In 1890 an assistant to Thomas Edison succeeded in taking a sequence of photographs on film on a large clumsy device called a Kinetograph. This was viewed by one person at a time in Kinetoscope ${ }^{8}$. Films were first projected in 1895 by the Lumière brothers, who produced short films of events, for example "Workers Leaving the Lumière Factory”. The cinema as such finally arrived on 28 December 1885 when the Lumière brothers showed some of their work to a paying public (Wyer, 1989:17).

Numerous technological innovations have occurred over the century of motion pictures. Some of the larger breakthroughs were sound which was introduced towards

\footnotetext{
${ }^{6} \mathrm{~A}$ toy where individual designs in slightly different positions were painted on a flat circle of board. When spun in front of a mirror and viewed through a slit, these became a continuous, animated sequence (Mast, 1986).

${ }^{7}$ Variation on the Phenakistiscope, which used a circular drum as apposed to a flat board (Mast, 1986).

${ }^{8}$ These films contained less than 30 seconds of action and were not edited, they were a simple bit of action, the first of which was "Fred Ott's Sneeze" (Wyer, 1989).
} 
the end of the $1920 \mathrm{~s}$, wide-screen introduced in the mid-50s, television whose first experimental broadcasts were as early as the 1920s, and more recently video (Wyer, 1989).

Special effects are not new to motion pictures. In the early days special effects were called 'tricks' They were aimed at convincing the audience they were seeing something different to what really happened. Over the years new and better ways have been found to produce these tricks. Special effects are usually thought of in terms of fantastic characters in science fiction films. The first special effects were as early as 1902, when The Dancing Midget showed an early example of the 'matte'. The matte is the basis for all special effects. A matte combines separate images on the same piece of film (Swain, 1992).

\subsubsection{History of Digital/Computer Technology}

"I think the three most important inventions of the twentieth century are the atomic bomb, the computer, and the transistor. They have had the greatest effect on our lives. The marriage of the last two, the computer and the transistor, has brought about a transformation unmatched since the industrial revolution of the nineteenth century"

(Shurkin, 1984:9)

In the motion picture industry the terms 'computer' and 'digital' are often used interchangeably. Editing and special effects may be carried out on dedicated hardware or a computer. A computer consists of general purpose software and hardware and dedicated hardware consists of hardware and software built for a specific task (Quantel, 1996). However both rely on similar base principles and the same technological breakthroughs in the past.

The term computer itself does not have a precise or clear meaning. Today it tends to mean 'digital electrical computer'. These are able to retain data and programs, and are capable of making decisions. Computers generally possesses five parts. These are, a 
central processor, a central control, a memory and input and output units (Augarten, 1984).

The early machines which captured, recorded and manipulated sound and pictures were analog. Today it is easier to produce digital equipment for the job. At this point the difference between analog and digital should be noted. The line between them is very distinct. A digital device 'counts' discrete objects. For example a digital computer represents a numerical quantity by a number of discrete signals or by the presence or absence of signals in particular positions (Walker, 1991). Something which 'measures' things is analog. An analog computer uses continuous physical variables such as voltage or pressure to represent and control the variables it handles (Walker, 1991). Analog computers are now usual special purpose computers only.

The history of the computer has two starting points. In a sense the history of the computer begins with the invention of the abacus. This was the first time humans used a machine of some sort to help them with intellectual work. No one knows exactly where or when the abacus was invented (Augarten, 1984). It is known the Greeks had them in 500 B.C. (Shurkin, 1984:9) This basic idea began hundreds of years of technological developments, wrong turns and dead ends, which eventually led to the stored-program computer which is know an integral part of the society we know today. This history had many great inventors, arguably one of the greatest was Babbage, who first conceived the idea that mathematical computations, logic and even analysis could be mechanised. Despite his innovative fertility, he failed, (Shurkin, 1984).

In another sense the history of the computer began during World War II when a group of scientists and engineers in America invented the ENIAC. This stood for Electronic Numerator, Integrator, Analyser and Computer. The ENIAC contained 18,000 vacuum tubes, and consumed so much power that it dimmed lights in a nearby town. ENIAC however was not entirely a computer in that it could not store a program. Soon after, in 1948, IBM produced a computer which ran a stored program. EDSAC ${ }^{9}$

\footnotetext{
${ }^{9}$ EDSAC stands for Electronic Delay Storage Automatic Computer.
} 
the first full scale electronic stored-program computer, began operating in 1949 (Augarten, 1984).

These inventions did not, however, profoundly change day-to-day life for the general population. The planar process for producing integrated circuits was introduced in 1959. It was this process that sparked the ever increasing race to produce smaller, more complex circuits (Bibby, 1996).

\subsubsection{Digital Technology in the Motion Picture Industry}

"As far as the motion-picture industry is concerned the impact of digital technology, both for picture and for sound, has been manifested as increased quality on screen, both in terms of increasing technical quality and also in removing existing limits to the full realisation of artistic creativity"

(Ricotta, 1994:211)

The last few decades have seen huge changes in the way technology is used in the motion picture industry. Much of this change is tied up with what is being called a 'paradigm shift', that is, the large shift from the use of analog technology to that of digital technology. This paradigm shift has been most evident in the area of postproduction. However the industry is still in a transition period where most postproduction houses still operate in a mixed digital and analog environment (Suydam, 1995).

The history of digital technology for the use in editing and special effects in the motion picture industry is fairly brief, as it began in 1977. Table 2 shows a summary of that history. 


\section{Table 2. History of Digital Technology in the Motion Picture Industry}

\begin{tabular}{|l|l|}
\hline Yeir & Divent \\
\hline 1977 & $\begin{array}{l}\text { The introduction of the motion control camera marks the start of the special effects era. } \\
\text { Used in the production of "Star Wars". This camera could revolve repeatedly around } \\
\text { stationary objects and remain in focus and hence simulate flight. }\end{array}$ \\
\hline 1982 & $\begin{array}{l}\text { The movie "Star Trek II: The Wrath of Khan" contains the first completely computer } \\
\text { generated scene. }\end{array}$ \\
\hline 1985 & "Young Sherlock Holmes", contains the first computer generated character. \\
\hline 1988 & $\begin{array}{l}\text { "Willow" contains a fluid transformation from one object to another produced by the } \\
\text { computer program "Morf". }\end{array}$ \\
\hline 1989 & "The Abyss" demonstrates the first computer generated 3D character. \\
\hline 1991 & $\begin{array}{l}\text { "Terminator 2: Judgement Day", has the first digitally created major character, created } \\
\text { due to the sophistication of morfing. }\end{array}$ \\
\hline 1992 & $\begin{array}{l}\text { The television series "The Young Indiana Jones Chronicles" contained digitally } \\
\text { created backgrounds and digitally replicated extras. }\end{array}$ \\
\hline 1994 & $\begin{array}{l}\text { Digital technology produces breathing creatures with skin, muscles and texture in the } \\
\text { box office hit "Jurassic Park". }\end{array}$ \\
$\begin{array}{l}\text { The movie "Forrest Gump" contains numerous breakthroughs, including the weaving } \\
\text { of fictional and historical footage; an amputee is portrayed by simply erasing the } \\
\text { actor's legs in post-production. Also helicopters and ping-pong balls are created } \\
\text { digitally. }\end{array}$ \\
\hline 1995 & $\begin{array}{l}\text { "Casper" contained the first digital lead character. Monkey fur and a lion's mane } \\
\text { were rendered hair by hair in "Jumanji". The world's first completely computer } \\
\text { animated movie, "Toy Story", was released. The film took four years to produce. This } \\
\text { type of production is a cinematic milestone, as at once it gives cartoons a new 3D look } \\
\text { and also all the information is stored in the computer and can therefore be quickly and } \\
\text { cheaply reproduced or adapted for future use. This will hugely reduce the amount of } \\
\text { labour and hence change the economics of animation (Schlender, 1995). }\end{array}$ \\
\hline 1997 & "Star Wars Special Edition" will demonstrate how far digital technology has come. \\
\hline
\end{tabular}

Source: Lane, 1996

Most of these events that mark technological breakthroughs demonstrate flashy or obvious effects; however other effects can be not at all obvious to the viewer. These are used as cost saving devices or to change filmed scenes with out re-shooting. When the actor died during shooting of the movie "The Crow", it was finished by pasting digitised images of the actor into unfinished scenes (The Economist, Dec 1995).

The radical rate of increase of use of digital technologies can also be shown in industry statistics. For example, roughly 50\% of the movies released in 1995 utilised digital visuals of some sort, compared to maybe 10\% in 1994 (Lane, 1996:123). Also 
"Seven of the ten biggest-grossing movies ever made have been 'effects' films." (The Economist, Dec 1995:87)

These changes have taken place world wide, with NZ having seen as much change as anywhere. New Zealand users are regarded as "innovative and computer literate" says Jack Swart of Digiteyes (Thorne, 1996:27). Amber Technology (NZ) Limited describes the Australian and NZ markets as "technically thirsty" and as markets which require strong local support before fully endorsing a product (Thorne, 1996:30).

Digital technology for editing and the production of special effects covers a wide range of technologies, from very low end cheap technologies to top of the range technologies used in high profile movies, TV programs and advertisements. There is also not a clear line between technologies used for editing and those used for special effects. Special effects are often carried out on computer work-stations, using many software packages e.g. painting and rendering packages. Editing tends to be carried out on dedicated hardware; however increasingly this hardware is also used for sophisticated special effects.

There are four steps that go into a typical special effect. These are: modelling, animation, painting and rendering. In modelling the shape and structure of the objects which will be seen on screen are created. Animation involves bringing the objects to life through movement. Painting simply involves colouring the picture. Rendering draws the completed image on screen. Compositing is another critical step in which images are combined into one sequence, whether it is combining footage for live action scenes or inserting computer-generated images into live action scenes (Zorpette, 1994). Software packages for producing these effects are increasing and becoming more sophisticated and it is now possible to produce these effects with extremely limited knowledge of computers.

There are different technologies again for film and video. Even once the film or video is digitised, different software packages are often used to produce effects. This is mainly because, as video and film look different technicians are trying to imitate 
different looks with their effects. The process and therefore technology of digitising film is different to that involved in digitising video.

Digital technology is changing the motion picture industry in many ways including the way production is carried out and training that is required. The subsequent text deals with nine such issues.

\subsubsection{The way production is done}

Digital technology is causing a revolution within news gathering and processing. Traditionally the footage was shot and editing involved physically cutting the tape up and reassembling it with sticky tape. Next the film was probably dubbed to video to insert cardboard graphics shot in the studio. Today NZ current affairs programme Assignment shoots on video and edits on computer. Any required changes can be performed very rapidly (Brown, 1996). A similar magnitude of changes exists in the rest of the motion picture industry.

\subsubsection{Cost of production}

A clear example of how digital technology is changing the costs of production is the 1996 film The American President. In one scene the President makes an address in the House of Representatives. Instead of the production company attempting to hire the House, the actor gave the speech in front of a fake dais and the rest was created digitally. Eighty extras were digitally manipulated to create an audience of 1,500 (Lane, 1996). Another trend which is lowering costs is virtual sets. Broadcasters can now purchase systems that create 3D backgrounds for news presenters in 'real time', that is, as fast as the newscaster can talk. These systems can be purchase for the same price as just one brick and mortar studio costs to build. The virtual set system can produce as many sets as the staff can dream up (Kessler, 1995).

\subsubsection{Training}

A big challenge the industry faces in the paradigm shift from analog to digital, is training both users and industry staff. Companies selling the hardware and software are increasingly using authorised education centres to train their clients. Some feel 
that the industry is going to have problems with talent as young people will increasingly work from home. Hence companies will have trouble getting staff in at the entry level, and will then have trouble filling positions higher up (Suydam, 1995).

\subsubsection{Heightened brand awareness}

The pace of technological change in the motion picture industry makes brand awareness an increasingly important issue. Some facility owners argue it is better to buy an obsolete machine with a great name than an unknown state-of-the-art machine. “..the mass mentality of your clients, upon whom you base your business, may demand that you not advance too quickly" (Avgerakis, 1995:104). Keeping up with what is the best and most practical technology is not an easy task. Another decision companies face, is whether to buy fully integrated systems with high brand recognition or to integrate their own systems, which can be much cheaper but also more problematic.

\subsubsection{Increased competition}

The rapid changes in digital technologies enhance the already competitive nature of the motion picture industry. However many companies are very secretive. There is an obsession with establishing what the other production houses are doing. This is due to the strong "first to own" syndrome, where the newest device is purchased to attract innovative customers. Furthermore post-production has thin margins so knowledge of competitor's plans can help make those margins positive. Lately however, the co-operation between competitors has increased. There are many ways that competitors can help each other through co-operation. One of the most obvious ways is informing others of non-paying clients, planning to use similar formats and managing legislation (Pierce, 1996). "The rush to acquire technology is a dangerous business. Being the first on the wave of new technology probably means you are paying over the odds for state-of the art and your equipment will be superseded by better cheaper kit in a short time" (Ad/media, 1992:31). 


\subsubsection{Evaluation of new technology}

The paradigm shift from analog to digital technology has resulted in enhanced options many of which are technologies industry practitioners may not be familiar with. The question arises, How do companies evaluate the new or the old technology? Many considerations must be taken into account. Film Facilities suggest the most important qualities in purchasing digital video systems are: quality image and sound; short learning curve; integrating with existing hardware/software; and utmost reliability (Thorne, 1996).

One of the largest decisions to be made when evaluating digital technology is between off-the-shelf computer systems and more 'traditional' solution or task specific digital video equipment. This topic has been hotly debated in the trade magazines, at industry conferences, in executives' offices and post-production houses around the globe. There are some requirements in terms of quality, speed and ease of use that are only recently being met by the off-the-shelf computer systems. Manufacturers of traditional video equipment are divided on the issue of dealing with the changes. Some still choose to market solution specific devices and others are forming partnerships with computer manufacturers (Estes, 1994).

The range of tasks a computer can achieve in the motion picture industry is large. They can provide: digital optics; 3D animation; on-air interactive graphics; film restoration and many tasks in post-production. This begs the question, Can solution specific devices truly and effectively be replaced with general purpose systems? (Estes, 1994).

In non-linear editing there has been an explosion of new computer-based products on the market. Non-linear means the recording medium is not tape. Non-linear is often used to describe an environment where there is quick access to 'clips' or segments of sequential frames (Quantel, 1996). The term non-linear is widely associated with offline editing, where an edit decision list is produced for use in the on-line room. However at the upper end of the editing spectrum on-line, non-linear editing systems are increasingly available. "These systems allow the user to have multiple layers of 
video and graphics stored as digital files on hard disk, which can then be manipulated in a number of ways and edited into a final master - all right on the work station" (Estes, 1994:158). Because of the large cost of these on-line, non-linear editing systems, there must be a distinct break point between traditional digital effects based systems and computer-based systems. Often very difficult purchasing and planning decisions must be made.

These high end systems can also provide a higher return on investment than traditional systems. This is because traditional systems have a linear process from one machine to the next and very seldom would tasks be completed in parallel. Hence machinery is sitting unused. Computer-based systems can be reallocated to a new task by simply opening a different software application. With computer-based systems the traditional idea that "this suite does these things and that suite does those", exists only for billing or other such purposes (Estes, 1994).

"Post-production and computer industries must work closely to define upcoming generations of digital media-focused computer systems, for there is a clear and distinct benefit to not only both industries, but to the viewing public as well."

(Estes, 1994:159)

\subsubsection{Communication through networks}

As post-production companies fill with computers, the issue of networking arises. Network centred computing is said to be the way of the future, some even say the stand alone computer system is dead. However motion picture industry systems still tend to operate on their own. Networks are only used for such functions as rendering 3D animation. Prisa Networks opened in 1994, with the sole aim of providing networks for the motion picture industry (Liebman, 1995). The introduction of networks is predicted to change post-production to the same magnitude as faxes changed business (Liebman, 1996).

In a networked digital studio, efficiency can be greatly improved by each member of the creative team having access to the media at all times. This can be achieved 
through a network of inexpensive desktop systems, served by a central digital server. This means there is a single up-to-date digital file which is randomly and instantly accessible to all members. This increased efficiency also means increased profitability, (Estes, 1994).

\subsubsection{Information storage}

Yet another choice to make is that of storage medias. Digital video can take many formats and come in many storage medias. The main ways to categorise digital video formats is as compressed and uncompressed. Uncompressed video is video digitised from tape or camera where all the quality of the original signal is maintained. Uncompressed video is very expensive because it takes very large amounts of storage space e.g. 100 gigabytes to store an hour. Uncompressed technology is used when quality is of the utmost importance e.g. TV shows like "Hercules". Most commercial non-linear editing and video server systems use some sort of compression. This reduces the amount of information that has to be stored, which in turn saves money.

A number of storage techniques are available, which technique is appropriate depends on the image quality and need for random access (Ferster, 1995). Data compression is used for editing, storage and transmission. This raises issues such as, How will compression affect the signal received by viewers? What will advertisers think? Can compressed signals be treated in the same ways as uncompressed ones? (Berger, 1993:217).

\subsubsection{The future}

The future must be different from the past as production, distribution and delivery systems are altered massively by digital technology. Also the technology changes will alter the structure of the motion picture industry. "During the transition time, while the information super-highway is being built, there will be many opportunities for those who keep up to participate and grow into and benefit from the new 'digital' world" (Berger, 1993:217). 
Bamborough (1996:164) asks readers to cast their minds to an on-line broadcasting suite three to five years into the future. This suite "is likely to have completed three broad parallel transitions that are already under way today. They are from analog to digital, from hardware-restricted interfaces to user formats responding directly to the needs of video artists, and - not least - from tape to disk". Bamborough also sees this suite will have been overtaken by the non-linear revolution, as the cost of storage and processing power will have come down. Also the whole system will be networked.

"With more people and more work stations and a movie going public ravenous for special effects, the time devoted to special effects will go up."

(Zorpette, 1994:22)

\subsection{CHAPTER SUMMARY}

New Zealand's first motion picture was shown in 1896. Today NZ has a well established motion picture industry which earns in excess of $\$ 80$ million per year. Organisations such as the Film Commission, NZ film archive, TVNZ and TV3 play "key rỏles" in the industry. "Little researčn" has" been carried out w̉hich àımed to increase the understanding of the industry. Tradenz has carried out several research initiatives including a strategic audit of the industry (1993).

The industry is heavily based on technology. Some of the key historical technological breakthroughs include: photography in 1826; the Kinetoscope in 1890; and the electronic stored program computer in 1946. Digital technology was introduced to the film industry in the 1970 , and is continuing to change the face of the industry. Changes include the way production is done, the cost, training required and the competitive environment. 


\section{METHODOLOGICAL}

\section{FRAMEWORK}

\subsection{INTRODUCTION}

The first part of this chapter outlines some of the schools of thought on adoption and diffusion research, comparing and contrasting popular methodological approaches. From this the theoretical framework of the present research is introduced. Finally the hypotheses to be tested are outlined.

\subsection{REVIEW OF ADOPTION AND DIFFUSION LITERATURE}

The adoption and diffusion literature is extremely large. In fact in 1995 the number of diffusion publications was approaching 4,000 (Rogers, 1995). To consider all the key issues in the adoption and diffusion field fully would take a life time of reading and even then the knowledge of this invisible college is growing at such a rate that it could not be kept up with. For the purposes of the present thesis, a few of the key methodological issues related to the present topic will be discussed. They are: diffusion elements, adopter categories, rate of adoption and attributes of innovations. Issues such as opinion leadership, diffusion networks and consequences of innovations will not be dealt with in any depth here. The reader is referred to the extensive diffusion literature that exists for such information.

Following the introduction of some of the basic ideas of adoption and diffusion, two key methodological approaches for the study of adoption of innovations will be considered. These are the variance approach and the process approach. 


\subsubsection{Concepts and Ideas in Adoption and Diffusion Literature}

Getting a new idea adopted, even a good one, is often difficult. For many innovations there is a long period between when they become available and when they are widely adopted. Hence increasing the rate of adoption is a common issue (Rogers, 1983).

A classic example of an advantageous diffusion which did not sell itself is that of scurvy control in the British Navy. The first successful trials using citrus juice to prevent scurvy began in 1601. One hundred and fifty years later further research was carried out, again very successful. However the British Navy did not adopt a policy of providing citrus juice on long voyages until 48 years after the second trials, i.e. 1795 (Rogers, 1995).

One might think that this could only happen in the past when scientific investigation was not so established. However the classic story of the nondiffusion of the Dvorak typewriter keyboard occurred not so long ago. The QWERTY keyboard was designed in 1873 by Christopher Latham Sholes. This layout of keys is extremely slow to use and hard to learn. It was designed to slow the typist down, as the technology at the time was not sophisticated enough to handle fast typing. In 1932 professor Dvorak of the University of Washington used time and motion studies to create an overwhelmingly more efficient keyboard (Rogers, 1983). As the reader will probably realise this thesis is being typed on a QWERTY keyboard. Over 50 years later Dvorak's innovation has still not been diffused.

Diffusion research began simultaneously and independently in many different disciplines. In the mid 1960s the boundaries between diffusion research in different disciplines broke down. A trend toward a more uniform cross-disciplinary approach began at this time and has continued until today (Rogers, 1983).

Innovation diffusion literature has focused on three questions (Abrahamson, 1991); What processes and contextual factors affect rates of diffusion of innovations? What characteristics differentiate early from late adopters? How does the structure of networks of adopters affect the sequence in which adoptions occur during diffusions? 


\subsubsection{Definitions}

When considering the adoption and diffusion literature, two crucial definitions need to be discussed. These are adoption and diffusion.

Metcalfe (1988:560) sees the study of diffusion as being "concerned with the process by which new technological forms are integrated into the economy to impose changes on its structure." In fact he uses "diffusion" and "structural economic change" as synonyms. Structural change may be considered at many levels, for example, the adoption of a technology by an industry (macro level) or a firm (micro level). In a sense diffusion is related to technological substitution (where 'new' technology replaces 'old'). Karshenas and Stoneman (1993:503) on the other hand define diffusion as "the process by which the use of new technology spreads,".

Rogers (1995:5) is probably the most widely known and referenced diffusion scholar. He states: "Diffusion is the process by which an innovation is communicated through certain channels over time among members of a social system. It is a special type of communication in that the messages are concerned with new ideas." He goes on to say diffusion is a kind of social change. Social change occurs when new ideas are invented, diffused, adopted or rejected. 'Diffusion' is often used to mean the spontaneous unplanned spread of ideas and 'dissemination' to mean planned diffusion.

Despite many differences in orthodox theories of diffusion there is a communis opinio among many diffusion scholars about the pattern of diffusion processes. This pattern of diffusion follows the band-wagon effect with a small number of originators and a slowly increasing number of imitators or followers. This pattern of diffusion is generally pictured as an s-shaped (sigmoid) curve (Hagedorn, 1989).

It is often assumed that an innovation involves a technology that does not change over time. Also, but less often it is assumed, that adoption and diffusion occur in an unchanging environment. These are not useful assumptions, as more often an 
innovation is a step in a series of innovations, where post-innovative improvements play a role in increasing diffusion rate in existing applications. Also technologies under threat from new technologies are often improved significantly, hence "the diffusion curve is shaped by the evolving pattern of competitive advantage between rival technologies" (called the sailing ship effect), (Metcalfe, 1988:562).

However we choose to see or define the diffusion process, the adoption process and the way it is influenced lie at the heart of the diffusion paradigm. The adoption process is defined as: "the process through which an individual or other decisionmaker unit passes from first knowledge of an innovation, to forming an attitude toward the innovation, to a decision to adopt or reject, to implementation of the new idea, and to conformation of the decision of this decision" (Rogers 1983:163 in Frambach, 1993). Some authors separate models into adoption models and diffusion models. However the research on variables influencing the adoption decision, such as Frambach's work $(1993,1996)$, is still carried out under the "diffusion research" banner. The relationship between the adoption pattern and the diffusion one depends on many complex factors including inter-firm differences in rate of adoption (Metcalfe, 1988:561).

\subsubsection{Main elements of diffusion}

Rogers (1995) sees that there are four main elements of diffusion. They are: innovations, communication channels, time and a social system.

\section{- Innovations}

Gatignon and Robertson (1989:35) think of innovation as "involving changes in current patterns of production or consumption. These changes may range from minor (continuous innovations) to major (discontinuous innovations)."

Rogers (1995) uses the terms technology and innovation as synonyms and bases his definition of technology on the uncertainty-reducing aspects of it. This is a view of technology that has not been widely accepted. "A technology is a design for instrumental action that reduces the uncertainty in the cause-effect relationships 
involved in achieving a desired outcome." (Rogers, 1995:12). This definition of technology, that it reduces uncertainty, carries with it the implication that at least to some degree technologies must be of some benefit to the potential adopter. This advantage is not always clear cut or spectacular.

Technology has a hardware and a software component. The hardware embodies the technology as physical components. The software aspect consists of the information base. For example we speak of computer hardware, which is semiconductors, transistors, electrical connections and a metal or other frame, and software which is the coded commands and instructions, that allow us to use the computer to our advantage.

Rates of adoption can be explained through the characteristics of innovations, as perceived by individuals. These include relative advantage, compatibility and complexity.

\section{- Communication channels}

Communication channels include mass media channels, and interpersonal channels. Most individuals do not make adoption decisions based on scientific studies; they make them by subjective evaluation of individuals like themselves who have already adopted.

\section{- Time}

Most behavioural research does not depend on time. However time is an integral component of diffusion research. Time is involved in three places: the innovation decision process, the earlyness/lateness of adoption, and the rate of adoption. The latter two will be considered in the following sections.

\section{- Social system}

It is important to remember that diffusion occurs in a social system. A social system is "a set of interrelated units that are engaged in joint problem-solving to accomplish a common goal" (Rogers, 1995:23). The members may be individuals or organisations. 
For the present research the social system is all organisations involved to a certain extent in editing and special effects in the NZ motion picture industry.

\subsubsection{Adopter categories and innovation}

Be not the first by whom the new are tried,

Nor the last to lay the old aside.

Alexander Pope (1711)

An essay of Criticism, Part II

More is known about innovativeness than about other concepts in diffusion research (Rogers, 1995:252). Innovativeness is the extent to which an adopter (individual or organisation) is relatively earlier to adopt new innovations than the other members of a social system. This is probably because increased innovativeness is the main objective of change agents, and much diffusion research is sponsored by change agents.

"We could describe each individual adopter in a social system in terms of time of adoption, but this would be extremely tedious. It is much more efficient to use adopter categories" (Rogers, 1995:252)

In the early days of diffusion research there were numerous ways for categorising adopters. Innovative individuals, among other things were called, "high-triers", "light houses", "advance scouts" and "ultra-adopters". The late adopters were called such value laden terms as "diehards" and "drones". Fortunately one method of categorisation proposed by Rogers in the 1960 s gained a dominant position. Adoption of innovations in the past has generally been shown on a bell shaped frequency over time curve. Rogers' categorisation shows the cumulative number of adopters over time on an s-shaped curve. See Figure 2: Diffusion ProcessFigure 2. 


\section{Figure 2: Diffusion Process}

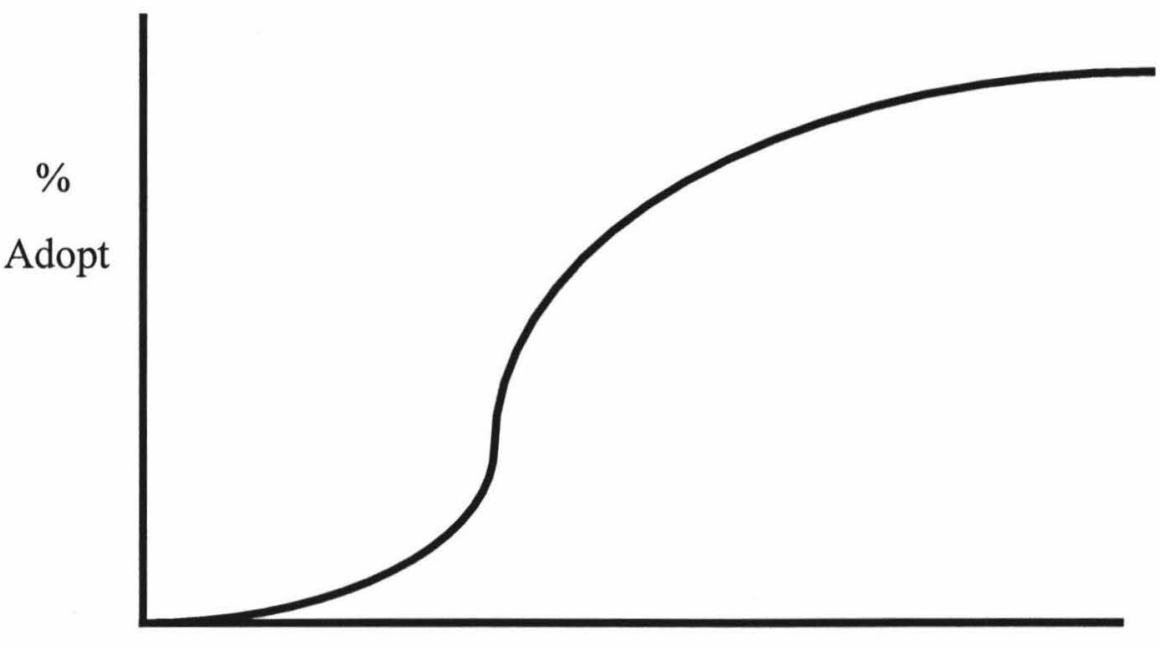

Time

This s-shaped distribution rises slowly when there are a few adopters. It then accelerates until half the social system has adopted and the increase then gradually slows down again as the few remaining individuals finally adopt. This curve is normal - why? The explanation rests on uncertainty reduction and information in the diffusion process. When individuals are faced with a new situation, they initially make many errors. The increase in learning per trial is proportionate to (1) the product of the amount learnt already and (2) the amount remaining to be learnt. Hence one would expect an adopter distribution to be normal.

If a social system is substituted for an individual in the learning curve, it is reasonable to assume experience of the innovation is gained as each member adopts. Each adoption in the social system is roughly equivalent to a learning trial by an individual.

"We expect normal adopter distributions because of the diffusion effect, defined ..... as the cumulatively increasing degree of influence upon an individual to adopt or reject an innovation, resulting from the activation of peer networks about the innovation in the social system"

(Rogers, 1983:244). 
The diffusion effect levels off after half way because there are less people who have not yet adopted for the new adopter to share their experience with.

A researcher seeking standardisation of adopter categories faces three key problems: determining the number of categories; deciding on the proportion of members to include in each category; and determining the method, statistical or otherwise of defining the adopter categories.

There is no question concerning the criterion for categorisation - it is innovativeness. Innovativeness is a 'relative' dimension, i.e. one has relatively more or less of it than others in a social system. Innovativeness is actually a continuous variable, hence breaking it into discrete categories is just a conceptual device, a lot like dividing social status into upper, middle and lower classes.

A set of categories should posses certain characteristics. These are: they should be exhaustive; they should be mutually exclusive; and they should be derived from one classification principle.

Rogers' (1983) classification uses the concepts of mean and standard deviation. See Figure 3. This uses two standard deviations to the left and one to the right of the mean, resulting in five categories. These are: innovators, early adopters, early majority, late majority and laggards. This is the most widely used classification today; however it is not exhaustive in that it does not allow for non-adopters. 'Laggards' as a term may be criticised for being a negative sounding nomenclature, and hence suffering pro-innovation bias. However, any term chosen would in time develop negative connotations. The reader is cautioned not to assume that laggards are somehow at fault for their late adoption. System blame may be more appropriate, (Rogers 1983). The author believes using the term 'blame' in this instance demonstrates pro-innovation bias. Adoption may be a poor decision for some 'laggards'. Hence they should be complimented for not adopting rather than blamed. 
Figure 3: Adopter Categories

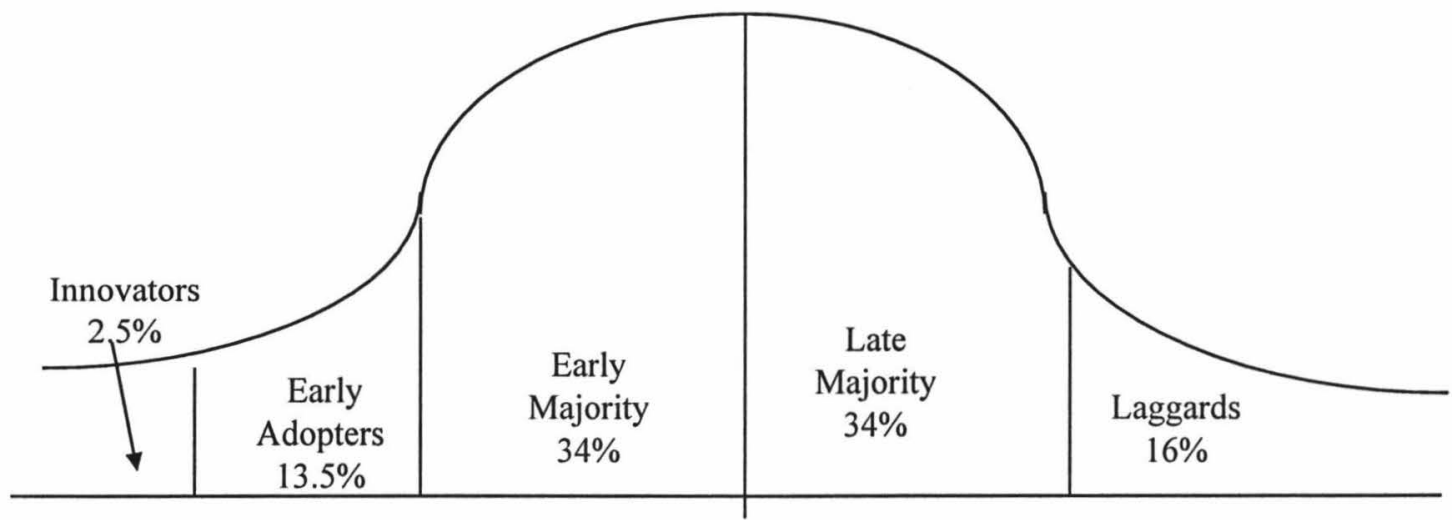

Source: Rogers, 1995, p 262

Clearly different adopter categories are going to posses different traits. Venturesomeness is nearing on an obsession with most innovators. They must also have appropriate financial means. Early adopters are respected by individuals in their social system and have high opinion leadership in their social system. The early majority have a relatively longer innovation decision period than the earlier categories. The opening quote by Alexander Pope clearly describes the mentality of the early majority. The late majority tend to be cautious and sceptical. Scarce financial resources mean uncertainty must be very low. The point of reference for laggards is the past. Their traditional orientation makes the decision making process extremely slow.

A key thing to note is innovators tend to be comparatively more educated, wealthier and have a higher social status. This begs the question, Do they innovate because they are rich or are they rich because they innovate? (Rogers, 1995:269). Individuals who most need the benefits of new innovations (for example less educated or poorer individuals) are mostly the last to adopt. Those who adopt early tend to need it least. This paradox works to widen the socio-economic gap between these two groups.

\subsubsection{Rate of adoption}

"Rate of adoption is the relative speed with which an innovation is adopted by members of a social system" (Rogers, 1995:22). As discussed above, the number of adopters plotted cumulatively over time produces an s-shaped curve. Most, if not all, 
innovations follow this s-shape. However different innovations or indeed the same innovations in different social systems can produce diffusion curves with markedly different slopes. The faster the rate of adoption through a social system the steeper the s-curve.

Individuals' perceptions of certain characteristics of innovations can be used to predict the rate of adoption of that innovation (Rogers, 1983). "If men perceive situations as real, they are real in their consequences" (Thomas and Znaniecki, 1927:81). Five different attributes are described, which are empirically related but conceptually distinct. It should not be forgotten that rate of adoption is also affected by characteristics of the adopter, the supplier and the industry. These variables will be discussed in more depth in following sections.

The issue of human rationality effects adoption, especially over-adoption, which is adoption when experts feel an individual should reject. It is often difficult however to determine when it is, or is not rational for an individual to adopt. Do we consider the objective rationality of the expert or the subjective rationality of the adopter?

\subsubsection{Variables}

Diffusion models in the past largely tended to take an adopter-side approach. That is, attributes of the adopter (consumer or organisation) and attributes of the innovation as perceived by the adopter. For example, perceived relative advantage of an innovation, which is defined as the degree to which the technology is perceived as being better than the idea it supersedes.

Diffusion researchers in several disciplines have discussed the relevance of supplyside factors in understanding the process of adoption and diffusion. For example in geography Brown (1981), and in economics Stoneman \& Ireland (1983). However despite the fact that research on the influence of supply-side factors has been carried out for some time, the "influence of supply-side factors on the organisational adoption process in the behavioural domain has not been given the attention it should have" (Frambach, 1993:28). 
In Rogers' book (1995:335) The Diffusion of Innovations which considers many years of diffusion research, a variable for the extent of "change agents" promotion effects is included in the diffusion model. The change agent is defined as "an individual who influences clients' innovation decisions in a direction deemed desirable by a change agency". The change agent may not necessarily seek to increase diffusion; on the contrary they may seek to slow it. Change agents may be teachers, consultants, development workers, salespeople and more. So a change agent may or may not be a member of the supplier firm.

The work of Frambach (1993) and Frambach et al (1996) goes much further and integrates traditional diffusion model variables (adopter-side) and the supply-side variables researched with the insights of innovation management and industrial marketing research (supply-side variables), thus producing one integrated framework of organisational adoption and diffusion of innovations. The supplier is a firm that is attempting to sell and/or market an innovation to the adopter. The marketing strategy and the innovation development activities of the supplier are included. This framework is shown in Figure 4.

\subsubsection{Organisational adoption}

Firstly, what is an organisation? Rogers and Agarwala-Rogers (1976:26) see an organisation as a stable system of individuals who work together to achieve common goals through a hierarchy of ranks and a division of labour. Organisations are created in order to carry out routine tasks and lend stability to human relationships. Organisational structure and stability is obtained through predetermined goals, prescribed roles, authority structure, rules and regulations and informal patterns (Rogers, 1983).

Marketing literature on adoption is sparse at the level of the organisation. It is mainly economics literature which has covered organisational diffusion. (Gatigon and Robertson, 1989). Earlier studies focus on the consumer as the adopter of technology. Consumer adopters differ from organisational adopters in several ways. 
Innovativeness of consumers is driven by personal characteristics. With organisations, organisational size and structure are important influences on innovativeness. Individuals adopt to satisfy their own needs, organisations adopt to carry out value adding activities. (Frambach et al, 1996).

Not until the 1960s did diffusion research start to consider organisations instead of individuals; however these studies were "very incomplete and over simplified" as data was obtained from a single individual (Rogers, 1983:355).

There was a tendency in the 1970s to transfer models and methods of innovativeness developed for individuals directly to studies of organisations. The size of an organisation has been found, consistently, to be related to its innovativeness ${ }^{1}$. However, size is probably a surrogate measure for certain other dimensions such as total resources, structure and so on. These intervening variables have not been clearly investigated.

Structural characteristics affecting innovativeness include centralisation, complexity, formalisation and organisational slack. These independent variables usually show rather low correlations with innovativeness of organisations. The basic reason for these disparities is that most of the variables are related in one direction during initiation and the opposite direction during implementation of an innovation.

\subsubsection{Criticisms of diffusion literature}

The diffusion paradigm originated in the 1940s. It was not until 1970s, however, that introspective criticism of diffusion research began. There are three common criticisms of the diffusion literature in general. These criticisms are pro-innovation bias, individual blame and the problem of recall.

Pro-innovation bias is the assumption that innovations will benefit organisations. This assumption limits questions that may be investigated e.g. Why do innovations diffuse or disappear? According to pro-innovation bias innovations diffuse when they

\footnotetext{
${ }^{1}$ Larger firms tend to be more innovative (Rogers, 1995)
} 
will benefit the organisation and disappear when they will not (Abrahamson, 1991). This is the implication that underlies most diffusion research that innovations should be diffused and they should be diffused more rapidly. This bias is not stated outright rather it tends to be implied or assumed. This has limited what the diffusion field has learnt. A classic understudied example is the anti-diffusion of harmful innovations, for example drugs, (Rogers, 1983).

Abrahamson (1991) suggests researchers must take three steps to research questions which do not reflect pro-innovation biases. Firstly they must examine assumptions that reinforce pro-innovation biases. For example, organisations make efficient choices because organisations within a group freely and independently choose to adopt a technology, and they are relatively certain about their goals. Secondly they must reject assumptions to reveal counter assumptions. Finally these less dominant perspectives must be developed.

Rogers' (1995) tips on overcoming pro-innovation bias include: use alternative research approaches; be more careful about the selection of the innovation; acknowledge rejection discontinuance and re-invention; research the broader context in which the innovation diffuses; and look into the motivations for adoption.

There has been a tendency for diffusion research to side with the promoters of diffusion or change agencies, rather than with the audience or adopters. There is often a degree of individual blame, as opposed to system blame, in diffusion research. That is the tendency to hold an individual responsible for their problems, rather than the system they are a part of. "In other words an individual blame orientation implies that 'if the shoe doesn't fit, there's something wrong with your foot'” (Rogers, 1983:103).

To overcome individual blame bias, researchers must keep an open mind about causes of social problems. It is also important that all participants become involved in the definition of the diffusion problem. Finally there should be more study of the source of innovations, e.g. the Research and Development system which produces an innovation, and communication system which diffuses it. 
The third key criticism of diffusion research is that of recall. That is, research results depend upon respondents recalling their date of adoption. This hindsight cannot be entirely accurate as it will depend on how important the innovation was to the respondent, as well as the respondent's education, memory and the like.

\subsubsection{Variance Versus Process Research}

Previous diffusion research has focused on collecting data from a large number of individuals, to determine the characteristics of more and less innovative individuals. "Diffusion research designs consist mainly of correctional analyses of cross sectional data gathered in one-shot surveys of respondents" (Rogers, 1983:113) This type of research is variance research. Early organisational studies transferred variance methods used for studies of individuals. These studies were typically large; hence analysis was quantitative. Independent variables of structure, formalisation and the like, were measured for each organisation. The dependent variable of innovativeness was measured on the adoption of 10 to 20 innovations. These studies found low relationships between the independent variables investigated and the dependent variable of innovativeness.

Variance research usually stopped short of implementation by focusing on the dichotomous adoption decision. Latter studies consider the innovation process within organisations; this is process research. Process research aims to determine the timeordered sequence of a set of events. "An in-depth approach means that only a much smaller sample of organisations can be studied with the same research resources and hence there is less basis for generalisations of the research results. But in return such an in-depth approach provides more reliable data and permits greater insight in tracing the nature of the innovation process in each organisation." (Rogers, 1983:358).

Variance research has had many criticisms levelled at it. For example, "the organisational innovativeness studies could not have been designed more appropriately to preclude understanding the innovation process in organisations" (Rogers, 1983:357). Rogers believes the relatively modest correlations of 
organisational structural variables with innovativeness help demonstrate the "futility" of understanding innovation in organisations through innovativeness surveys.

Variance research is convenient. However, it is intellectually destructive of the process aspect of diffusion, due to such factors as the recall problems discussed above. The one shot survey can tell us which independent variables are correlated to the dependent variable (usually innovativeness). But it can not tell us why. A further criticism levelled at the variance approach is that because these studies usually gathered data from only the top executives there was no way of telling how well these opinions truly represented the whole organisation.

It is usually implied that the independent variables 'lead to' companies/individuals being innovative; however it is usually unclear or unstated whether they cause innovativeness.

"In order for variable $X$ to be the cause of variables $Y$, (1) X must precede $Y$ in timeorder, (2) the two variables must be related, or co-vary and (3) X must have a "forcing quality" on $Y$. Most diffusion researches [sic] only determine that various independent variables co-vary with innovativeness; correlational analysis of one-shot survey data does not allow the determination of time-order."

(Rogers 1983:115)

This problem is compounded by the fact that innovativeness variables, which are mostly about perceptions, are measured in the present and the adoption is measured in the past. How can perceptions now affect adoption in the past?

Earlier adoption studies (variance research) helped illuminate characteristics of innovative organisations. However they focused heavily on adopter-side variables, hence suffering largely from individual blame. How could the supplier or any other unit be blamed, when they were not considered? To a large extent process research has built on what has already been learnt from the variance research. Hence given that much of the traditional variance research (both for individuals and organisations) is 
missing a fundamental component (supply-side variables), then it makes eminent sense to revisit the variance research approach. Especially as an in-depth process type approach that considered supply-side variables would be near impossible if there was not some understanding of what the independent supply-side variables affecting innovativeness might be.

Also through careful research planning many of the criticisms of variance research can be overcome. Respondent recall problem may be minimised through: selecting innovations for study that have recently diffused rapidly and are salient to the adopters (unfortunately, this increases pro-innovation bias); gathering time of adoption data from other sources; carefully pre-testing the survey; and using well trained interviewers.

Criticisms can be addressed through focusing on the outcome of the process, in terms of an implemented decision to adopt. Frambach et al (1996) take this approach because adoption can be observed in a relatively clear cut fashion, in comparison to the preceding stages of awareness and evaluation. And the adoption decision can be can be observed by interviewing a single member of the organisation.

An advantage in the variance approach is that more organisations can be studied with the same amount of resources, although there is a definite trade-off to be made. In variance research the researcher learns more about less, rather than less about more (Rogers, 1995). 


\subsection{THEORETICAL FRAMEWORK}

\subsubsection{Summary of Main Theoretical Ideas}

The theoretical framework for this thesis was produced with the preceding arguments in mind. After serious consideration the core goal of this thesis which is to understand more about the adoption and diffusion of digital technology in the NZ motion picture industry, was thought to be best met through a variance type research approach modelled of the work of Frambach (1993) and Frambach et al (1996).

Frambach (1993) produced an organisational model of adoption and diffusion of innovations. This model integrates research in industrial marketing (which traditionally takes an adopter-side perspective to diffusion research) and innovation management research (which points out the relevance of supply-side variables). Frambach states that integrating the findings from innovation management and industrial marketing, aids in solving some of the main points of criticism of diffusion research discussed above. The two criticisms that Frambach feels the integrated approach, which takes a broader perspective, solves are those of pro-innovation bias and individual blame. Figure 4 shows an outline of Frambach's framework.

Frambach's model contains a series of hypotheses relating a set of variables to the dichotomous adoption decision ${ }^{2}$. Figure 2 shows an overview of some of the groups of variables which determine the rate of adoption and diffusion of innovations in the organisational setting. Note not all arrows imply casual relationships.

In 1996 Frambach et al tested the integrated model of adoption of innovations, proposed in 1993, on a service innovation in the Netherlands. The full model including supply-side and adopter-side variables was empirically compared to the 'traditional' type model which includes only adopter-side variables. This research was conducted in the business-to-business context. The empirical results supported

\footnotetext{
${ }^{2}$ These hypotheses are not explicitly listed here, as they are very similar to Frambach et al's (1996) work which will be considered in some depth in following sections.
} 
the premise of the research that supply-side factors are important determinants of innovation adoption. Supply-side factors were tested in terms of their perceptions by adopters, not the actual characteristics of the supplier firms. Also the dependent variable for this research was based around the dichotomous adoption/non adoption decision.

\section{Figure 4. Integrated Framework of Organisational Innovation Diffusion}

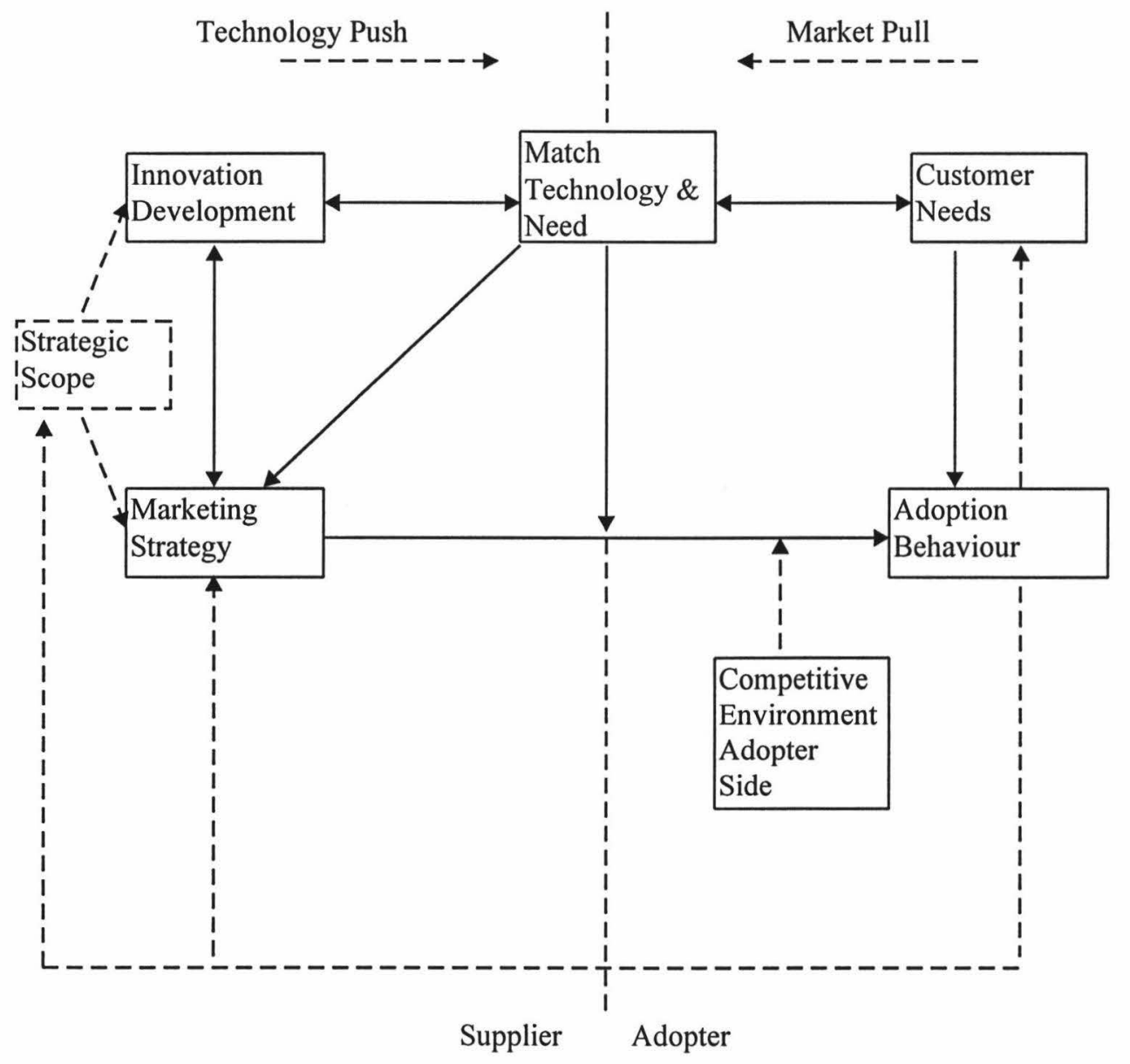

Source: Frambach, 1993, p35

NB: Arrows indicate the strength of the relationship, bold arrows indicate stronger relationships.

Frambach et al (1996) concluded their work with several recommendations for further study. One was "the validity of the formulated model or organisational innovation should be investigated further by replicating the study for innovations other than the one chosen here" (Frambach et al, 1996:23). Secondly, 
"In order to gain more insight in innovation adoption behaviour in future studies, one could focus on aspects like the time of adoption, the extent of adoption and nonadoption of innovations"

(Frambach et al, 1996:24)

\subsubsection{Present Research}

Frambach's model was chosen as it integrates many years of diffusion research and includes supply-side variables which most studies ignore. Also Frambach's model was deemed highly appropriate for the present study as it is an organisational model based on a service innovation in the business-to-business context (electronic banking).

Frambach et al's (1996) advice states further research should consider a different innovation to electronic banking. They also state time and extent of adoption should be considered as opposed to the dichotomous decision. This thesis heeded this advice and considers time and extent of adoption of digital technology. Digital technology was chosen as it covers many areas of technology and it is being widely and rapidly adopted. Many tasks that were previously done manually or with analog technology, are being overtaken with digital technology. Digital technology is now being used right across the NZ motion picture industry for special effects editing, sound, even moving of equipment on a set. To make the research manageable the scope is narrowed down to visual technologies, that is, those which directly control what the public will see on screen. This includes digital technologies for special effects and editing.

In the present research, 'suppliers' are companies supplying digital technology tools for editing or producing effects. 'Adopters' are NZ organisations that adopt and use digital technology for editing or the production of special effects for film television or video. 'Customers' are those for whom effects or editing are being produced for example production companies, television companies, or corporates. How Frambach's model will fit the NZ motion picture industry is shown diagrammatically below. 


\title{
Figure 5. Adoption and Diffusion in NZ motion picture industry
}

\author{
Suppliers e.g. Quantel, Grass Valley
}

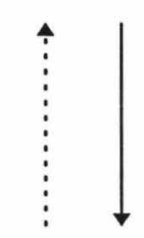

Adopters e.g. Editing and Special Effects Firms

\section{Customers e.g. TVNZ, Production Companies}

The dependent variables to be considered are the time and extent of adoption. Time of adoption is the time of the dichotomous decision to adopt an innovation. The extent of adoption is indicated in such ways as the percentage of total sales devoted to purchasing digital technology. There are many independent variables (see Table 3 ) to be considered. They can be broken roughly into adopter-side and supply-side variables.

The approach to be taken is a variance approach, with one-shot mail out surveys. Non-adopters were not considered as the dependent variable was time of actual adoption. Also, in this industry there are very few non-adopters of digital technology. Adoption of digital technology has been very wide spread among the firms editing or producing special effects.

Only one decision maker was surveyed as they were deemed to be able to answer questions concerning time of adoption, even though the process is an organisational one. They were chosen for their technical expertise and responsibility. Most firms are small, hence one staff member could answer questions for the entire organisation. 
Criticisms of the variance research approach have been addressed in several ways. Firstly through focusing on the outcome of the decision making process in terms of the time and extent of adoption. Secondly respondents' recall problem is overcome through selecting a technology that is salient to adopters and recently diffused. Recall is also overcome by asking respondents their perceptions of whether they are usually an early or late adopter. Recall is not a problem for the extent variables as here the research is trying to isolate the extent of use in the present. The recall problem is also dealt with through very careful pretesting. Another double check used was to use several questionnaire items to try and isolate the time and extent of adoption.

\subsubsection{Variables}

There are two dependent variables, these are the time of adoption and the extent of adoption. From here on these variables will be shown in italics. There are many independent variables, which break roughly into supply-side and adopter-side variables. These variables are shown in Table 3 below, with their corresponding relationship to the dependent time and extent variables. That is, whether the correlation between the independent variables and the timelextent of adoption is positive (+), negative (-), or not specified (ns). 
Table 3: Independent Variables

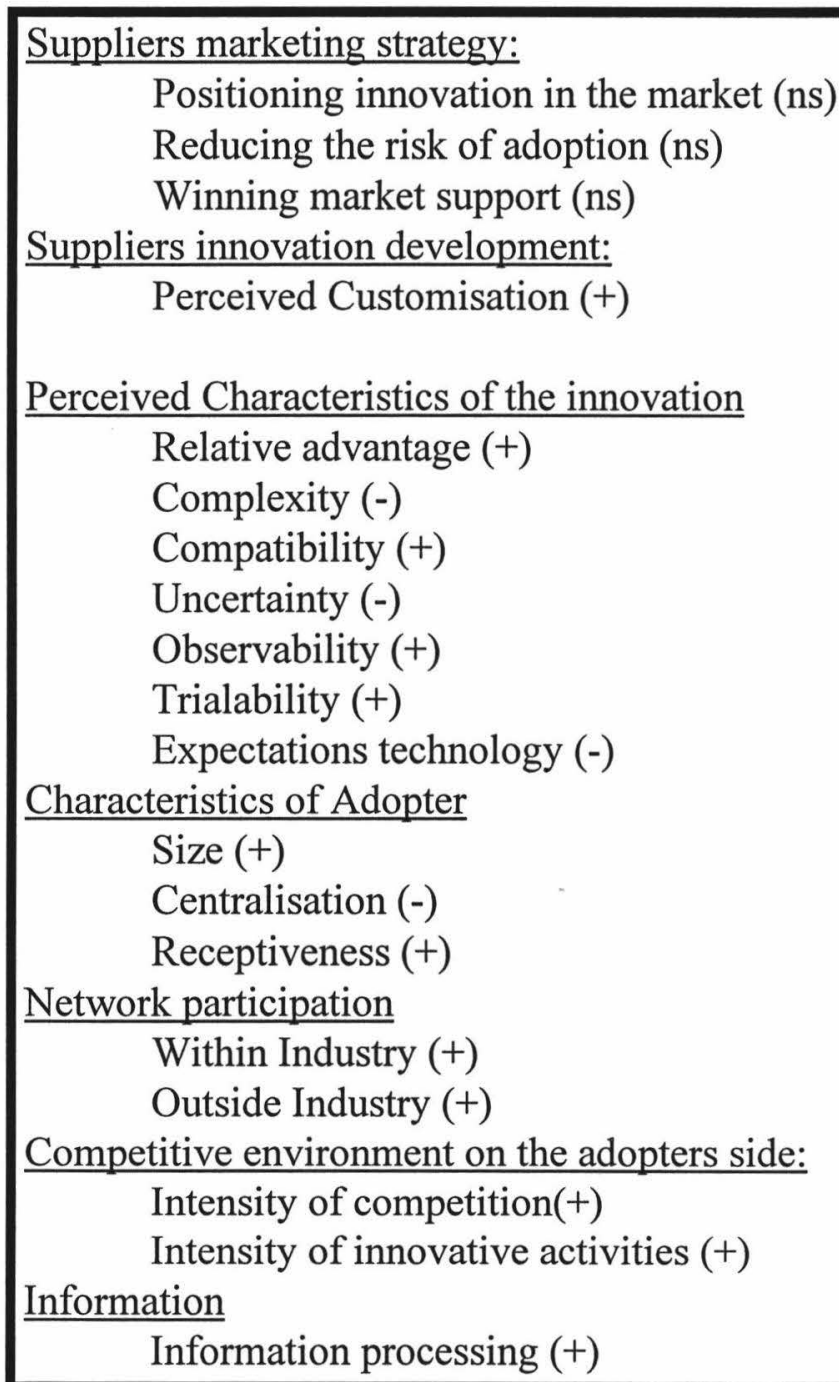

Source: Adapted from Frambach, 1993, p35

Many of these variables are self explanatory; however the perceived innovation characteristics require a little explanation.

The relative advantage of an innovation is the degree to which it is perceived as being better than the idea it supersedes (Frambach et al 1996; Rogers, 1995). The degree of relative advantage is often expressed in terms of economic profitability or status giving. Dramatic price decrease of an innovation obviously increases its rate of adoption. Relative advantage has been found to be one of the best predictors of rate of adoption. 
Compatibility concerns how an innovation can be compatible or incompatible with sociocultural values and beliefs, previously introduced ideas or clients needs. Old ideas are the main tools with which new ideas are assessed. Technologies are often not viewed separately, but are viewed more in a cluster. Sometimes it is useful to market these clusters together.

Complexity is the level to which an innovation is perceived as difficult to use and understand. Trialability is the degree to which the innovation is able to be experimented for a limited time. Observability is the level to which the results of an innovation are visible.

\subsubsection{The Model}

Figure 6 shows the integrated model of adoption of digital technology for the use in editing and special effects in the NZ motion picture industry. 
Figure 6: Integrated Model of Adoption of Digital Technology in the Motion Picture Industry

Supplier-side

Adopter-side

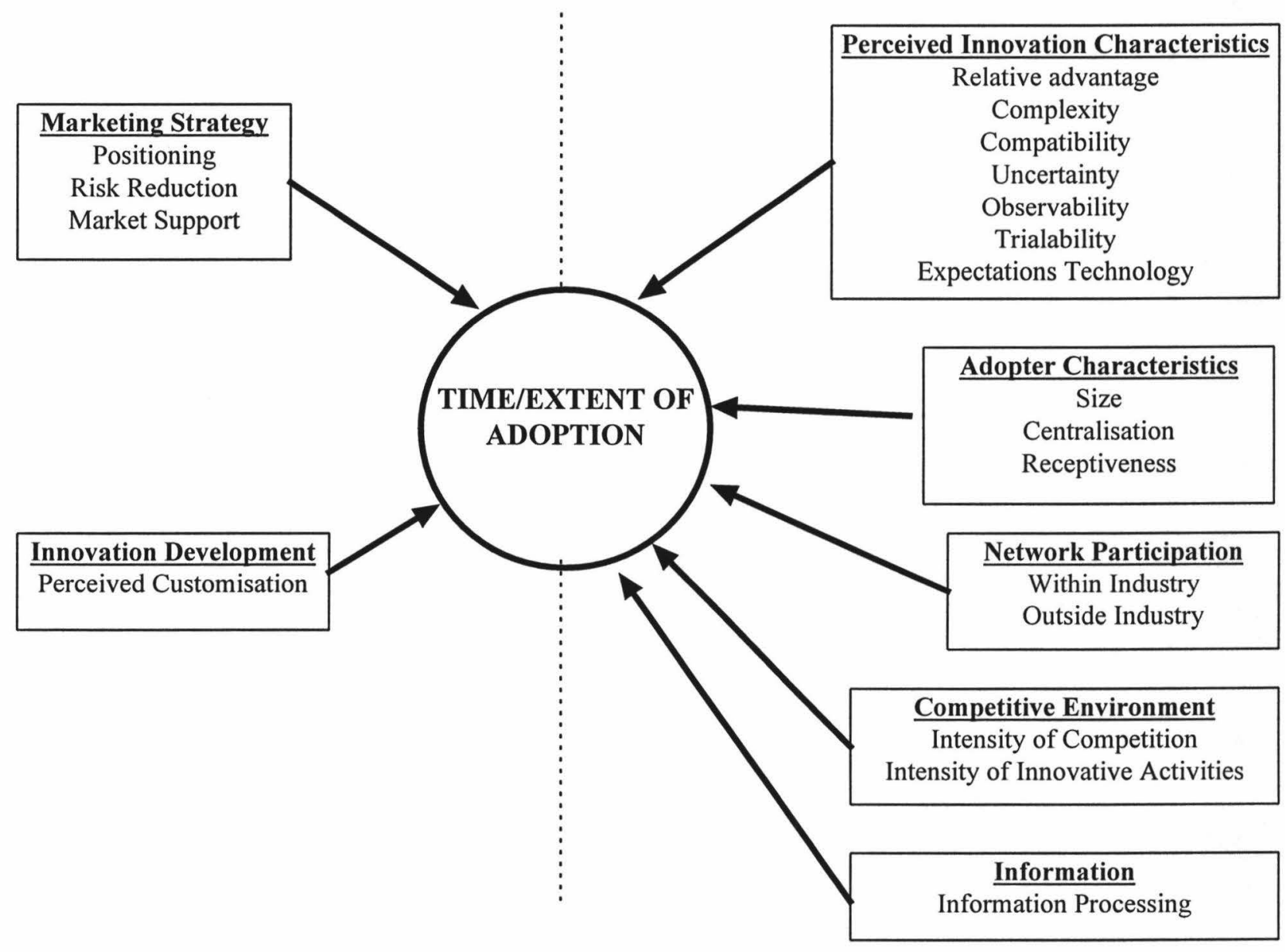

Source: Adapted from Frambach et al 1996

\subsection{HYPOTHESES}

The following hypotheses are based heavily on Frambach et al's (1996) survey instrument. The key change is the addition of the 'time and extent' criteria and the replacement of electronic banking with digital technology. Time and extent hypotheses are separate, however they are worded the same, hence they are presented together with 'extent' shown in brackets. The hypotheses are written as alternative hypotheses. Some of the hypotheses do not specify the direction of relationship (i.e. positive or negative) as Frambach et al (1996) did. This is due in the most part to the 
limitations of the statistical tests that could be carried out on the type and amount of data obtained.

\subsubsection{Supplier Side}

\subsubsection{Marketing strategy}

- Positioning: An association exists between the adopters' perceptions of suppliers positioning activities for the technology and the time (extent) of adoption of digital technology.

- Risk Reduction: An association exists between the adopters' perceptions of suppliers' risk reduction activities for the technology and the time (extent) of adoption of digital technology.

- Market Support: An association exists between the adopters' perceptions of suppliers' reputation and the time (extent) of adoption of digital technology.

\subsubsection{Innovation development}

- Perceived Customisation: The more a potential adopter of digital technology perceives the innovation to be customised by the supplier to the organisation's needs, the higher the speed (extent) of adoption.

\subsubsection{Adopter Side}

\subsubsection{Perceived innovation characteristics}

- Relative Advantage: The perceived relative advantage of digital technology (defined as the degree to which the technology is perceived as being better than the idea it supersedes) is positively related to the time (extent) of adoption.

- Complexity: The perceived complexity of digital technology (defined as the degree to which the technology is perceived as relatively difficult to understand and use) is negatively related to the time (extent) of adoption.

- Compatibility: The perceived compatibility of digital technology (defined as the degree to which the technology is consistent with existing values, past experiences, and needs of potential adopters) is positively related to time (extent) of adoption. 
- Uncertainty: The perceived uncertainty of digital technology is negatively related to the time (extent) of adoption.

- Observability: The perceived observability of digital technology (defined as the degree to which the results of an innovation are visible to others) is positively related to time (extent) of adoption.

- Trialability: The perceived trialability of digital technology (defined as the degree to which a technology may be experimented with on a limited basis) is positively related to time (extent) of adoption.

- Expectations Technology: Adopters feel that their time of adoption is slowed because technology is developing very fast in this area.

\subsubsection{Adopter characteristics}

- Size: The size of the adopter of digital technology is positively related to the time (extent) of adoption.

- Centralisation: A high degree of centralisation in the adopting organisation may obstruct time (extent) of adoption.

- Receptiveness: The receptiveness of the adopting organisation is positively related to time (extent) of adoption of digital technology.

\subsubsection{Network participation}

- Within Industry: Participation of adopting organisation members in informal networks within the motion picture industry may enhance the time (extent) of adoption of digital technology.

- Outside Industry: Participation of adopting organisation members in informal networks in different industries may enhance the time (extent) of adoption of digital technology.

\subsubsection{Competitive environment}

- Intensity of Competition: The degree of competitiveness in the motion picture industry is positively related to the time (extent) of adoption of digital technology. 
- Intensity of Innovative Activities: The intensity of innovative activities in the motion picture industry is positively related to the time (extent) of adoption of digital technology.

\subsubsection{Information}

- Information processing: The extent to which adopting firms have processed information on digital technology is positively related to the time (extent) of adoption.

\subsubsection{Additional Hypotheses}

Some additional hypotheses arose in the preliminary exploratory investigations which are specific to the NZ motion picture industry. Some of the following are null hypotheses and others alternate. This is because it is standard policy that the null hypothesis be that there is no relationship. In order to present the hypotheses in line with preliminary investigations alternative hypotheses are given.

- Competition: That the competition in the motion picture industry is not seen as significantly different in NZ to competition overseas.

- Success of Industry: That NZ firms perceive the NZ motion picture industry to be successful overseas.

- Technical Success: That NZ editing and special affects firms are perceived to be successful overseas.

- Branding: That branding is perceived to effect the amount of work received.

- Marketing: That NZ organisations invest more in marketing of new products or services in NZ than they do overseas.

\subsection{SUMMARY}

Just because an innovation is good, it will not necessarily be adopted. There are many definitions for diffusion and for adoption. A common theme, however, is that diffusion is a process through a system over time. Adoption is a decision to reject or 
take on an innovation. The key elements of diffusion are innovations, communication channels, time and a social system. Organisations in a system can be broken into adopter categories. The most common classification system breaks organisations into innovators, early adopters, early majority, late majority and laggards. The diffusion literature has faced several key criticisms. These are pro-innovation bias, individual blame, and dependence on recall.

Diffusion research has been approached through process research and variance research. Both of which have strengths and weaknesses. The present research elected to use a variance approach. The key criticisms of diffusion research were addressed through an integrated approach, focusing on the outcome of the decision making process, and choosing a salient technology and through careful pre-testing.

The independent variables are the time and extent of adoption. Independent variables were separated into adopter-side and supplier-side variables. Hypotheses tested the relationships between these variables. Several extra hypotheses also arose from the exploratory research. 


\section{DATA COLLECTION}

\subsection{INTRODUCTION}

Data collection was divided into two key sections. The first is the initial exploratory research. This research was carried out in a qualitative fashion, consisting mainly of informal interviews. After an understanding of the industry and topic was gained the core of the research was quantitative. Section two of this chapter describes the population and sample definitions and the questionnaire design for the quantitative research.

The latter half of this chapter looks at data processing and analysis. This includes how the data was managed, reliability issues and the statistical analysis tools used in hypotheses testing.

\subsection{EXPLORATORY/QUALITATIVE RESEARCH}

The first interview with a high profile post-production company aimed to define and narrow down the topic. The interviewee stated that in the NZ motion picture industry there are large differences in management, costs and support services for production and post-production companies to that which exists overseas. The introduction of digital technology has had major ramifications in the NZ motion picture industry with a series of flow down effects, in terms of software, hardware and computer laboratories. The impact of digital technology on the NZ motion picture industry has been particularly dramatic in the area of post-production. In NZ there is a lack of staff, and the introduction of digital technology has increased the ability to recruit. Some topic suggestions included: a case study of the motion control camera; 
comparison of time spent in pre-production and post-production in the past and today; and education of production crews about processes in post-production.

Soon after this interview the topic was narrowed down to look at the adoption of digital technology in the NZ motion picture industry. The next step was to clearly define the population. Digital technology is widely used in exhibition and many areas of production. It is used in filming, recording sound, editing the sound and pictures and in theatres to play back the resulting product.

The decision was made to narrow down the population to NZ organisations using computer technology for use in special effects for film, television and video. Eight individuals from organisations which would be in the potential population were contacted by phone, in person or via email. They were asked to comment on this population definition. These individuals were located through the Databook (Onfilm, 1997) and through recommendations from others in the industry

The resounding finding was that a clear line between editing and special effects did not exist. What some called 'low grade' special effects others called editing. Also when talking about editing some of the hardware was specialised and hence not considered a 'computer'. As a result the population definition was expanded to include editing. The term 'computer' was replaced with the broader term 'digital'.

Other comments received through informal discussions with the above industry members included:

- Much adoption of digital technology is competitively driven;

- Technology may be adopted because it is what looks good or is known to the clients;

- Technology is not a limiting factor in NZ i.e. we have enough up-to-date technology;

- New Zealand is ahead of Asian countries in editing and effects;

- New Zealand is very technically competitive, for example what we are achieving with the weather and The Americas Cup; 
- Kiwis are innovative (good old number eight fencing wire mentality);

- Many organisations have editing equipment that did not exist two years ago;

- New Zealand is up with or ahead of America in terms of editing and special effects; This is because New Zealanders hold off buying new technology for ages and then go out and buy something totally up-to-date or ahead of the play.

Hypotheses arising from the preliminary investigations are shown in Chapter Three, under the heading 'Additional Hypotheses'.

\subsection{QUANTITATIVE RESEARCH}

The core of the research was quantitative and revolved around mail out surveys. This section details the rationale behind mail out surveys, population definition, sampling techniques, questionnaire design and the pilot study.

\subsubsection{Surveys}

Surveys have been chosen for several reasons. Surveys are versatile, they can range in length anywhere from a few minutes to an hour. The level of complexity of surveys is a matter of choice by the researcher. Surveys are efficient because survey research uses sampling, therefore information about large populations can be obtained without surveying the entire population (Alreck \& Settle, 1985).

Mail out surveys were chosen for the present research because (Alreck \& Settle 1985):

- This task does not necessarily require the sort of interaction that personal interviews require;

- Reasonably accurate mailing lists are available;

- Responses can be easily recorded by the respondent;

- The number in the sample is large;

- Respondents have a large geographical separation, making personal interviews time consuming and very costly. 


\subsubsection{Population and Sample}

The target population is the entire group from which information would ideally be received (Department of Statistics, 1992). The target population for the present research is:

All NZ organisations with at least one full time equivalent (FTE) staff member working with digital technology for editing or the production of special effects for film, television or video.

One FTE was chosen as many of these companies are very small and it was necessary to ensure those companies run by only one person were not excluded from the survey. Also this is a measure that will not differ between companies, as say a percentage of staff hours would.

The survey population is the group which has a chance of being selected in the sample (Department of Statistics, 1992). The survey population for the present research is:

All NZ organisations (with at least one FTE staff member working with digital technology for editing or the production of special effects for film television or video) which are listed in the Databook, the Telecom Yellow Pages, The Broadcasters Yearbook, the 1987 Film and TV Directory or have had personal contact with the research team.

The sampling frame is a list of elements attempting to cover the target population. For the present research that is:

All organisations listed under certain specific headings in Databook, the Telecom Yellow Pages, The Broadcasters Yearbook, 1987 Film and TV Directory or which have had personal contact with the research team.

These sources were effective as they provided up-to-date information, each unit is distinguishable from another, and each unit will be counted only once (as in most 
cases duplication is obvious). The sampling frame is bigger than the survey population as some companies contacted did not fit the criteria for inclusion in the target population.

The Databook is published by Onfilm Magazine and is updated biannually. It lists most organisations and many individuals in or relating to the NZ motion picture industry. The directory is put together with the help of regular industry surveys by Onfilm staff. Also, companies can approach Onfilm to request that they be included. However, the companies must have done some work in the industry, as industry references are required. Listing is free of charge for up to six headings. The companies decide themselves which headings they wish to be listed under.

There are 110 organisations listed under "Special Effects", "Computer Animation and Graphics" and "Editing" and "TV Stations"1 in the June 1996 Databook. This made up the majority of respondents. Organisations listing under "Production" were not included as production companies that carry out any editing or effects appear to list under the "Special Effects", "Computer Animation and Graphics" or "Editing" as well. Other references were used to double check. These included: the 1994 TV Broadcaster Yearbook, 1996 Telecom Yellow Pages (under "broadcasters" and "TV Stations"), and The 1987 NZ Film and Television Directory. These resources uncovered 16 companies, resulting in a sample frame of 126 companies. See Table 4 for a break down.

The sample surveyed was all the survey population. That is, all organisations in the sampling frame shown in Table 4 which fit the criteria to be included in the target population. This approach, to sample the whole survey population, was chosen to ensure that the accepted survey response minimum of 30 respondents (Alreck \& Settle, 1986:58) was satisfied. This industry is renowned for very low response rates to surveys. There may be a high level of variance in responses to questions, supporting the need for a large sample.

\footnotetext{
${ }^{1}$ The appropriateness of selecting using these headings was checked with three personal contacts in the industry.
} 
Table 4: Source of addresses

\begin{tabular}{|l|c|}
\hline Source \& Heading & Number Of Firms \\
\hline Databook - Computer Animation and Graphics & 23 \\
Databook - Editing, Film Post-production & 14 \\
Databook - Editing, Non-linear & 24 \\
Databook - Editing, Video Post-production & 24 \\
Databook - Special Effects, Electronic & 6 \\
Databook - Special Effects Companies & 8 \\
Databook - Television Stations & 9 \\
Television Broadcasters Yearbook & 2 \\
Yellow Pages - Broadcaster & 8 \\
Yellow Pages - TV Stations & 7 \\
Personal contact & 1 \\
TOTAL & $\mathbf{1 2 6}$ \\
\hline
\end{tabular}

There are several possibilities for bias. This sample frame may suffer visibility bias, self-selection bias and non-response bias. However it will not suffer order bias, accessibility bias, cluster bias or affinity bias.

Visibility bias is bias caused if some types of units in the population are more visible than others. In this case numbers not listed in the 1996 Databook, 1994 TV Broadcasters Yearbook, 1996 Telecom yellow pages, and 1987 NZ Film and Television Directory cannot be sampled using the suggested sample frame. However, companies in the population are hi-tech firms trying to sell a service, hence the probability of them not having a phone or not listing in one of the directories discussed is slim. An area for self selection bias is that the companies chose whether to be listed in the sample frame. This raises the same issues as those addressed under the visibility bias.

Non-response bias is caused when there is an interaction between response rate and survey content. For example in a survey to measure purchase probability of a new consumer product, people who require the product will be more likely to respond. The most important variable in the present survey is the time or extent of adoption. It may well be that early adopters are more likely to respond as they have a higher interest and are more 'innovative'. Unfortunately there is almost always some level of non- 
response bias with surveys. This will simply have to be tolerated. This was minimised in the present study by having several levels of contact with the respondents through phone, mail and fax. Also through intensive follow-up procedures, and firm assurances of confidentiality.

A further non-response issue is that of incomplete surveys. All surveys at least $75 \%$ complete will be included in the analysis.

An important issue is that many organisations listed under these headings are made up of only one person. Immediately the questions arise, Can we apply Frambach's organisational model to these people? Are they organisations? How will they answer questions such as those concerning interpersonal relationships? This research was interested in the business as an entity and that entity may be one person, so this situation was overlooked.

\subsubsection{Logistics of data collection}

Letters requesting participation of firms where mailed to the 126 organisations shown in Table 4 (See Appendix A for letters). Respondents were advised that the research would be completely confidential i.e. no firms would be identifiable. And that confidential data would be destroyed after it was coded and entered on the computer. Attached to the letter was a brief summary of the research project and a fax response sheet (see Appendices B and C).

For the most part the letters were addressed to the person given as a contact in the Databook. This was due to the fact that the companies chose the contact names themselves and the nature of the headings they were listing under would make them the most appropriate contact. For those who did not have a contact name the job title editing/effects supervisor ${ }^{2}$ was used.

\footnotetext{
2 The appropriateness of this job title was verified by an industry contact.
} 
Before the letters were sent ethics approval was obtained from Victoria University of Wellington's Human Ethics Committee, to ensure the research process would not breach any human ethics regulations.

Follow-up phone calls were commenced two weeks after the mailing of the first letter and further follow-up calls were made the following week. These calls resulted in several more letters and faxes, as some had gone to the wrong person or been misplaced. Of the 126 organisations: five were doubled up, i.e. the company was mentioned twice under two names; 63 agreed they fitted the criteria and would participate in the study; three said they fitted the criteria but would not participate in the study; 36 did not fit the criteria; four were away for long periods of time or had closed down. No response was received from 15 respondents. See Table 5.

\section{Table 5: Results from contact letter}

\begin{tabular}{|l|l|l|}
\hline Result & Number & Percent \\
\hline Duplicate names & 5 & 4 \\
Yes, fit criteria and will participate & 63 & 50 \\
Yes, fit criteria but will not participate & 3 & 2 \\
No, does not fit criteria & 36 & 29 \\
Away/disconnected/closed & 4 & 3 \\
No response & 15 & 12 \\
Total & $\mathbf{1 2 6}$ & $\mathbf{1 0 0}$ \\
\hline
\end{tabular}

The next contact was made with respondents to pilot test the survey. Eight organisations were randomly chosen (using Microsoft Excel 5.0 random numbers) from the 63 organisations who fitted the criteria and were willing to participate. A covering letter was sent explaining that the organisation had been chosen for a pilot test (see Appendix D) and the seven page survey was included along with post-paid addressed envelope, and a consent form (Appendix E). Respondents were requested to return the survey within eight working days of the date it was sent. Pilot surveys were also sent to six 'experts" ${ }^{3}$ with a covering letter asking for their comments on the wording or content of the survey (Appendix F). The experts were also supplied with post-paid envelopes and asked to return them within eight working days.

\footnotetext{
${ }^{3}$ Experts explained in Section 4.3.5
} 
Three weeks after the pilot surveys were sent, outstanding responses were followed up through phone, fax and email. Six weeks following the postage of the pilots all 14 pilots were returned (100\% response rate).

The final survey was sent to 64 organisations. This included the eight already pilot tested as the changes meant they had to re-do parts of the survey. There was also one extra respondent located through personal communication by the researcher, during the stage of the pilot testing. The package included: a covering letter (Appendix G); the eight page survey (Appendix $\mathrm{H}$ ); a consent form; and a post-paid addressed envelope. The eight organisations that had previously been pilot tested received their own personalised package, as they needed only to fill out those questions or sections which had been changed. Follow-up phone calls were made three and a half weeks following the date of sending the surveys.

Of the 64 organisations, responses were received from 43 organisations $(67 \%$ response rate). However three of these organisations changed their status to 'No, we do not fit the criteria' and one was no longer able to complete the survey ${ }^{4}$.

\subsubsection{Questionnaire Design}

An eight page questionnaire (Appendix $\mathrm{H}$ ) was designed to test the research hypotheses (Chapter Three). These included the adopter-side and supply-side variables. Many of the items were taken from the work of Frambach et al (1996). In cases where suitable items where not available, new ones were created or adapted to meet the requirements of the study. Items were measured in various ways. These included: a five point Likert scale ranging from (1) strongly agree to (5) strongly disagree; a five point scale ranging from (1) very high to (5) very low, from strongly increased (1) to strongly decreased (5), from very successful (1) to not at all successful (5); some 'tick-the-box' type questions; and various short answers.

\footnotetext{
${ }^{4}$ Reasons withheld due to confidentiality.
} 
The survey asked respondents about 'digital technology'. However, alone this term covers much more than the focus of this research. Hence, this was explained to the respondents and digital technology was italicised through the survey to remind respondents that it possessed a particular meaning (See Appendix H).

\subsubsection{Dependent variables}

There are two dependent variables. These are the time of adoption and the extent of adoption. The time of adoption is measured in several ways. Firstly the time of purchase of digital technology after it became available. This was measured in relation to the organisation's first purchase of digital technology and most recent purchase. Respondents were asked when they purchased a particular item and when it became available. The aim of this was to obtain a more objective answer than would be obtained by asking respondents to calculate themselves how long after a particular item became available they purchased it. Secondly, it amied to find out how fast respondents felt they adopted compared to competitors. This was asked through two very similar questions. Finally respondents were asked how long on average after an item of digital technology became available did they purchase it.

Extent of adoption in its crudest form is 'how much' an organisation adopts. However this amount must be relative and hence must be, where possible, adjusted for the size of the firm. But then 'how much' is not exactly clear as there are issues of numbers of units of technology versus money spent. The extent of adoption is measured through two perception type questions and three actual measurements. One of the perception based variables was obtained through asking respondents outright: "In general does your organisation adopt digital technology to a high or low extent?". This answer was a five point Likert type scale. The second was operationalised through asking respondents if they felt their technology to be high or low end. The terms 'high end' and 'low end' where based very much on industry jargon about the technology. High end appears to have connotations of hi-tech and expensive.

The three measurement type questions produced ratio data. The first asked the number of items of digital technology purchased in the last year. This response was 
not corrected for the firm size. The second measured the percentage of the organisation's full time staff members that worked with digital technology. The last considered the percentage of sales spent on digital technology. The last two were asked in two parts i.e. respondents were asked how much the organisation made and how much was spent on digital technology. This approach was deemed much more accurate that outright asking them what percentage of their sales they spent on digital technology. The FTE variable was broken down in a similar fashion.

\subsubsection{Adopter-side variables}

Size was operationalised through the number of FTE staff members and sales in the last financial year. Centralisation and receptiveness were operationalised through six (three each) questions using Likert scales.

Network participation within the industry was operationalised through two Likert questions. Network participation outside the industry was investigated through a scaled question concerning the extent of discussions with 'outside' organisations, and also a direct question on the frequency of external advice.

Questions concerning the competitive environment focused on the perceived competitiveness according to the adopter, as organisational behaviour is driven by the perceptions of competitiveness as opposed to the actual levels of competition (Frambach et al, 1996). Eight Likert type questions were used; several were broken into perceptions of $\mathrm{NZ}$ and overseas.

Information processing of the adopters was operationalised through measurement of the number of meetings, brochures and exhibitions concerning digital technology.

The assessment of perceived innovation characteristics was carried out through 18 Likert type questions. These questions were largely derived from Fambachs et al's (1996) questions on electronic banking. However questions were modified, added or deleted to particularly suit the case of digital technology in the NZ motion picture 
industry. This was based on many sources e.g. expert interviews, industry magazines, and the trade exhibition attended.

\subsubsection{Supply-side variables}

The measurement of the supply-side variables is carried out from the perspective of the non-adopter. It is the adopter's perceptions of the supplier's marketing strategy and innovation development activities that affect the rate of adoption. Hence measurement of perceptions is preferred over the measurement of the actual activities; "If men perceive situations as real, they are real in their consequences" (Thomas and Znaniecki, $1927: 81)$.

Marketing strategy of suppliers was operationalised through measuring the extent to which the adopter was exposed to activities which positioned the innovations in the market place, activities which reduced the risk of adoption or activities which aimed to win market support by promoting the supplier's reputation.

Positioning was investigated through questions about pre-announcement of the innovation, personal selling, direct mail, communication of price or product features and invitations to trade exhibitions. Risk reduction by suppliers was tested through asking respondents whether they were offered a trial period. Winning market support as a market strategy was tested through asking respondents if suppliers had stressed their distinctive capabilities in the domestic market, internationally, and with respect to editing and special effects. Respondents were also asked if suppliers had pointed out other users.

Perceived customisation was measured by a Likert type scale. The two issues addressed were sophistication of the product and the extent to which suppliers took into account the adopter's needs and wants.

\subsubsection{Additional hypotheses}

The first additional hypothesis was tested through two questions. The first asked how respondents would rate competition in NZ, the other asked how they rated it overseas. 
The second and third hypotheses concerning perceptions of NZ industry and effects firms in particular overseas, where tested through asking respondents outright to rate these thing's on a scale from (1) very successful to (5) not at all successful. The perception of branding was tested through a Likert question stating that branding affects work received. The last hypothesis was tested through two questions asking to what extent their organisations invested in marketing in NZ and overseas, respectively.

\subsubsection{Pretests}

A questionnaire has many issues to consider to ensure it is valid and usefully testing the researcher's aims. Just some of the things the researcher must be sure of are the: length of questions and survey; social desirability; sequencing of questions; ambiguity of questions; and recall-dependent questions.

Hence the present survey was pilot tested with the eight randomly chosen respondents mentioned. Also the pilot surveys were sent to six 'experts' in different areas pertaining to the research and research design. These individuals were:

- Mathematical Statistician, Survey Methods, Statistics NZ;

- Survey Design Statistician, Statistics NZ;

- Lecturer, Department of Theatre and Film, Victoria University of Wellington;

- Professor Ruud Frambach, Marketing, Ghent University, Belgium;

- Freelance video Producer;

- Systems Analyst, in the NZ Motion Picture Industry.

The opinions given by any of these individuals are not necessarily the opinions of their organisations.

Any changes made to the pilot survey, came about from a combination of the comments from the 'experts' and a close examination of how the eight respondents from the population had answered the questions and what comments they had written on the paper. 
The biggest change brought about by the consideration of the responses was that the survey was not tailored enough for smaller firms and many of them could not see how to answer. Hence the instructions in the introductory definition box were altered to indicate that self employed respondents where also suitable. Several other key pieces of advice were offered, these are discussed in the following sections.

Have you considered the possible inclusion of a "don't know" or "not applicable option"?

The problem with a "don't know" category is that respondents may find it a lot easier to tick this option than seriously considering the question. The respondents filing out the pilot survey seemed to leave questions blank or write $n / a$ beside them if they were not appropriate. Hence it was deemed suitable to leave the questions as they were, i.e. excluding a "don't know" option.

By focusing a whole section on "the most recent piece of digital technology" answers will be excluding laggards and information will be very limited when considering just one piece of technology.

This suggestion raised many issues that needed very careful consideration particularly as the pilot survey had 12 questions under this section, several of which tested core hypotheses. There were three options for dealing with this. Firstly to leave the questions based on the most recent technology. This option had the benefit of the respondent being able to clearly answer the questions, as they could be specific. Also the recall problem is diminished as they are being questioned on a recent event. However, as discussed earlier, there is more than one question which measures the time of adoption, of the organisation. Leaving the survey as it was meant those independent variables being tested in this section could not be tested against all the time of adoption measures. The other disadvantage about basing this section around the most recent purchase is that respondents would be talking about different technologies. Lastly, there is no extent of adoption questions under this section, so extent of adoption could not be compared to the given independent variables. 
The second option was to focus the section around the respondent's first purchase of digital technology. However this raised exactly the same issues as the first option.

The third option was to still ask respondents a few questions about the most recent purchase, but to remove the "independent variable testing questions" and put them in the "digital technology in general section". However in this case the responses may not be as clear or specific. Also this was a fairly large change without a pilot test. However, the industry does seem to be capable of lumping the digital technology concept into one and discussing it in general. This was demonstrated by the lack of problems respondents had answering the section that asked them to think of digital technology in "general" in the pilot survey. The major advantage of this approach is that the time and extent of adoption variables can then be compared to all parts of the survey. Also the most recent purchase could become another measurement of time of adoption. After carefully considering all three options, the third was elected.

\subsubsection{Other suggestions}

Many other minor suggestions were implemented right away. One of these was keeping all the positive answers to one side of the page. That is, make the "high extent" response match the "very successful" response.

The opening definition was deemed not to be clear enough or prominent enough. Hence it was altered to attract more attention and read more clearly. Many very minor grammatical, spelling and wording recommendations were taken on board.

Most comments received were positive. The survey overall was said to be well laid out and very clear.

\subsection{DATA PROCESSING AND ANALYSIS}

The following section explains the details of data processing and analysis. The topics to be covered are: coping with incomplete data; packages used; and the appropriate statistical methods for each stage of analysis. 


\subsubsection{Incomplete Data}

Of the thirty nine complete responses, nine respondents did not in fact purchase or lease digital technology at any stage. However they still fitted the criteria as their organisation had over one FTE staff member working with digital technology for editing or special effects for the motion picture industry. The technology they used, however, was owned by another organisation, usually that they were contracting their time to. This begs the question, Are these organisations adopters? They are certainly adopters in the sense that they have made a conscious decision to use digital technology over analog. Although have they? If a respondent has chosen to contract members of their organisation to another organisation to do certain editing or effects tasks and the organisation in question has only digital technology available, is the respondent's organisation a conscious adopter?

For argument's sake, assume they are adopters in the true sense of the word. Then it would stand to reason that these nine respondents would be included in the analysis as per normal. However the dependent variables are the time and extent of adoption and these must be measured to some degree effectively to include a respondent in the analysis. Unfortunately the time of adoption questions are not worded in a way that would make sense to these nine respondents e.g.. there are questions concerning when they obtained, adopted, or bought articles of digital technology. These questions should have been worded slightly differently to obtain appropriate information from the nine respondents. Hence the nine respondents were removed for the testing of the hypotheses. However they were included when considering some industry demographics.

\subsubsection{Coding/Analysis Packages}

The remaining 30 responses were coded. Coding was straightforward for the yes/no questions and the Likert type questions. Open-ended questions were briefly examined to get a feel for the types of responses. Responses were then broken into categories and those that did not fit any category were coded under "other". 
The data was entered into Microsoft Excel 5.0, where some basic descriptive statistics were produced. More complicated statistical analysis was carried out on SYSTAT 6.0. The data was copied from Excel 5.0, after the column headings were removed and blank cells replaced with full stops. The statistical package S-Plus was also used for that which SYSTAT could not compute.

The analysis is broken into three parts. Part one gives an initial feel for the data with some descriptive statistics. Part two considers the reliability of the data. Finally the hypotheses are tested. The following discussion of the approaches used in the analysis is broken into the same three sections.

\subsubsection{Descriptive Statistics}

The descriptive statistics, i.e. mean, standard deviation, maximum and minimum values, were obtained through simple formulas in Microsoft Excel 5.0. Demographics such as type of firm, sex of respondents and age of respondents were collated, counted, sorted and graphed through Excel 5.0.

\subsubsection{Reliability}

The reliability of the data is a test of its 'goodness'. Another issue when considering the goodness of data is the validity. Validity measures whether the data is correct, that is, whether you are effectively and accurately measuring what you attempt to. The validity is very difficult to measure. There are many ways to ensure the data is valid, including carefully pilot testing the research instrument, avoiding biased questions, selecting appropriate contacts to interview. All efforts in this sense have been made and are discussed throughout the first half of this chapter.

Reliability is a more technical measure of 'goodness'. For the present research many of the independent variables are measured through several questionnaire items. Cronbach's alpha was used to test the reliability of the measures. Also the dependent variables are measured through different survey items. Cronbach's alpha may be used to test the reliability of the measures for the dependent variables also. 
Alpha can be viewed as the lower bound for the correlation between the variables being tested and all other tests and scales which can be constructed to measure the same characteristic of interest. For example, if we test the variable 'positioning' through six questions and the alpha is 0.5 , we can say that the correlation between the sum of the six questions and the sum of any other group of questions which test positioning in the same population would have a correlation of at least 0.5 . This seems like a rather abstract concept. However what is useful is that a high Cronbach's alpha may only be possible if the six questions used in the first place 'hang together' well, i.e. if they really are testing the same thing. Or, put another way, a high Cronbach's alpha would indicate that the questions asked are reliable measures.

Cronbach's alpha ranges from -1.0 to +1.0 , where negative values show a negative correlation. For example if two questions effectively tested the same thing on a Likert scale and one was framed in the positive and one in the negative, the Cronbach's alphas would be expected to be close to negative one.

Factor analysis was not carried out because the number of companies was not large enough. Also the basic assumptions of factor analysis do not very appropriately fit the kind of data obtained from mail out surveys.

\subsubsection{Hypothesis Testing}

\subsubsection{Regression}

Previously it has been stated that the present research contains dependent and independent variables. It would hence seem obvious that the hypotheses should be tested through multiple regression. Regression fits a line through a set of observation using the least squares method (Microsoft, 1993). Regression seeks to analyse (and produce equations) for how one or more independent variables affect a dependent variable, so that future situations can be predicted. In the present case the aim would be to enable researchers to predict the time or extent of adoption by firms with certain characteristics. 
However the principle of least squares that lies behind regression often carries with it an assumption that the observations are normally distributed. This is a very dangerous assumption for the present research where much of the data is binary, or categorical. Regression is also not a desirable technique to use when there are a small number of respondents comparative to the number of independent variables. In this case the independent variables are measured through 57 questions and the dependents through 14. Hence the regression approach is not deemed appropriate for the present research.

\subsubsection{Measures of association}

The data gathered falls into three categories: ratio, ordinal and binary. As regression was deemed inappropriate, ratio and categorical data are examined through Pearson's and Spearman's correlations. Biserial correlation, and chi-square measures of association are also used when appropriate. Table 6 shows which measures are appropriate for which combinations of data types.

The ratio measurement scale can indicate how many times as great one object or event is than another as well as by how much they differ (Daniel, 1977). Ordinal data distinguishes one object or event from another on the basis on whether or not it has more or less of some characteristic than another object or event. For example the Likert type scale in the survey instrument gives ordinal data. Binary data is data with only two possible forms or categories e.g. yes or no. 
Table 6: Rules For Statistical.

\begin{tabular}{|l|c|l|l|}
\hline DATA TYPE & RATIO & ORDINAL & BINARY \\
\hline RATIO & Pearson's & Spearmans & Biserial \\
ORDINAL & - & Spearmans & Chi-square table \\
BINARY & - & - & Chi-square table \\
\hline
\end{tabular}

Source: Personal communication, Peter Smith, 1997, Victoria University of Wellington.

\subsubsection{Correlation}

Given that regression is not appropriate correlation may still be used. Correlation can be used to determine whether two ranges of data move together. If large values of one set are associated with large values of the other the correlation is positive correlation. On the other hand if small values of one set are associated with large values of the other the correlation is negative correlation. If the values in both sets are unrelated the correlation nears zero.

The Pearson correlation is popular measure of association between variables. It is used when both data sets are ratio or continuous data. The Pearson product-moment correlation coefficient varies between -1 and +1 , where +1 indicates a perfect positive correlation (SYSTAT, 1992). A Pearson correlation of zero indicates that neither of the two variables in question can be predicted from the other with a linear equation (SPSS Inc. 1996).

Spearman's correlation produces a Spearman rank-order correlation coefficient. Spearman's correlation is used for ordinal and ordinal, or ratio and ordinal combinations. Spearman's correlation coefficient is the same as a Pearson correlation computed on the same data after it has been ranked.

Pearson's and Spearman's correlations have an assumption of linearity. That is, that the relationship can be represented by a straight line. This assumption is a reasonable one as long as the graphed data do not indicate any obvious trend to the contrary. The 
present data did not show any obvious non-linear trends, hence the assumption of linearity is applicable to the present scenario.

Correlation investigates how two data sets change together and hence does not strictly have dependent and independent variables. However to avoid these terms altogether would be pedantic, so the terminology is maintained.

\subsubsection{Chi-square Test}

Some of the independent variables were operationalised through yes/no questions, i.e. binary data. For testing the relationship between these and the independent variables, which are ordinal and ratio, Pearson's and Spearman's correlations are not appropriate.

When testing the correlation between two sets of binary data or one binary and one ordinal, a chi-square test of association may be used. The cross-tabulation function in SYSTAT was used to produce a two-way table. There are several tests and measures for two-way tables. The most familiar is the Pearson chi-square test for independence (SYSTAT, 1996). The chi-square test is a non-parametric test, which determines whether an observed pattern in a two-way table of any size is due to chance or not. This test operates on the principle of expected and actual frequencies (Sekaran, 1984). Pearson's chi-square test of independence was carried out for or the ordinal and binary combinations.

Cramers V can be used to show the strength of the association, where Cramers V is calculated by:

$$
V=\sqrt{\frac{\chi^{2}}{N}}
$$

Where $\chi^{2}$ is the chi-square value and $N$ is the sample size used to calculate the chisquare. 


\subsubsection{Biserial}

The Biserial correlation refers to the association between two variables $\mathrm{X}$ and $\mathrm{Y}$, where $\mathrm{X}$ is binary and $\mathrm{Y}$ is ratio. The choice of the correct parameter to measure such an association depends on the nature of the population and even then it is open to debate.

For the present research the association will be measured by the point Biserial correlation, where $\mathrm{X}=0$ and 1 and $\mathrm{Y}$ is normal. The point Biserial correlation coefficient $r_{p b}$ is calculated as follows:

$$
r_{p b=}(p q)^{1 / 2}\left(\overline{y_{1}}-\overline{y_{o}}\right) / s_{y}
$$

Where:

- $\left(x_{1}, y_{1}\right),\left(x_{2}, y_{2}\right) \ldots \ldots \ldots . . .\left(x_{n} y_{n}\right)$ is a sample from the $(\mathrm{X}, \mathrm{Y})$ population,

- $\bar{y}_{1}$ and $\bar{y}_{0}$ are the mean y-values of observations having $\mathrm{x}_{\mathrm{i}}=1$ and $\mathrm{x}_{\mathrm{i}}=0$, respectively,

- $\mathrm{S}_{\mathrm{y}}$ is the sample variance of $\mathrm{Y}$, and

- $\mathrm{p}$ is the proportion of the $\mathrm{X}$-sample with $\mathrm{x}_{\mathrm{i}}=1$,

- $(q=1-p)$,

The correlation coefficient is an estimation of the population coefficient. By definition the population coefficient cannot be greater than one (or less than negative one). However the sample correlation coefficient in some circumstances will exceed one (or be less than negative one). In such cases the correlation is strong (as it is close to one). However the p-value cannot be calculated.

The test statistic $t$ is then used to test the null hypothesis, where $t$ is as below and is distributed as a Student $t$ with n-2 degrees of freedom. 


$$
t=(n-2)^{1 / 2} r_{p b}\left(1-r_{p b}^{2}\right)^{-1 / 2}
$$

The statistical packages used did not have function for the above calculations, hence formulas had to be written in Excel to calculate $t$.

\subsubsection{Probabilities}

These correlation coefficients need more information before they can be interpreted, namely a p-value. A p-value is the probability that a given correlation coefficient of at least the given size would occur even if the variables are uncorrelated. For example a p-value of 0.05 means there is a $5 \%$ percent chance that a correlation would show up even if the two given variables were unrelated.

To obtain p-values for Spearman's, the data was ranked and a Pearson correlation coefficient and corresponding p-value were calculated. This was done because only the Pearson Option in SYSTAT produces p-values. Pearson's and Spearman's produce two-sided p-values. However they are mostly being used in this research to test one-sided hypotheses. That is, the alternative or test hypothesis has a direction e.g. a positive correlation exists between $\mathrm{X}$ and $\mathrm{Y}$. Hence the two-sided p-value produced by SYSTAT must be halved.

P-values calculated for the Biserial correlation and the chi-square test are being used to test two-sided hypotheses. That is, the alternative or test hypothesis has no direction e.g. there is an association between $\mathrm{X}$ and $\mathrm{Y}$. Hence the p-values are not halved.

Each hypothesis is tested through a series of individual correlations. Hence Bonferroni probabilities should be calculated to allow for this multiple testing. These calculations are outside the scope of the present research; however this is accounted for in the analysis, through very conservative $p$-values. 


\subsubsection{Missing data}

SYSTAT 6.0 provides several options for dealing with missing data. Listwise deletion was chosen as it is the default. If a variable specified has a missing value, the case is omitted from computation. That is, any case with missing data for any variable in the list is excluded. Case here means for example if a respondent did not respond to one question being correlated, then that respondent would be removed for the correlation in question. Hence when matrices of correlations were run (i.e. more than one correlation at a time) the number of observations became very low. This necessitated running only one correlation at a time, in order to keep the number of observations as high has possible.

\subsubsection{Additional hypotheses}

Of the five hypotheses, two ask, Is there a significant difference between two questions? That is, Is any difference in response attributed to chance alone? This is tested through Wilcoxon's signed pairs rank sum test in SYSTAT. The remaining three hypotheses were tested by single Likert type questions. In order to accept or reject these hypotheses a column of neutral responses was produced and then Wilcoxon's signed pairs rank sum tests were run to see if the responses given were significantly different to neutral.

\subsection{CHAPTER SUMMARY}

Exploratory research was carried out through personal interviews, email, and telephone interviews, in order to gain a clearer understanding of the industry and narrow down the topic and population definition.

The population to be surveyed was: All NZ organisations with at least one FTE staff member working with digital technology for editing or the production of special effects for film television or video. The sample frame was 126 organisations, to which letters were sent asking if they fitted the population criteria and whether they wished to be included in the study. Surveys were pilot tested with both the respondents and some 'experts'. The final survey was sent to 64 organisations. 
The survey aimed to test the hypotheses in stated in Chapter Three. The majority of the questions were adopted from Frambach et al's 1996 study in the Netherlands. A few extra questions were created to investigate the industry's demographics and the additional hypotheses. The dependent variables of time and extent of adoption were measured through several questions, some of which asked for measurements (for example sales) and others for perceptions. The surveys were carefully pilot tested and altered accordingly.

Incomplete surveys were removed from the analysis. Responses were coded and entered into an Excel spreadsheet. SYSTAT was used to calculate what Excel could not. Statistical tools used to test hypotheses included Pearson's correlations, Spearman's correlation, Cronbach's alpha, chi-square tests and Biserial correlations. 


\section{RESULTS - DESCRIPTIVE}

\section{STATISTICS}

\subsection{INTRODUCTION}

Analysis of the survey results has been separated into two chapters. This chapter presents the descriptive statistics and examines the data reliability. The following chapter discusses hypothesis testing.

The analysis is based mainly on 30 survey responses, although 39 responses were obtained. See Chapter Four (Section 4.4.1) for the rationale behind removing nine responses from the analysis. Not all survey responses are discussed in depth, as there were many survey questions and a few which produced nothing meaningful are not considered.

\subsection{DESCRIPTIVE STATISTICS}

One of the objectives of this thesis was to obtain more demographics on the NZ motion picture industry. The first section of this chapter presents the descriptive statistics under four headings: the population size, the industry statistics, the organisation and the respondent (Refer to Appendix $\mathrm{H}$ for the questionnaire).

\subsubsection{Population Size}

As per Chapter Four (section 4.3.3) surveys were sent to 64 organisations, of which 42 responded (66\% response rate). However three respondents changed their status to 
not fitting the population, hence did not complete the survey. Thirty nine completed surveys were received.

Of the 126 organisations located, nine were closed or registered under two names. This left 117 organisations. However, one more participant was identified through personal communication with an industry member. Hence there were 118 organisations which were potentially in the population ${ }^{1}$. Of these 64 fitted the population definition criteria, 39 did not and 15 did not respond ${ }^{2}$.

\section{Table 7: Sampling Frame}

\begin{tabular}{|l|l|l|}
\hline Status & Number & Percent \\
\hline In Population & 64 & 54 \\
Not it Population & 39 & 33 \\
No response & 15 & 13 \\
TOTAL & 118 & 100 \\
\hline
\end{tabular}

If it is assumed the non respondents fit the population definition in the same proportion as the respondents, the estimated size of the population is 73 organisations. That is, there are estimated to be $73 \mathrm{NZ}$ organisations which have at least one FTE staff member working with digital technology for editing or the production of special effects for film television or video.

As discussed in Chapter Four the number of firms that fit the population but are outside the sampling frame ${ }^{3}$ is likely to be very limited. Hence 73 organisations is a reasonable estimation of the population size.

The number of firms responding was 39 , which is a $53 \%$ of the estimated population. The number of organisations with data being analysed is 30 (41\% of the population). However this is still a very high response rate for this industry. For example, the

\footnotetext{
${ }^{1}$ The population is: all NZ organisations with at least one FTE staff member working with digital technology for editing or the production of special effects for film television or video.

${ }^{2}$ These figures differ from those in Chapter 4, this is due to the 3 respondents who changed status at the time the surveys were sent.

${ }^{3}$ The sampling frame is: the 118 organisations, attempting to cover the target population.
} 
Strategic Audit of the industry received a $27 \%$ response rate, which was considered high (Miles and Fuller, 1993:13).

\subsubsection{Industry Statistics}

Question 1 asked respondents to tick adjectives they felt described their industry. This question allowed for multiple responses. Figure 7 shows the percentage of respondents who selected each adjective. The two responses under "Other" were, "cut throat" and "frustrating". The most popular adjectives chosen by respondents to describe their industry were "creative" and "competitive", which were selected by $90 \%$ and $86.6 \%$ respectively. The least popular adjectives were "unique" and "conservative", both scoring $20 \%$.

\section{Figure 7: Which of the following adjectives would you use to describe your}

\section{industry?}

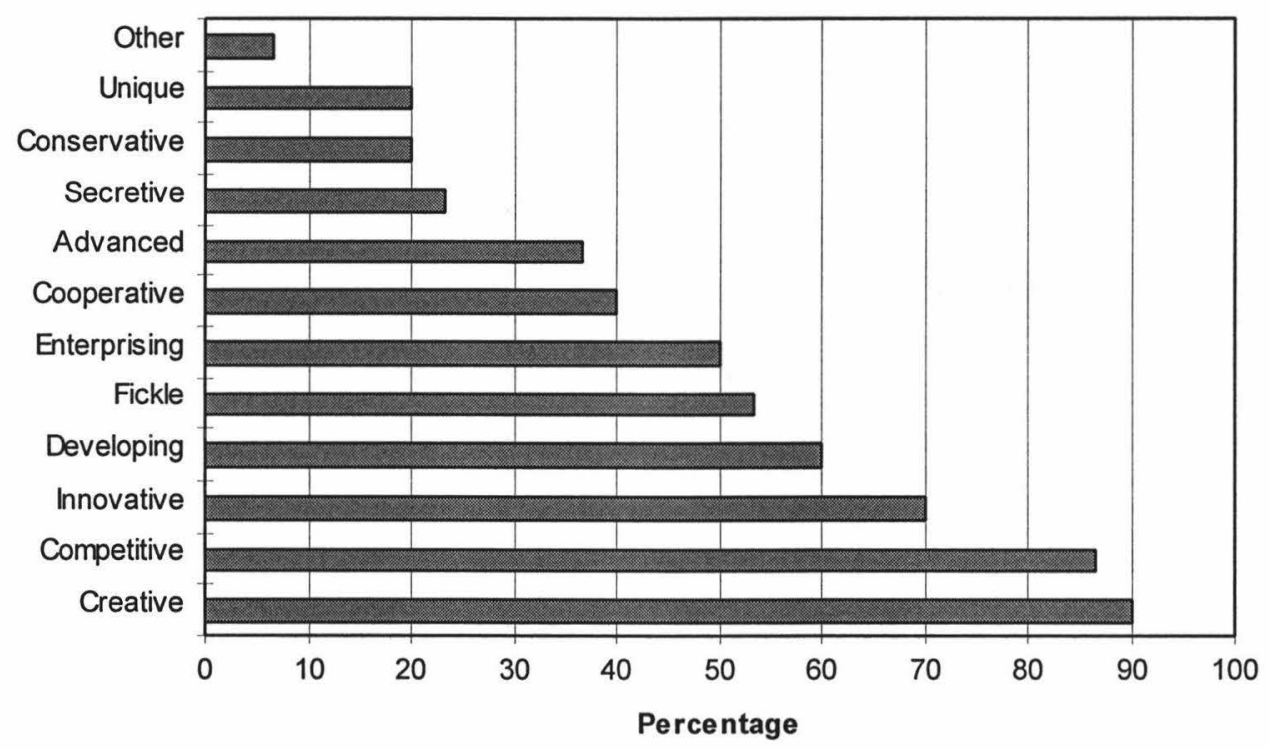

The mean sales revenue per annum of respondents was in excess of $\$ 2$ million, around $11 \%$ of which is spent on digital technology. Hence, it is estimated that NZ firms with over one FTE staff member working with digital technology for the use in editing and special effects have a combined sales revenue of $\$ 160$ million. The total NZ motion picture industry size was estimated in 1993 (Miles and Fuller) to be $\$ 300$ million. Foreign exchange earnings nearly doubled between 1993/1994 and 1994/5 
(Colmar Brunton, 1996). Hence the total motion picture industry size (domestic and international sales) is likely to be somewhat higher than \$300 million for 1996. However, the editing and special effects firms (earning \$160 million) appear to make up a large part of the industry's earnings. Appendix L compares these results with results including the nine extra respondents which were not used for analysis.

\section{Table 8: Spending}

\begin{tabular}{|l|c|c|c|c|}
\hline & Respondents & Mean & Total & $\begin{array}{c}\text { Population } \\
\text { estimation }\end{array}$ \\
\hline Dollars spent on digital technology & 26 & $\$ 240,000$ & $\$ 6.4$ million & $\$ 18$ million \\
No. of items of digital technology & 26 & 2.9 & 74 & 210 \\
FTE staff members & 30 & 58 & 1,700 & 4,200 \\
FTE working with digital technology & 29 & 5.7 & 160 & 410 \\
Sales revenue of organisation & 20 & $\$ 2.2$ million & $\$ 44$ million & $\$ 160$ million \\
\hline
\end{tabular}

*Numbers are rounded to two significant figures.

\subsubsection{Organisation Details}

Table 8 shows the average number of FTE staff members in responding organisations to be 58. However, the industry is made up of a few large players and many smaller players. If the largest three organisations are removed, the mean number of FTE drops to seven. The strategic audit of the motion picture industry (Miles and Fuller, 1993) showed the average number of employees per company to be slightly less than six people. This was also excluding the larger firms as they did not respond.

The main purpose of $33 \%$ of the responding organisations fell under 'post-production activities'. Responses under 'other' included mission type statements e.g. "to be creative". 
Figure 8: What is the main purpose or mission of your organisation?

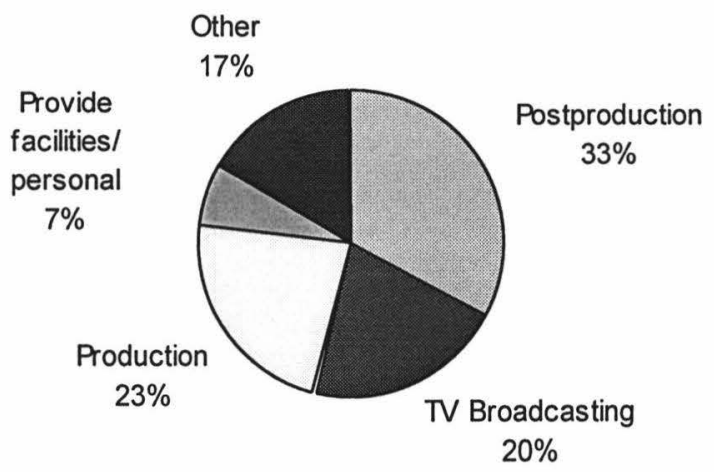

Similar proportions of respondents said they did: mostly editing(26\%); mostly editing and special effects (FX) (27\%); and complete post-production activities (27\%). A relatively small proportion of respondents (7\%) specialised in FX.

Figure 9: What main tasks does your organisation do in the area of editing and special effects?

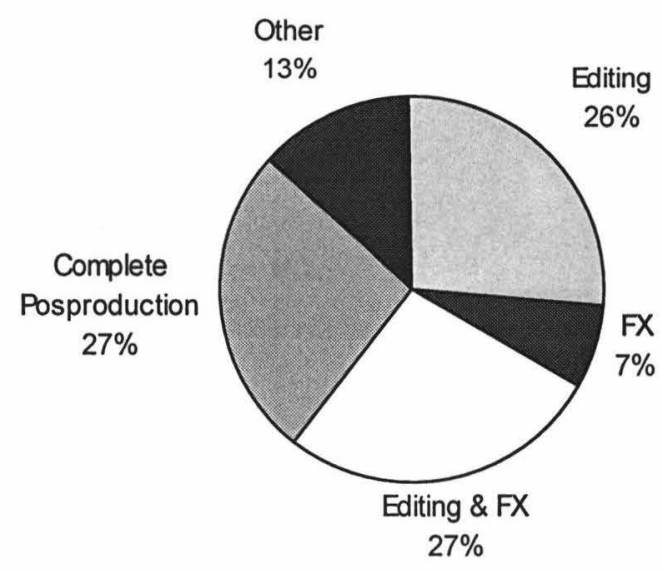

Respondents were asked to comment on what percentage of their output was in the areas of film, television, video and other. They were asked to ensure that their responses summed to $100 \%$. This was the case with all but one response. Figure 10 shows the average output in each area. The large majority of output by respondents was in the area of television, which showed an average of $65 \%$. This was followed by 
video at $19 \%$, and film at $11 \%$. Less than two respondents chose the 'other' category. These responses were 'multimedia' and 'presentation graphics'.

\section{Figure 10: Output of editing and FX}

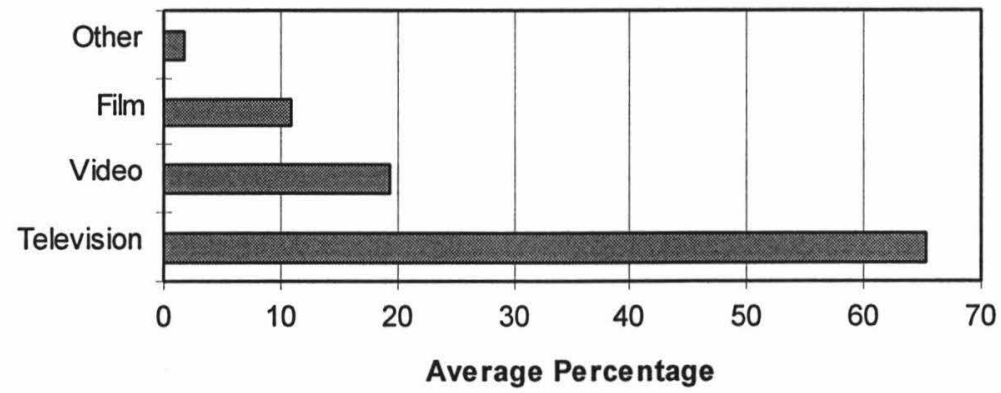

Respondents were asked what percentage of their sales were distributed locally, around NZ and overseas. Three respondents did not comment. The average of local sales was $70.7 \%$, with a standard deviation of $31.3 \%$. An average of $20.4 \%$ (standard deviation of $22.7 \%$ ) were distributed through the rest of NZ. An average of $8.4 \%$ were overseas, with a standard deviation of $16.4 \%$.

\section{Figure 11: Distribution of Sales}

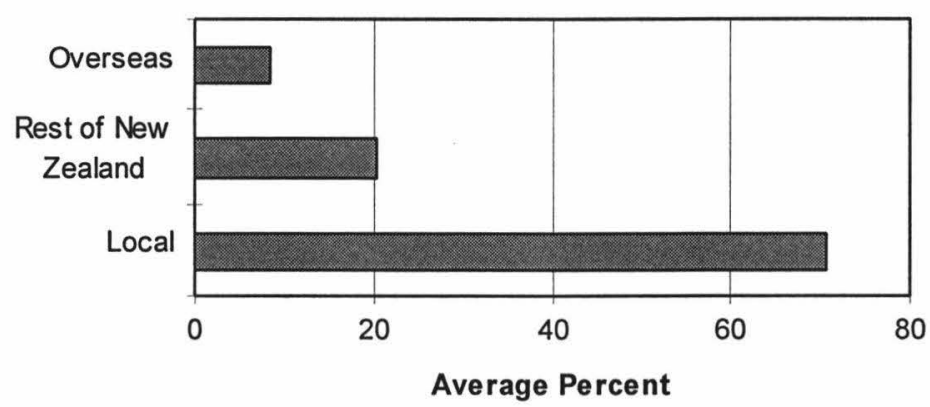

Respondents were asked when their company commenced business and when they began editing or producing special effects. The average start date was December 1989, with a standard deviation of a little over six years. The earliest start date was January 1973 with the most recent being March 1996. The average date for beginning editing and special effects was April 1989, with a standard deviation of nearly six years. 


\subsubsection{Respondents}

The final section in the questionnaire asked for some demographics on respondents. These were, sex, age and job title. A massive 93\% percent of respondents were male.

\section{Figure 12: Sex of Respondents}

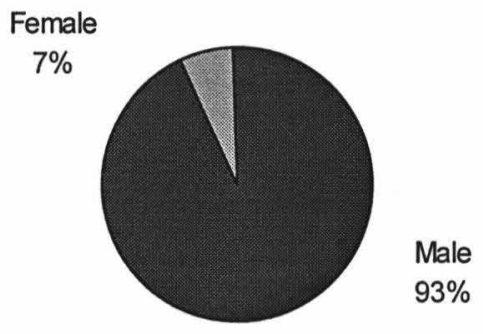

All respondents were between the ages of 26 and 55, 80\% of whom were between 26 and 45 years of age.

\section{Figure 13: Age of Respondents}

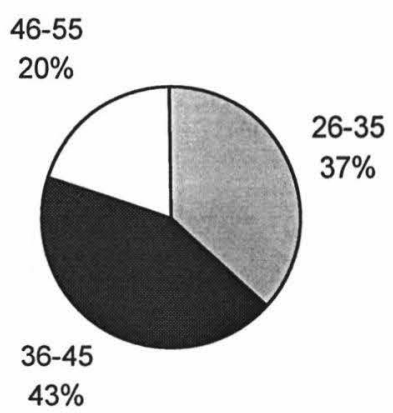

Figure 14 shows the job titles of respondents. The largest category was 'other' (30\%). This covered a range of similar job titles including Governing Director, Executive Director, and also Editor and Editing Supervisor. The majority of positions appear to be positions of some form of authority. It is worth noting in the motion picture industry the job title "Director" will have different connotations and responsibilities from a "Director" in most other industries. The Producer is responsible for the 
financial and project planning side of a production. The Director is responsible for more creative elements of production. As demonstrated, sometimes these roles are taken on by one person.

Figure 14: Job Title of Respondent

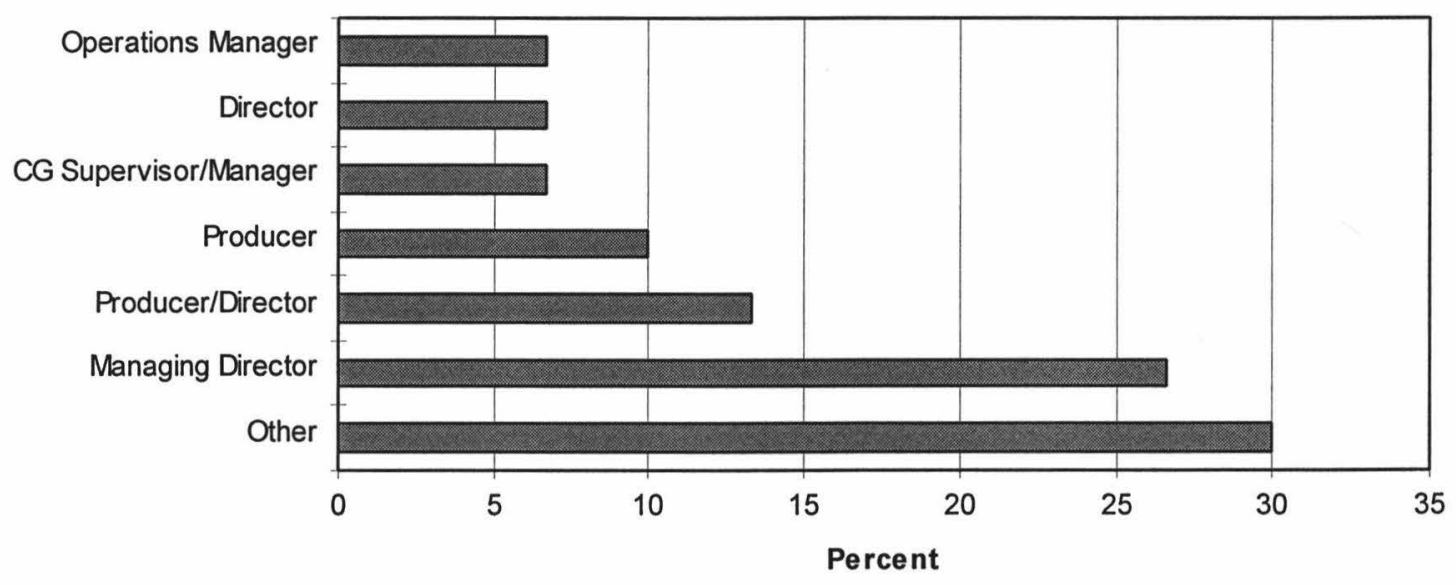

\subsubsection{Suppliers}

The question on who supplied respondents with their digital technology yielded many different responses that were not open to coding or collating. Firms mentioned at least two times were Amber, Film Facilities, Silicon Graphics and Sony NZ.

\subsection{GOODNESS OF DATA/RELIABILITY}

Tables 9 and 10 show the Cronbach's alpha values for those variables that were tested through more than one survey question. This excluded Observability, Trialability and Expectations Technology which were all measured through one question. Table 9 shows alpha values for the independent variables and Table 10 for the dependent. 
Table 9: Cronbach's Alpha - Independent Variables

\begin{tabular}{|l|c|c|c|}
\hline Variable Tested & $\begin{array}{c}\text { Number of } \\
\text { Questions }\end{array}$ & $\begin{array}{c}\text { Number of } \\
\text { Cases }\end{array}$ & $\begin{array}{c}\text { Cronbach's } \\
\text { Alpha }\end{array}$ \\
\hline Intensity of innovative activities & 6 & 27 & $* * *$ \\
Perceived customisation & 2 & 28 & 0.83 \\
Uncertainty & 3 & 29 & 0.78 \\
Market support & 4 & 27 & 0.77 \\
Centralisation & 3 & 25 & 0.74 \\
Receptiveness & 3 & 28 & 0.64 \\
Network participation - within & 2 & 29 & 0.55 \\
Relative advantage & 7 & 26 & 0.53 \\
Positioning & 6 & 27 & 0.50 \\
Intensity of competition & 4 & 29 & 0.49 \\
Complexity & 2 & 29 & -0.47 \\
Compatibility & 4 & 29 & 0.40 \\
Information & 3 & 22 & -0.00 \\
Size & 2 & 20 & 0.00 \\
Network participation - outside & 2 & 25 & 0.00 \\
\hline
\end{tabular}

*** 3 Questions were linearly related to one another, hence an accurate alpha could not be obtained

\section{Table 10: Cronbach's Alpha - Dependent Variables}

\begin{tabular}{|l|c|c|c|}
\hline Variable Tested & $\begin{array}{c}\text { Number of } \\
\text { Questions }\end{array}$ & $\begin{array}{c}\text { Number of } \\
\text { Cases }\end{array}$ & $\begin{array}{c}\text { Cronbach's } \\
\text { Alpha }\end{array}$ \\
\hline Extent of adoption & 5 & 18 & -0.40 \\
Time of adoption & 5 & 19 & -0.02 \\
\hline
\end{tabular}

There is no standard or accepted 'cut-off' point for Cronbach's alpha. It is useful, however, to consider the comparisons and to notice the very small and very large responses.

Cronbach's alpha tests the reliability of data or how well data 'hangs together'. Here Cronbach's alpha is testing if questions used to test one variable actually test the same thing. Those alpha values that are zero, that is, 'size' and 'network participation' are not reliable measures of the same thing. 'Perceived customisation' and 'uncertainty' on the other hand are very reliable measures.

Signs of the alpha values are as expected, as all groups of questions testing independent variables are asked in the same 'direction' except complexity. Also the 
dependent extent variable has three elements going in the other 'direction' to the other two, hence the negative alpha is to be expected.

Some of these Cronbach's alpha values are very low. 'Size' and 'network participation' for example have zero alphas to three decimal places. This could be looked at from several angles. Firstly, some of the questions concerning 'information', 'adopters size' and 'network participation', postulated by Frambach et al (1996), are in fact poor identifiers of the desired variables. Alternatively the questions used to test these variables are not suitable for the NZ motion picture industry. The questions were designed for adoption of electronic banking in the Netherlands. The banking industry is much less diverse than the motion picture industry. For the banking industry there is likely to be a substantially stronger correlation between variables such as revenue and number of staff, than in the motion picture industry.

Thirdly, it could be argued that the particular questions asked, even if they are not testing, the same or similar things add up to produce the desired variable. Organisation size is measured by the organisation's sales and the number of staff. Although these are measuring different things (which, in the motion picture industry do not appear to be closely related), perhaps staff numbers and sales are both crucial aspects of an organisation's size, and must be considered together.

\subsection{CHAPTER SUMMARY}

The key findings from the descriptive statistics were:

- The population size is estimated to be 73 organisations;

- $41 \%$ of the estimated population was used in analysis;

- Key adjectives used to describe the industry were 'creative' and 'competitive';

- The combined sales revenue of the population is estimated to be $\$ 160$ million;

- Most organisations have around 7 FTE staff members;

- The main purpose of most responding organisations fell under 'post-production' activities; 
- The main tasks carried out by responding organisations were 'editing and FX' and 'complete post-production';

- By far the majority of sales were for television;

- By far the majority of sales were local;

- $93 \%$ of respondents were male;

- $43 \%$ of respondents were aged between $36-45$;

- The most common job title of respondents was 'Managing Director';

- Suppliers were many and varied.

A range of Cronbach's alpha values were calculated. The very low Cronbach's alphas were for the dependent variables 'size' (of adopter) and 'network participation outside the industry' (of adopter) and the dependent variable time of adoption. 


\section{RESULTS - HYPOTHESES TESTING}

\subsection{INTRODUCTION}

This chapter discusses the hypotheses tested. Firstly the statistical tests used are briefly discussed, and operational definitions are introduced. Also before the hypotheses tests are presented, the dependent variables are analysed. Frambach's hypotheses are considered under seven key headings: two supply-side (marketing strategy and innovation development) and five adopter-side (perceived innovation characteristics, adopter characteristics, network participation, competitive environment, and information). The final section considers the 'additional hypotheses' which arose from the exploratory research.

\subsection{STATISTICAL TESTS}

Four different measures of association were used. Namely Pearson's, Spearman's, chi-square and Biserial. These measures were the bases of the following sections. Further details of analysis are given in Appendix L.

Of the 570 measures of association carried out, those presented here are only those with p-values less than or equal to five percent. The remaining statistical data is available on request from the author, however it is not deemed necessary to present it here. 


\subsection{OPERATIONAL DEFINITIONS}

It is important to outline some operational definitions to aid with navigation through the results. Operational definitions are made up of a concept, which has dimensions, which in turn contain elements. The concept in this case is the adoption of new technology. The dimensions are both the dependent variables of the time and extent of adoption and the independent variables e.g. 'relative advantage' of the innovation (See Chapter Four for full explanation of variables). The elements are the actual units that measure the variables. For the dependent variables the elements correspond directly to survey questions. The elements of the independent variables will be introduced in some depth in subsequent sections. Figure 15 outlines the operational definitions.

Figure 15: Operational Definitions

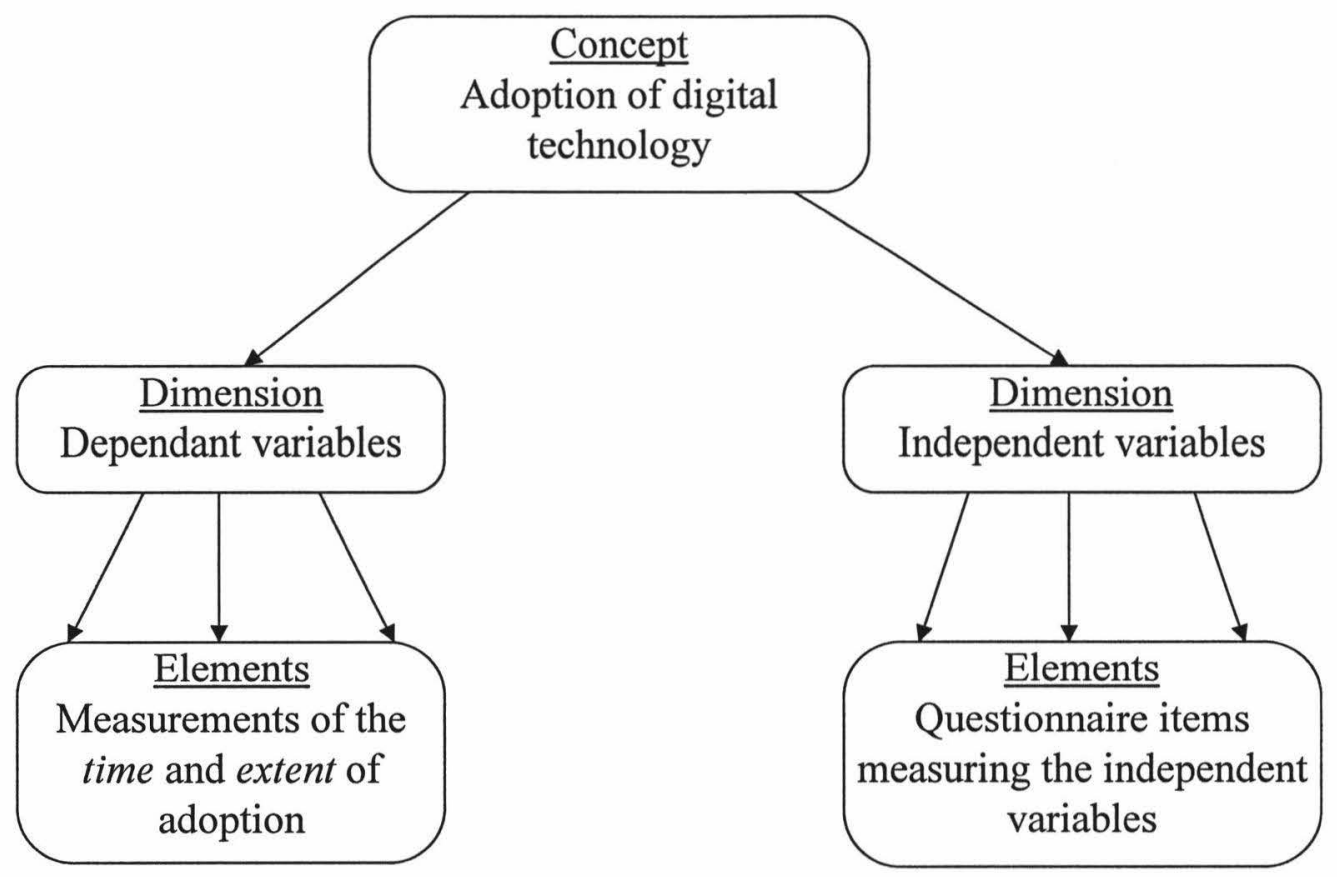




\subsection{TIME AND EXTENT VARIABLES}

Before the hypotheses concerning the relationships between the dependent and independent variables could be tested, the elements used to rate the dependent variables of time and extent must be investigated. There were fourteen survey questions used to try and 'calculate' each organisation's time and extent of adoption. These questions produced five time elements and five extent elements. These elements are defined in Table 11 and Table 12.

\section{Table 11: Time of Adoption Elements}

\begin{tabular}{|l|l|l|l|}
\hline Variable & Definition & Question & Data Type \\
\hline T1 & $\begin{array}{l}\text { Time in days of purchase of most recent piece of } \\
\text { digital technology after it became available. } \\
\text { Time in days of purchase of first piece of digital } \\
\text { technology after it became available }\end{array}$ & 17 and 18 & Ratio \\
T3 & $\begin{array}{l}\text { How fast respondents felt they obtained digital } \\
\text { technology compared to their competitors }\end{array}$ & 50 & Ratio \\
T4 & $\begin{array}{l}\text { Respondents' perceptions of their average time of } \\
\text { purchase after availability of digital technology } \\
\text { How often respondents perceived themselves to be } \\
\text { 'ahead of others' in buying digital technology }\end{array}$ & 64 & Ordinal \\
T5
\end{tabular}

*See Appendix $\mathrm{H}$ for details of questions.

Table 12: Extent of Adoption Elements

\begin{tabular}{|l|l|l|l|}
\hline Variable & Definition & Question & Data Type \\
\hline E1 & $\begin{array}{l}\text { Whether respondents felt the digital technology they } \\
\text { used was high end or low end }\end{array}$ & 49 & Ordinal \\
E2 & $\begin{array}{l}\text { Number of items of digital technology purchased in the } \\
\text { last two years } \\
\text { Percentage of FTE staff members in the organisation } \\
\text { working with digital technology }\end{array}$ & 53 & Ratio \\
E3 & $\begin{array}{l}\text { Percentage of sales spent on digital technology } 55 \\
\text { Respondents' perceptions of their extent } \text { of adoption }\end{array}$ & $\begin{array}{l}52 \text { and 56 } \\
60\end{array}$ & $\begin{array}{l}\text { Ratio } \\
\text { Ratio } \\
\text { E4 } \\
\text { E5 }\end{array}$
\end{tabular}

Pearson's or Spearman's ${ }^{1}$ correlations were used to investigate the strength of correlations between each of the five time elements and each of the five extent elements. The correlation coefficients for the correlations between the five extent

\footnotetext{
${ }^{1}$ Different correlations are apropriate in different situations, see section 4.4.5.3
} 
elements is shown in Table 13 and for the five time elements in Table 14. Adjacent tables show the p-values.

It is expected that if these elements are effectively testing the same thing that they will be positively correlated. The values in brackets show the expected signs if the correlation is positive (once the direction of the questions is taken into account).

\subsubsection{Extent Elements}

Table 13: Correlation Coefficients - Extent Variables P-values

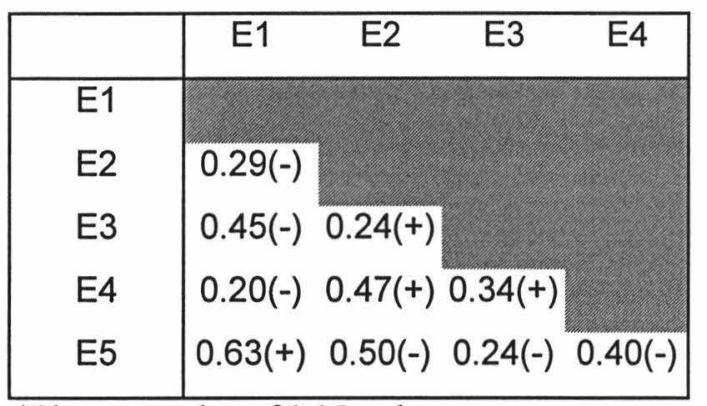

\begin{tabular}{|c|c|c|c|c|}
\hline & E1 & E2 & E3 & E4 \\
\hline E1 & & & & \\
\hline E2 & 0.075 & & & \\
\hline E3 & $0.010^{*}$ & 0.130 & & \\
\hline E4 & 0.215 & $0.025^{*}$ & 0.080 & \\
\hline E5 & $0.000 *$ & $0.005^{*}$ & 0.110 & $0.050 *$ \\
\hline
\end{tabular}

*Shows p-value of 0.05 or less

Only two of the possible 10 correlations between the elements of the extent of adoption have come out in the right direction and with a p-value less than $5 \%$. The Cronbach's alpha of -0.40 indicates a stronger overall correlation than this. However Cronbach's alpha does not take into account the expected direction of association.

There appears to be evidence to indicate a negative correlation between respondents' perceptions of their extent of adoption (E5) and the number of items of digital technology purchased (E2) and percentage of sales spent on digital technology (E4). There also appears to be a negative correlation between the percentage of staff working with digital technology (E3) and respondents' perceptions on whether they are high end or low end users (E1). 


\subsubsection{Time Elements}

Table 14: Correlation Coefficients - Time Variables P-values

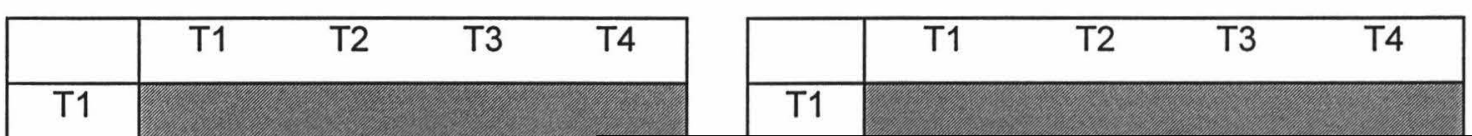


will be tested through each of the five extent elements and each of the five time elements.

The independent variables are tested through up to seven elements. Hence one hypothesis may have up to 35 individual associations that require testing, that is, five dependent elements against seven independent elements. Consider the null hypothesis; no association exists between the adopters' perceptions of suppliers' market positioning and the extent of adoption. Extent is measured through five elements and perception through six. Hence there are 30 individual associations to test, in order to test the hypothesis.

To emphatically accept or reject the null hypotheses in favour of the alternative, Bonferronni intervals would need to be employed, in order to correct for the multiple tests used. However such tests are out of the scope of this research. The present analysis will use a descriptive approach to interpret hypotheses. The descriptive approach considers the proportion of individual associations for an hypothesis which have a p-value of less than 5\%. A p-value of five percent is a conservative value, however it has been chosen as the adjusted (Bonferroni) probabilities would be higher than the p-values presented. The conservative p-value was chosen to allow for this.

This descriptive approach will state whether there is 'no', 'some', 'moderate', 'strong', or 'compelling' evidence to reject the null hypothesis in favour of the alternative hypothesis. Rationale for different terms is based on the proportion of possible associations which exist as shown in Table 15. It is important to take in to account that, with a p-value of $5 \%, 5 \%$ of the time an association is likely to be shown when in fact there is no association present $t^{2}$. Hence any hypotheses with $5 \%$ associations or less, must be considered to have 'no' evidence to reject the null hypothesis.

${ }^{2}$ See Chapter 4, Section 4.4.5.6 for explanation of p-values. 
Table 15: Descriptive Definitions for Hypotheses Testing

\begin{tabular}{|l|l|}
\hline$\%$ of associations & Description \\
\hline $0-5$ & None \\
$6-20$ & Some \\
$21-30$ & Moderate \\
$31-40$ & Strong \\
$41-$ & Compelling \\
\hline
\end{tabular}

Hypotheses are presented in the same order as they appear in Chapter Three and in Appendix I and J. Supplier-side hypotheses are considered under sections 'marketing strategy' and 'innovation development'. Adopter-side hypotheses are under sections, 'perceived innovation characteristics', 'adopter characteristics', 'network participation', 'competitive environment', and 'information'. Each independent variable has two hypotheses associated with it, one for extent and one for time; extent is presented first.

The expected sign shows the sign the correlation would have in order to accept the alternative or 'test' hypothesis (see Appendix M for a complete list of expected signs). This is not entirely intuitive as the expected sign sometimes changes direction within one hypothesis. This is due to the different wording of the survey questions (the survey was carefully worded to avoid bias and to keep the ranks (1 to 5) consistently in the same direction). Please note; the expected sign will not necessarily be the same as the direction of the alternative hypothesis. The expected sign is the sign for a given correlation between two variables which would support the alternative hypothesis. However, two questions may be worded in such a way that a positive correlation between them would lend support for negative association between the two variables being tested by them.

If the 'test value' of an individual association is in the opposite direction to the 'expected sign', the said association can not be counted as support for rejecting the null hypotheses. For chi-square and Biserial measures of association, an expected sign is not given, as these measures were used to test two-sided hypotheses. 
Hypotheses analyses should be read in conjunction with: Table 11 and Table 12 for dependent element definitions; Chapter Five for Cronbach's alpha; Appendix I for independent element details and survey question numbers; and Appendix $M$ for expected signs (remember these are not always intuitive).

Results of associations with p-values less than $5 \%$ are presented in the following tables. The tables show: the dependent variable; the survey question number (Ques no); sample size; type of test and measure used; the expected sign; the value of the correlation coefficient or other measure (test value); and the p-value.

\subsection{MARKETING STRATEGY}

\subsubsection{Positioning}

\subsubsection{Extent of Adoption}

Table 16: Positioning vs Extent

\begin{tabular}{|l|l|l|l|l|l|l|l|}
\hline Dependent & $\begin{array}{l}\text { Ques } \\
\text { no }\end{array}$ & $\begin{array}{l}\text { Sample } \\
\text { size }\end{array}$ & Test type & Measure & $\begin{array}{l}\text { Expected } \\
\text { Sign }\end{array}$ & $\begin{array}{l}\text { Test } \\
\text { Value }\end{array}$ & P-value \\
\hline E3 & 30 & 26 & Biserial & Coeff. & na & 1.281 & unknown* \\
E3 & 31 & 25 & Biserial & Coeff. & na & 1.271 & unknown \\
E3 & 32 & 27 & Biserial & Coeff. & na & 0.368 & 0.029 \\
E3 & 34 & 26 & Biserial & Coeff. & na & 0.801 & 0.000 \\
E3 & 35 & 27 & Biserial & Coeff. & na & 0.778 & 0.000 \\
E4 & 30 & 18 & Biserial & Coeff. & na & 0.617 & 0.003 \\
E5 & 34 & 28 & Biserial & Coeff. & na & 0.360 & 0.029 \\
E5 & 35 & 29 & Chi-square & Cramers V & na & 0.556 & 0.023 \\
\hline
\end{tabular}

*P-values cannot be calculated when the test value exceeds one, however the size of the test value indicates a strong association.

The association between 'positioning' and extent of adoption was examined through 30 individual associations, of which eight were significant at the $5 \%$ level. Hence, there is moderate evidence for rejecting the null hypothesis in favour of the alternative hypothesis, that an association does exist between 'positioning' and the extent of adoption.

\footnotetext{
${ }^{3} \mathrm{na}-$ not applicable, as the measure of assocation does not have a direction.
} 


\subsubsection{Time of adoption}

The association between 'positioning' and time of adoption was examined through 30 individual associations, of which none were significant at the 5\% level. Hence, there is no evidence for rejecting the null hypothesis that there is no association between 'positioning' and the time of adoption.

\subsubsection{Risk Reduction}

\subsubsection{Extent of adoption}

\section{Table 17: Risk Reduction vs Extent}

\begin{tabular}{|l|l|l|l|l|l|l|c|}
\hline Dependent & $\begin{array}{l}\text { Ques } \\
\text { no }\end{array}$ & $\begin{array}{l}\text { Sample } \\
\text { size }\end{array}$ & Test type & Measure & $\begin{array}{l}\text { Expected } \\
\text { Sign }\end{array}$ & $\begin{array}{l}\text { Test } \\
\text { Value }\end{array}$ & P-value \\
\hline E3 & 36 & 26 & Biserial & Coeff. & na & 0.418 & 0.016 \\
\hline
\end{tabular}

The association between 'risk reduction' and extent of adoption was examined through five individual associations, of which one was significant at the $5 \%$ level. Hence, there is some evidence for rejecting the null hypothesis in favour of the alternative hypothesis, that an association does exist between 'risk reduction' and the extent of adoption.

An association exists between individual elements E3 (\% of FTE working with digital technology) and the question 36 (offering of a trial period by the supplier).

\subsubsection{Time of adoption}

The association between 'risk reduction' and time of adoption was examined through five individual associations, of which none were significant at the $5 \%$ level. Hence, there is no evidence for rejecting the null hypothesis that there is no association between 'risk reduction' and the time of adoption. 


\subsubsection{Market Support}

\subsubsection{Extent of adoption}

Table 18: Market Support vs Extent

\begin{tabular}{|l|l|l|l|l|c|l|c|}
\hline Dependent & $\begin{array}{l}\text { Ques } \\
\text { no }\end{array}$ & $\begin{array}{l}\text { Sample } \\
\text { size }\end{array}$ & Test type & Measure & $\begin{array}{l}\text { Expected } \\
\text { Sign }\end{array}$ & $\begin{array}{l}\text { Test } \\
\text { Value }\end{array}$ & P-value \\
\hline E3 & 37 & 26 & Biserial & Coeff. & na & 1.145 & unknown \\
E3 & 38 & 20 & Biserial & Coeff. & na & 0.700 & 0.000 \\
E3 & 40 & 27 & Biserial & Coeff. & na & 0.572 & 0.001 \\
E4 & 37 & 18 & Biserial & Coeff. & na & 0.507 & 0.015 \\
E4 & 39 & 18 & Biserial & Coeff. & na & -1.098 & unknown \\
\hline
\end{tabular}

The association between 'market support' and extent of adoption was examined through 20 individual associations, of which five were significant at the $5 \%$ level. Hence, there is moderate evidence for rejecting the null hypothesis in favour of the alternative hypothesis, that an association does exist between 'market support' and the extent of adoption.

Individual associations exist between individual elements E3 (\% FTE working with digital technology) and questions 37, 38, 40 (reputation of the market leader, international reputation and pointing out other uses, respectively). Also a strong association exists between the individual elements E4 (\% sales spent on digital technology ) and question 37.

\subsubsection{Time of adoption}

The association between 'market support' and time of adoption was examined through 20 individual associations, of which none were significant at the $5 \%$ level. Hence, there is no evidence for rejecting the null hypothesis that there is no association between 'market support' and the time of adoption. 


\subsection{INNOVATION DEVELOPMENT}

\subsubsection{Perceived Customisation}

\subsubsection{Extent of adoption}

Table 19: Percieved Customisation vs Extent

\begin{tabular}{|l|l|l|l|l|l|l|c|}
\hline Dependent & $\begin{array}{l}\text { Ques } \\
\text { no }\end{array}$ & $\begin{array}{l}\text { Sample } \\
\text { size }\end{array}$ & Test type & Measure & $\begin{array}{l}\text { Expected } \\
\text { Sign }\end{array}$ & $\begin{array}{l}\text { Test } \\
\text { Value }\end{array}$ & P-value \\
\hline E1 & 41 & 28 & Pearson & Coeff. & + & 0.459 & 0.007 \\
E1 & 42 & 28 & Pearson & Coeff. & + & 0.422 & 0.013 \\
E5 & 41 & 28 & Pearson & Coeff. & + & 0.364 & 0.029 \\
\hline
\end{tabular}

The correlation between 'perceived customisation' and the extent of adoption was examined through 10 individual associations, of which three were significant at the $5 \%$ level. Hence, there is moderate evidence for rejecting the null hypothesis in favour of the alternative hypothesis, that a positive correlation exists between 'perceived customisation' and the extent of adoption.

A positive correlation exists between individual elements; E1 (respondents' perceptions of their equipment i.e. high or low end) and questions 41 and 42 (suppliers taking account of customers' needs, and sophistication of the product). Also between E5 (respondents' perception of their extent of adoption) and question 41.

Note: the 'perceived customisation' variable has a high Cronbach's alpha (0.83). Hence, it would be expected that if one element of 'perceived customisation' correlated with an element of extent, then all elements of 'perceived customisation' would correlate with that same element of extent. This was the case with element E1, but not E5. A similar observation can be made with time of adoption (below). 


\subsubsection{Time of adoption}

Table 20: Percieved Customisation vs Time

\begin{tabular}{|l|l|l|l|l|l|l|c|}
\hline Dependent & $\begin{array}{l}\text { Ques } \\
\text { no }\end{array}$ & $\begin{array}{l}\text { Sample } \\
\text { size }\end{array}$ & Test type & Measure & $\begin{array}{l}\text { Expected } \\
\text { Sign }\end{array}$ & $\begin{array}{l}\text { Test } \\
\text { Value }\end{array}$ & P-value \\
\hline T4 & 41 & 25 & Pearson & Coeff. & + & -0.371 & 0.034 \\
\hline
\end{tabular}

The correlation between 'perceived customisation' and the time of adoption was examined through 10 individual correlations, none of which were significant at the $5 \%$ level. Hence there is no evidence to reject the null hypothesis in favour of the alternative that a positive correlation exists.

The correlation coefficient (test value) between individual elements T4 (respondents' perceptions of their average time of adoption) and question 41 (suppliers taking account of needs of adopters) is negative. This contradicts the alternative hypothesis that there is a positive correlation between 'perceived customisation' and the time of adoption.

\subsection{PERCEIVED INNOVATION CHARACTERISTICS}

\subsubsection{Relative Advantage}

\subsubsection{Extent of adoption}

Table 21: Relative Advantage vs Extent

\begin{tabular}{|l|l|l|l|l|l|l|c|}
\hline Dependent & $\begin{array}{l}\text { Ques } \\
\text { no }\end{array}$ & $\begin{array}{l}\text { Sample } \\
\text { size }\end{array}$ & Test type & Measure & $\begin{array}{l}\text { Expected } \\
\text { Sign }\end{array}$ & $\begin{array}{l}\text { Test } \\
\text { Value }\end{array}$ & P-value \\
\hline E2 & $21 \mathrm{~F}$ & 25 & Pearson & Coeff. & - & 0.698 & 0.000 \\
E3 & $21 \mathrm{D}$ & 26 & Pearson & Coeff. & - & 0.334 & 0.048 \\
E3 & 21F & 27 & Pearson & Coeff. & - & 0.339 & 0.042 \\
\hline
\end{tabular}

The correlation between 'relative advantage' and the extent of adoption was examined through 35 individual correlations, none of which were significant at the $5 \%$ level. Hence there is no evidence to reject the null hypothesis in favour of the alternative that a positive ${ }^{4}$ correlation exists.

\footnotetext{
${ }^{4}$ Do not confuse 'expected' sign with the sign of the alternative hypothesis. They do not need to match, but are connected, see Section 6.5.
} 
All three correlations in Table 21 were not included as they are in the wrong direction (compare 'expected sign' with the sign of 'test value') to support the alternative hypothesis that there is a positive relationship between 'relative advantage' and the extent of adoption.

In the present instance this is due to 'relative advantage' (defined as the degree to which the technology is perceived as being better than the idea it supersedes) being difficult to measure. Question 21F and 21D asked respondents if the new technology had 'lowered maintenance costs' or 'changed the way they worked'. These questions were based on the idea that lowered maintenance costs and a new way of working were 'advantages'. This logic may have been flawed.

\subsubsection{Time of adoption}

Table 22: Relative Advantage vs Time

\begin{tabular}{|l|l|l|l|l|l|l|c|}
\hline Dependent & $\begin{array}{l}\text { Ques } \\
\text { no }\end{array}$ & $\begin{array}{l}\text { Sample } \\
\text { size }\end{array}$ & Test type & Measure & $\begin{array}{l}\text { Expected } \\
\text { Sign }\end{array}$ & $\begin{array}{l}\text { Test } \\
\text { Value }\end{array}$ & P-Value \\
\hline T4 & $21 \mathrm{~F}$ & 26 & Pearson & Coeff. & + & -0.475 & 0.007 \\
T4 & $21 G$ & 27 & Pearson & Coeff. & + & -0.448 & 0.009 \\
\hline
\end{tabular}

The correlation between 'relative advantage' and the time of adoption was examined through 35 individual correlations, none of which were significant at the $5 \%$ significance level. Hence there is no evidence to reject the null hypothesis in favour of the alternative that a positive correlation exists.

Again all correlations that showed a small p-value were in the opposite direction to the alternative or test hypothesis. The explanation is the same as that for extent of adoption. 


\subsubsection{Complexity}

\subsubsection{Extent of adoption}

Table 23: Complexity vs Extent

\begin{tabular}{|l|l|l|l|l|l|l|c|}
\hline Dependent & $\begin{array}{l}\text { Ques } \\
\text { no }\end{array}$ & $\begin{array}{l}\text { Sample } \\
\text { size }\end{array}$ & Test type & Measure & $\begin{array}{l}\text { Expected } \\
\text { Sign }\end{array}$ & $\begin{array}{l}\text { Test } \\
\text { Value }\end{array}$ & P-Value \\
\hline E3 & $21 \mathrm{H}$ & 28 & Pearson & Coeff. & - & 0.387 & 0.021 \\
E3 & $21 \mathrm{~K}$ & 27 & Pearson & Coeff. & + & -0.348 & 0.0375 \\
\hline
\end{tabular}

The correlation between 'complexity' and the extent of adoption was examined through 10 individual correlations, none of which were significant at the $5 \%$ significance level. Hence there is no evidence to reject the null hypothesis in favour of the alternative that a negative correlation exists.

All correlations that showed a small p-value were in the opposite direction to the alternative or test hypothesis. The alternative hypothesis states that as 'complexity' increases the extent of adoption decreases (i.e. 'complexity' inhibits adoption). The results in Table 23, when interpreted, indicate that as 'complexity' increase the extent of adoption (measured through FTE working with digital technology) also increases. This is likely to be due to the nature of the industry. namely the fact that the adopters are very technically competent organisations. Unlike electronic banking (used by Frambach et al, 1996) these adopters do not require a new innovation to be very simple. On the contrary, adopters may be drawn to complex innovations. They may feel complex innovations will, in fact, provide substantially better products for their clients.

\subsubsection{Time of adoption}

The correlation between 'complexity' and the time of adoption was examined through 10 individual correlations, none of which were significant at the $5 \%$ level. Hence there is no evidence to reject the null hypothesis in favour of the alternative that a correlation exists. 


\subsubsection{Compatibility}

\subsubsection{Extent of adoption}

Table 24: Compatibility vs Extent

\begin{tabular}{|l|l|l|l|l|l|l|c|}
\hline Dependent & $\begin{array}{l}\text { Ques } \\
\text { no }\end{array}$ & $\begin{array}{l}\text { Sample } \\
\text { size }\end{array}$ & Test type & Measure & $\begin{array}{l}\text { Expected } \\
\text { Sign }\end{array}$ & $\begin{array}{l}\text { Test } \\
\text { Value }\end{array}$ & P-value \\
\hline E1 & $21 \mathrm{~L}$ & 30 & $\begin{array}{l}\text { Pearson } \\
\text { E5 }\end{array}$ & Coeff. & + & 0.325 & 0.040 \\
\hline
\end{tabular}

The correlation between 'compatibility' and the extent of adoption was examined through 20 individual correlations, two of which were significant at the $5 \%$ level. Hence there is some evidence to reject the null hypothesis in favour of the alternative that a positive correlation exists.

Individual correlations existed between question 21L (how well the digital technology matched their needs) and E1 and E5 (respondents' perceptions of their equipment and their perceptions of their extent of adoption).

\subsubsection{Time of adoption}

Table 25: Compatibility vs Time

\begin{tabular}{|l|l|l|l|l|l|l|c|}
\hline Dependent & $\begin{array}{l}\text { Ques } \\
\text { no }\end{array}$ & $\begin{array}{l}\text { Sample } \\
\text { size }\end{array}$ & Test type & Measure & $\begin{array}{l}\text { Expected } \\
\text { Sign }\end{array}$ & $\begin{array}{l}\text { Test } \\
\text { Value }\end{array}$ & P-value \\
\hline T2 & 22 & 27 & Pearson & Coeff. & + & -0.398 & 0.020 \\
T3 & $21 \mathrm{~L}$ & 30 & Pearson & Coeff. & + & 0.455 & 0.006 \\
\hline
\end{tabular}

The correlation between 'compatibility' and the time of adoption was examined through 20 individual correlations, one of which was significant at the $5 \%$ level. Hence there is no evidence to reject the null hypothesis in favour of the alternative that a positive correlation exists.

Individual correlations were between question 21L (how well the digital technology matched their needs) and T3 (how fast respondents felt they obtained digital technology compared to their competitors).

The correlation between question 22 and element $\mathrm{T} 2$ is in the wrong direction. The test value shown indicates that faster adopters tended not to have sufficient knowledge 
to handle the adoption, but that slower adopters did have sufficient knowledge. This is opposite to the proposed positive relationship between 'compatibility' and time of adoption.

\subsubsection{Uncertainty}

\subsubsection{Extent of adoption}

Table 26: Uncertainty vs Extent

\begin{tabular}{|c|c|c|c|c|c|c|c|}
\hline Dependent & $\begin{array}{l}\text { Ques } \\
\text { no }\end{array}$ & $\begin{array}{l}\text { Sample } \\
\text { size }\end{array}$ & Test type & Measure & \begin{tabular}{|l|} 
Expected \\
Sign
\end{tabular} & \begin{tabular}{|l|} 
Test \\
Value
\end{tabular} & P-value \\
\hline E1 & 24 & 30 & Pearson & Coeff. & - & -0.312 & 0.047 \\
\hline E3 & 24 & 28 & Pearson & Coeff. & + & 0.329 & 0.043 \\
\hline
\end{tabular}

The correlation between 'uncertainty' and the extent of adoption was examined through 15 individual correlations, two of which were significant at the $5 \%$ level. Hence there is some evidence to reject the null hypothesis in favour of the alternative that a negative correlation exists.

\subsubsection{Time of adoption}

The correlation between 'uncertainty' and the time of adoption was examined through 15 individual correlations, none of which were significant at the $5 \%$ level. Hence there is no evidence to reject the null hypothesis in favour of the alternative that a negative correlation exists.

\subsubsection{Observability}

\subsubsection{Extent of adoption}

The correlation between 'observability' and the extent of adoption was examined through five individual correlations, none of which were significant at the $5 \%$ level. Hence there is no evidence to reject the null hypothesis in favour of the alternative that a positive correlation exists. 


\subsubsection{Time of adoption}

Table 27: Observability vs Time

\begin{tabular}{|l|l|l|l|l|l|l|c|}
\hline Dependent & $\begin{array}{l}\text { Ques } \\
\text { no }\end{array}$ & $\begin{array}{l}\text { Sample } \\
\text { size }\end{array}$ & Test type & Measure & $\begin{array}{l}\text { Expected } \\
\text { Sign }\end{array}$ & $\begin{array}{l}\text { Test } \\
\text { Value }\end{array}$ & P-value \\
\hline T5 & 26 & 30 & Pearson & Coeff. & + & 0.338 & 0.034 \\
\hline
\end{tabular}

The correlation between 'observability' and the time of adoption was examined through five individual correlations, one of which was significant at the $5 \%$ level. Hence there is some evidence to reject the null hypothesis in favour of the alternative that a positive correlation exists.

Individual correlation existed between the elements T5 (Respondent's perceptions of how often they are ahead of others) and question 26 (use of the latest and greatest brands).

\subsubsection{Trialability}

\subsubsection{Extent of adoption}

Table 28: Trialability vs Extent

\begin{tabular}{|l|l|l|l|l|l|l|l|}
\hline Dependent & $\begin{array}{l}\text { Ques } \\
\text { no }\end{array}$ & $\begin{array}{l}\text { Sample } \\
\text { size }\end{array}$ & Test type & Measure & $\begin{array}{l}\text { Expected } \\
\text { Sign }\end{array}$ & $\begin{array}{l}\text { Test } \\
\text { Value }\end{array}$ & P-value \\
\hline E1 & 28 & 29 & Pearson & Coeff. & + & 0.317 & 0.047 \\
\hline
\end{tabular}

The correlation between 'trialability' and the extent of adoption was examined through five individual correlations, one of which was significant at the $5 \%$ level. Hence there is some evidence to reject the null hypothesis in favour of the alternative that a positive correlation exists.

\subsubsection{Time of adoption}

The correlation between 'trialability' and the time of adoption was examined through five individual correlations, none of which were significant at the $5 \%$ level. Hence there is no evidence to reject the null hypothesis in favour of the alternative that a positive correlation exists. 


\subsubsection{Expectations Technology}

The hypothesis concerning 'expectations technology' (and the time of adoption) is tested through a perception based question. Respondents where asked outright if their rate of adoption was slowed due to the rapid development of technology. Hence this hypothesis was tested through Wilcoxon signed-rank test. The responses to the questions were compared to a row of neutral responses. The p-value was 0.210 hence there is not enough evidence to reject the null hypothesis; Respondents do not feel their time of adoption is affected by the speed of technological advances in this area.

\subsection{ADOPTER CHARACTERISTICS}

\subsubsection{Size}

\subsubsection{Extent of adoption}

Table 29: Size vs Extent

\begin{tabular}{|l|l|l|l|l|l|l|l|}
\hline Dependent & $\begin{array}{l}\text { Ques } \\
\text { no }\end{array}$ & $\begin{array}{l}\text { Sample } \\
\text { size }\end{array}$ & Test type & Measure & $\begin{array}{l}\text { Expected } \\
\text { Sign }\end{array}$ & $\begin{array}{l}\text { Test } \\
\text { Value }\end{array}$ & P-value \\
\hline E2 & 54 & 26 & Pearson & Coeff. & + & 0.411 & 0.019 \\
E3 & 56 & 20 & Pearson & Coeff. & + & -0.382 & 0.049 \\
\hline
\end{tabular}

The correlation between adopter 'size' and the extent of adoption was examined through 10 individual correlations, one of which was significant at the $5 \%$ level. Hence there is some evidence to reject the null hypothesis in favour of the alternative that a positive correlation exists.

An individual association exists between no of times of digital technology and number of FTE employed by an organisation (elements E2 and 54).

The correlation that exists between E3 and question 56 is in the wrong direction. This indicates that a high sales revenue of an adopter corresponds to a low percentage of staff working with digital technology and vice versa. This may be due to the nature of the industry. Smaller firms tend to be more specialised; hence if they edit or produce 
special effects, then most of the staff would be devoted to this. On the other hand a larger organisation tends to have other departments and although they may actually do 'more' special effects, the number of staff working on special effects (as a percentage of the whole organisation) may be very small.

\subsubsection{Time of adoption}

The correlation between adopter 'size' and the time of adoption was examined through 10 individual correlations, none of which were significant at the $5 \%$ level. Hence there is no evidence to reject the null hypothesis in favour of the alternative that a positive correlation exists.

\subsubsection{Centralisation}

\subsubsection{Extent of adoption}

Table 30: Centralisation vs Extent

\begin{tabular}{|l|l|l|l|l|l|l|c|}
\hline Dependent & $\begin{array}{l}\text { Ques } \\
\text { no }\end{array}$ & $\begin{array}{l}\text { Sample } \\
\text { size }\end{array}$ & Test type & Measure & $\begin{array}{l}\text { Expected } \\
\text { Sign }\end{array}$ & $\begin{array}{l}\text { Test } \\
\text { Value }\end{array}$ & P-value \\
\hline E1 & 61 & 26 & Pearson & Coeff. & + & -0.42 & 0.017 \\
E2 & 63 & 22 & Pearson & Coeff. & - & -0.37 & 0.047 \\
E4 & 61 & 15 & Pearson & Coeff. & - & 0.46 & 0.043 \\
\hline
\end{tabular}

The correlation between adopter 'centralisation' and the extent of adoption was examined through 15 individual correlations, one of which was significant at the $5 \%$ level. Hence there is some evidence to reject the null hypothesis in favour of the alternative that a negative correlation exists.

An individual correlation exists between the elements E2 (number of items of digital technology) and question 63 (level of joint decision making).

The unexpected correlation coefficient for E1 and question 61 and E4 and question 61 , indicates that those who adopt to a higher extent tend to be more centralised ${ }^{6}$. This is exactly the opposite to the alternative hypothesis which postulates that a high degree of 'centralisation' may obstruct adoption.

${ }^{6}$ This calculation takes into account the direction of the questions. 


\subsubsection{Time of adoption}

\section{Table 31: Centralisation vs Time}

\begin{tabular}{|l|l|l|l|l|l|l|l|}
\hline Dependent & $\begin{array}{l}\text { Ques } \\
\text { no }\end{array}$ & $\begin{array}{l}\text { Sample } \\
\text { size }\end{array}$ & Test type & Measure & $\begin{array}{l}\text { Expected } \\
\text { Sign }\end{array}$ & $\begin{array}{l}\text { Test } \\
\text { Value }\end{array}$ & P-value \\
\hline T2 & 61 & 23 & Pearson & Coeff. & + & 0.35 & 0.049 \\
T3 & 61 & 26 & Pearson & Coeff. & + & -0.43 & 0.014 \\
T4 & 63 & 24 & Pearson & Coeff. & + & 0.37 & 0.039 \\
T5 & 61 & 26 & Pearson & Coeff. & + & -0.33 & 0.050 \\
\hline
\end{tabular}

The correlation between 'centralisation' and the time of adoption was examined through 15 individual correlations, two of which were significant at the $5 \%$ level. Hence there is some evidence to reject the null hypothesis in favour of the alternative that a negative correlation exists.

However the negative correlation coefficient for question 61 and T5 and 61 and T3, indicates that earlier adopters tend to be more centralised. This is exactly the opposite of the alternative hypothesis, which as mentioned postulates that a high degree of 'centralisation' may obstruct adoption. This result is startlingly similar to that found in the extent hypothesis above.

Both the time and extent hypotheses have found several correlations indicating that high 'centralisation' is associated with time/extent of adoption. This is likely to be due to the nature of this industry. Many organisations in the motion picture industry have only one or two shareholders (Miles and Fuller, 1993) and most staff are on a part time basis. Hence these organisations would appear centralised on answering the questions in the survey, as the part time employees would not be involved in decision making. This is not so much because these organisations are 'centralised' in the true sense of it, but more because they operate in a different fashion. 


\subsubsection{Receptiveness}

\subsubsection{Extent of adoption}

Table 32: Receptiveness vs Extent

\begin{tabular}{|l|l|l|l|l|l|l|c|}
\hline Dependent & $\begin{array}{l}\text { Ques } \\
\text { no }\end{array}$ & $\begin{array}{l}\text { Sample } \\
\text { size }\end{array}$ & Test type & Measure & $\begin{array}{l}\text { Expected } \\
\text { Sign }\end{array}$ & $\begin{array}{l}\text { Test } \\
\text { Value }\end{array}$ & P-value \\
\hline E1 & 64 & 30 & Pearson & Coeff. & + & 0.54 & 0.001 \\
E1 & 65 & 30 & Pearson & Coeff. & + & 0.348 & 0.030 \\
E2 & 64 & 26 & Pearson & Coeff. & - & -0.401 & 0.021 \\
E3 & 64 & 28 & Pearson & Coeff. & - & -0.343 & 0.037 \\
E3 & 66 & 26 & Biserial & Coeff. & Na & -1.901 & unknown \\
E5 & 64 & 30 & Pearson & Coeff. & + & 0.464 & 0.005 \\
E5 & 65 & 30 & Pearson & Coeff. & + & 0.423 & 0.010 \\
\hline
\end{tabular}

The correlation between 'receptiveness' and the extent of adoption was examined through 15 individual correlations, seven of which were significant at the $5 \%$ level. Hence there is compelling evidence to reject the null hypothesis in favour of the alternative that a positive association exists between the adopters' 'receptiveness' and the extent of their adoption.

\subsubsection{Time of adoption}

Table 33: Receptivenenss vs Time

\begin{tabular}{|l|l|l|l|l|c|l|l|}
\hline Dependent & $\begin{array}{l}\text { Ques } \\
\text { no }\end{array}$ & $\begin{array}{l}\text { Sample } \\
\text { size }\end{array}$ & Test type & Measure & $\begin{array}{l}\text { Expected } \\
\text { Sign }\end{array}$ & $\begin{array}{l}\text { Test } \\
\text { Value }\end{array}$ & P-value \\
\hline T1 & 64 & 23 & Pearson & Coeff. & + & 0.394 & 0.0315 \\
T2 & 65 & 27 & Pearson & Coeff. & + & 0.333 & 0.0445 \\
T3 & 64 & 30 & Pearson & Coeff. & + & 0.664 & 0.00 \\
T3 & 65 & 30 & Pearson & Coeff. & + & 0.379 & 0.0195 \\
T4 & 64 & 27 & Pearson & Coeff. & + & 0.343 & 0.04 \\
T5 & 65 & 30 & Pearson & Coeff. & + & 0.475 & 0.004 \\
\hline
\end{tabular}

The correlation between 'receptiveness' and the time of adoption was examined through 15 individual correlations, six of which were significant at the $5 \%$ level. Hence there is strong evidence to reject the null hypothesis in favour of the alternative that a positive correlation exists between the adopters' 'receptiveness' and the time of their adoption. 


\subsection{NETWORK PARTICIPATION}

\subsubsection{Within industry}

\subsubsection{Extent of adoption}

Table 34: Within Industry vs Extent

\begin{tabular}{|l|l|l|l|l|l|l|l|}
\hline Dependent & $\begin{array}{l}\text { Ques } \\
\text { no }\end{array}$ & $\begin{array}{l}\text { Sample } \\
\text { size }\end{array}$ & Test type & Measure & $\begin{array}{l}\text { Expected } \\
\text { Sign }\end{array}$ & $\begin{array}{l}\text { Test } \\
\text { Value }\end{array}$ & P-value \\
\hline E1 & 3 & 29 & Pearson & Coeff. & + & 0.321 & 0.045 \\
E3 & 3 & 27 & Pearson & Coeff. & - & -0.392 & 0.0215 \\
\hline
\end{tabular}

The correlation between 'network participation within the industry' and the extent of adoption was examined through 10 individual correlations, two of which were significant at the 5\% level. Hence there is some evidence to reject the null hypothesis in favour of the alternative that a positive correlation exists.

\subsubsection{Time of adoption}

The correlation between 'network participation within the industry' and the time of adoption was examined through 10 individual correlations, none of which were significant at the 5\% level. Hence there is no evidence to reject the null hypothesis in favour of the alternative that a positive correlation exists.

\subsubsection{Outside Industry}

\subsubsection{Extent of adoption}

Table 35: Outside Industry vs Extent

\begin{tabular}{|l|l|l|l|l|c|l|l|}
\hline Dependent & $\begin{array}{l}\text { Ques } \\
\text { no }\end{array}$ & $\begin{array}{l}\text { Sample } \\
\text { size }\end{array}$ & Test type & Measure & $\begin{array}{l}\text { Expected } \\
\text { Sign }\end{array}$ & $\begin{array}{l}\text { Test } \\
\text { Value }\end{array}$ & P-value \\
\hline E1 & 4 & 30 & Pearson & Coeff. & + & 0.423 & 0.010 \\
E2 & 4 & 26 & Pearson & Coeff. & - & -0.519 & 0.004 \\
E3 & 4 & 28 & Pearson & Coeff. & - & -0.513 & 0.002 \\
E5 & 4 & 30 & Pearson & Coeff. & + & 0.386 & 0.018 \\
\hline
\end{tabular}

The correlation between 'network participation outside the industry' and the extent of adoption was examined through 10 individual correlations, four of which were 
significant at the 5\% level. Hence there is strong evidence to reject the null hypothesis in favour of the alternative that a positive correlation exists.

It is interesting to note that question 4 was correlated but the second element which was used to test Network Participation outside the industry (question 13) was correlated with none of them. The fact that the two elements of the 'network participation outside the industry' variable behave so differently is supported by the very low Cronbach's alpha (0.00).

\subsubsection{Time of adoption}

Table 36: Outside Industry vs Time

\begin{tabular}{|l|l|l|l|l|l|l|l|}
\hline Dependent & $\begin{array}{l}\text { Ques } \\
\text { no }\end{array}$ & $\begin{array}{l}\text { Sample } \\
\text { size }\end{array}$ & Test type & Measure & $\begin{array}{l}\text { Expected } \\
\text { Sign }\end{array}$ & $\begin{array}{l}\text { Test } \\
\text { Value }\end{array}$ & P-value \\
\hline T3 & 4 & 30 & Pearson & Coeff. & + & 0.459 & 0.006 \\
T4 & 4 & 27 & Pearson & Coeff. & + & 0.36 & 0.033 \\
T5 & 4 & 30 & Pearson & Coeff. & + & 0.425 & 0.010 \\
\hline
\end{tabular}

The correlation between 'network participation outside the industry' and the time of adoption was examined through 10 individual correlations, three of which were significant at the 5\% level. Hence there is moderate evidence to reject the null hypothesis in favour of the alternative that a positive correlation exists.

The same phenomena exists here as in the extent of adoption hypothesis, where question 4 was correlated with several dependent elements and the other element used to measure 'network participation outside the industry' was correlated with none. Again this is supported by the Cronbach's alpha (0.00). 


\subsection{COMPETITIVE ENVIRONMENT}

\subsubsection{Intensity of Competition}

\subsubsection{Extent of adoption}

Table 37: Intensity of Competition vs Extent

\begin{tabular}{|l|l|l|l|l|l|l|l|}
\hline Dependent & $\begin{array}{l}\text { Ques } \\
\text { no }\end{array}$ & $\begin{array}{l}\text { Sample } \\
\text { size }\end{array}$ & Test type & Measure & $\begin{array}{l}\text { Expected } \\
\text { Sign }\end{array}$ & $\begin{array}{l}\text { Test } \\
\text { Value }\end{array}$ & P-value \\
\hline E3 & 8 & 27 & Pearson & Coeff. & - & -0.385 & 0.024 \\
E5 & 6 & 30 & Pearson & Coeff. & + & 0.432 & 0.009 \\
\hline
\end{tabular}

The correlation between 'intensity of competition' and the extent of adoption was examined through 20 individual correlations, two of which were significant at the $5 \%$ level. Hence there is some evidence to reject the null hypothesis in favour of the alternative that a positive correlation exists.

\subsubsection{Time of adoption}

The correlation between 'intensity of competition' and the time of adoption was examined through 20 individual correlations, none of which were significant at the $5 \%$ level. Hence there is no evidence to reject the null hypothesis in favour of the alternative that a positive correlation exists.

\subsubsection{Intensity of Innovative Activities}

\subsubsection{Extent of adoption}

Table 38: Intensity of Innovative activities vs Extent

\begin{tabular}{|l|l|l|l|l|l|l|l|}
\hline Dependent & $\begin{array}{l}\text { Ques } \\
\text { no }\end{array}$ & $\begin{array}{l}\text { Sample } \\
\text { size }\end{array}$ & Test type & Measure & $\begin{array}{l}\text { Expected } \\
\text { Sign }\end{array}$ & $\begin{array}{l}\text { Test } \\
\text { Value }\end{array}$ & P-value \\
\hline E3 & 67 & 28 & Pearson & Coeff. & - & -0.468 & 0.006 \\
E3 & 68 & 28 & Pearson & Coeff. & - & -0.344 & 0.037 \\
E4 & 68 & 18 & Pearson & Coeff. & - & -0.426 & 0.039 \\
\hline
\end{tabular}

The correlation between 'intensity of innovative activities' and the extent of adoption was examined through 20 individual correlations, three of which were significant at the $5 \%$ level. Hence there is some evidence to reject the null hypothesis in favour of the alternative that a positive correlation exists. 


\subsubsection{Time of adoption}

The correlation between intensity of innovative activities and the time of adoption was examined through 20 individual correlations, none of which were significant at the $5 \%$ level. Hence there is no evidence to reject the null hypothesis in favour of the alternative that a positive correlation exists.

\subsection{INFORMATION}

\subsubsection{Information processing}

\subsubsection{Extent of adoption}

Table 39:Information vs Extent

\begin{tabular}{|l|l|l|l|l|l|l|l|}
\hline Dependent & $\begin{array}{l}\text { Ques } \\
\text { no }\end{array}$ & $\begin{array}{l}\text { Sample } \\
\text { size }\end{array}$ & Test type & Measure & $\begin{array}{l}\text { Expected } \\
\text { Sign }\end{array}$ & $\begin{array}{l}\text { Test } \\
\text { Value }\end{array}$ & P-value \\
\hline E2 & 73 & 24 & Pearson & Coeff. & + & 0.511 & 0.006 \\
E2 & 75 & 26 & Pearson & Coeff. & + & 0.639 & 0.000 \\
E4 & 73 & 17 & Pearson & Coeff. & - & 0.432 & 0.042 \\
E4 & 75 & 18 & Pearson & Coeff. & - & 0.431 & 0.037 \\
\hline
\end{tabular}

The correlation between 'information processing' and the extent of adoption was examined through 15 individual correlations, four of which were significant at the $5 \%$ level. Hence there is moderate evidence to reject the null hypothesis in favour of the alternative that a positive correlation exists.

\subsubsection{Time of adoption}

Table 40: Information vs Time

\begin{tabular}{|l|l|l|l|l|l|l|l|}
\hline Dependent & $\begin{array}{l}\text { Ques } \\
\text { no }\end{array}$ & $\begin{array}{l}\text { Sample } \\
\text { Size }\end{array}$ & Test type & Measure & $\begin{array}{l}\text { Expected } \\
\text { Sign }\end{array}$ & $\begin{array}{l}\text { Test } \\
\text { Value }\end{array}$ & P-value \\
\hline T2 & 73 & 24 & Pearson & Coeff. & - & 0.39 & 0.030 \\
T2 & 75 & 27 & Pearson & Coeff. & - & 0.569 & 0.001 \\
T5 & 73 & 26 & Pearson & Coeff. & - & -0.415 & 0.018 \\
\hline
\end{tabular}

The correlation between 'information processing' and the time of adoption was examined through 15 individual correlations, one of which was significant at the $5 \%$ level. Hence there is some evidence to reject the null hypothesis in favour of the alternative that a positive correlation exists. 
The correlation between T2 (time of adoption of first piece of digital technology) and questions 72 and 75 (number of meetings and trade exhibitions attended) is the opposite to the expected sign. This indicates early adopters (of the first piece) attended less meetings and trade fairs. This result may be spurious because it is comparing adoption of something a long time ago with 'information processing' characteristics in the last year.

\subsection{ADDITIONAL HYPOTHESIS}

Wilcoxon signed-rank tests were run on all five additional hypotheses. The p-values for the hypotheses are shown in Table 41. Probabilities given are two-sided probabilities using a normal approximation, that is, an approximation to a normal distribution. Four of the five hypotheses tests are one sided, the p-values are halved.

\section{Table 41: P-values}

\begin{tabular}{|l|c|c|}
\hline Hypothesis & Ques no & P-values \\
\hline Competition & 5 and 6 & 0.118 \\
Competition & 7 and 8 & 1.000 \\
Success of Industry & 9 and neutral & 0.002 \\
Technical Success & 11 and neutral & 0.083 \\
Branding & 27 and neutral & 0.153 \\
Marketing & 68 and 69 & 0.043 \\
\hline
\end{tabular}

The following text shows the hypotheses to accept and reject, using the cut-off of a pvalue of 5\%. Hypotheses are numbered corresponding to Table 41.

\subsubsection{Competition}

Null Hypothesis 1: That the competition in the NZ motion picture industry is not seen as significantly different from that overseas.

This null hypothesis is accepted. In fact the p-value of one in comparing questions 7 and 8 gives very strong support for the acceptance of this hypothesis. 


\subsubsection{Success of Industry}

Null Hypothesis 2: That the NZ motion picture industry is perceived to be neither successful nor unsuccessful overseas.

A p-value of 0.003 shows that the null hypothesis must be rejected in favour of the alternative hypothesis, that the NZ motion picture industry is seen as successful overseas. This is supported by the mean of 2.5 , i.e. towards the successful end.

\subsubsection{Technical Success}

Null Hypothesis 3: That NZ editing and special effects firms are perceived to be neither successful nor unsuccessful overseas.

The null hypothesis must be accepted (at the 5\% level) as there is no evidence to reject it. However the null hypothesis would be rejected at the $10 \%$ significance level in favour of the alternative hypothesis that NZ editing and effects firms are perceived to be successful overseas.

\subsubsection{Branding}

Null hypothesis 4: Branding is not perceived to affect the amount of work received.

This hypothesis must be accepted as there is no evidence to reject it.

\subsubsection{Investment}

Null hypothesis 5: That there is no difference in investment in marketing of new products or services in $\mathrm{NZ}$ and overseas, by $\mathrm{NZ}$ firms.

The null hypothesis is rejected ( $p$-value of 0.043) in favour of the alternative hypothesis that NZ firms spend more on marketing of new products and services in $\mathrm{NZ}$ than overseas. 


\subsection{CHAPTER SUMMARY}

Hypotheses were tested through several statistical measures of association between two variables. Correlations between the extent elements and the time elements, show that time and extent of adoption are very difficult concepts to gain an objective, correct measure for.

Of the possible 18 associations between extent of adoption and the independent variables: one showed 'compelling' evidence to reject the null hypothesis; two produced 'strong' evidence; four were 'moderate'; and eight showed 'some' evidence. A much smaller five of the 19 time hypothesis showed evidence to reject the null hypothesis. These results are summarised in Table 42.

Other findings include: competition in the $\mathrm{NZ}$ motion picture industry is not seen as significantly different to competition overseas; NZ motion picture industry is perceived to be successful overseas; NZ editing and special effects firms are not seen as successful or unsuccessful overseas; brands of digital technology are not perceived to affect the amount of work received; and more money is spent by NZ firms marketing in $\mathrm{NZ}$ than overseas. 
Table 42: Summary

\begin{tabular}{|c|c|c|}
\hline Independent Variables & extent & time \\
\hline Suppliers' marketing strategy: & & \\
\hline Positioning innovation in the market (ns) & moderate & nil \\
\hline Reducing the risk of adoption (ns) & some & nil \\
\hline Winning market support (ns) & moderate & nil \\
\hline Suppliers' innovation development: & & \\
\hline Perceived Customisation (+) & moderate & nil \\
\hline Perceived Characteristics of the innovation & & \\
\hline Relative advantage $(+)$ & nil & nil \\
\hline Complexity (-) & nil & nil \\
\hline Compatibility $(+)$ & some & nil \\
\hline Uncertainty (-) & some & nil \\
\hline Observability $(+)$ & nil & some \\
\hline Trialability $(+)$ & some & nil \\
\hline Expectations technology (-) & not tested & nil \\
\hline Characteristics of Adopter & & \\
\hline Size $(+)$ & some & nil \\
\hline Centralisation (-) & some & some \\
\hline Receptiveness (+) & compelling & strong \\
\hline Network participation & & \\
\hline Within Industry $(+)$ & some & nil \\
\hline Outside Industry (+) & strong & moderate \\
\hline Competitive environment on the adopters' side: & & \\
\hline Intensity of competition( $(+)$ & some & nil \\
\hline Intensity of innovative activities $(+)$ & some & nil \\
\hline Information & & \\
\hline Information processing $(+)$ & moderate & some \\
\hline
\end{tabular}




\section{CONCLUSIONS AND RECOMMENDATIONS}

\subsection{INTRODUCTION}

The detailed process of analysis was outlined in the previous two chapters. This chapter takes an holistic view and proposes models of the time and extent of adoption. The models are produced by drawing out the re-occurring 'themes', the hypotheses based around Frambach's (1993) integrated model of adoption and diffusion of innovations. The latter part of this chapter: considers the limitations of this research; summarises the findings; considers the managerial implications of these findings; and produces recommendations for future research.

\subsection{MODELS OF THE TIME AND EXTENT OF ADOPTION OF DIGITAL TECHNOLOGY}

Pearson's correlations, Spearman's correlations and Cronbach's alpha values indicate individual elements ${ }^{1}$ which aimed to test the extent of adoption, do not appear to reliably test the same 'thing'. This is also the case for the time of adoption.

Although individual elements may not be testing the exact same thing they are still all components of the time or extent of adoption. It may be argued that the definition of extent of adoption of innovations includes: money spent on technology; the number of items of technology; and the adopters' perceptions of their extent of adoption. Hence, it is not relevant whether these things are strongly correlated, as each element does not measure the extent of adoption in its own right. On the contrary, the five elements add

\footnotetext{
${ }^{1}$ Refer to Section 6.3 for definition of elements
} 
up to give an overall extent of adoption. The same rationale can be applied to the time of adoption.

With this in mind, the models are presented; extent of adoption in Figure 16 and time of adoption in Figure 17. The first model presents all the independent variables that were shown to have an association with the dependent variable of extent of adoption. This is the Extent of Adoption Model. Model Two, the Time of Adoption Model, presents all the independent variables that were shown to have an association with the dependent variable of time of adoption. These two models diagrammatically summarise the core findings of this research.

The dependent variables of time and extent are shown at the centre of the models. The independent variables are separated into supply-side variables, presented at the left, and adopter side variables, to the right.

The strength of the relationships between dependent and independent variables is based on descriptive categories demonstrating the amount of evidence which exists to reject the null hypothesis in favour of the alternative hypothesis that a relationship exists. These categories are: no, some, moderate, strong, and compelling. These categories are based on the proportion of individual test for one relationship which had p-values under $5 \%$. The strength of relationships between variables is demonstrated in the models by the thickness of the arrows.

Those independent variables that showed 'no' evidence of being correlated to the dependent variables are not shown in the models. A key is presented to aid with interpretation of the arrows. The extent and time models should be considered in conjunction with the research model. That is, the original model, which includes all variables hypothesised to influence the time or extent of adoption. Hence this model has been reproduced in Figure 18

Figure 16 Model One indicates that most independent variables that were hypothesised to influence the extent of adoption, did so. All the supply-side 
independent variables are present. Those adopter-side variables which were not found to be associated with the extent of adoption are: 'relative advantage', 'compatibility', 'observability', and 'expectations technology'. Of the relationships shown: one has 'compelling' evidence; two show 'strong' evidence; the remaining relationships show 'some' or 'moderate' evidence, in support of rejecting the null hypothesis that no association exists.

The Time of Adoption Model demonstrates that no associations exist between supplyside variables and the time of adoption. Only five of the potential 15 adopter-side variables, show an association with the time of adoption. Observability is the only 'perceived innovation characteristic' likely to affect the time of adoption.

Comparing the two models reveals something quite remarkable. That is, if adopters perceive suppliers to be very active with their (the suppliers') marketing strategy and innovation development, they are likely to adopt to a larger extent, but are not likely to adopt sooner.

The independent variables which are represented in both models are those that fall under the adopter-side category 'adopter characteristics'. These variables are receptiveness and centralisation of the adopter. The third 'adopter characteristic', size, is only present in the extent of Adoption Model. However the independent variable, centralisation, must be treated with caution as there was also some evidence that showed centralisation to have a negative relationship with both the time and extent, which is contrary to the hypothesis which stipulates a positive relationship. 
The model was produced through a descriptive approach to interpreting results. Hence the results show general themes, and must be interpreted with caution. The overall findings show:

- Supply-side variables impact upon the extent of adoption of digital technology in the NZ motion picture industry;

- Adopter-side variables impact upon the extent adoption of digital technology in the NZ motion picture industry;

- Supply-side variables do not impact upon the time of adoption of digital technology in the NZ motion picture industry;

- Some adopter-side variables impact upon the time of adoption of digital technology in the NZ motion picture industry. 
Figure 16: Model One: Extent of Adoption Model
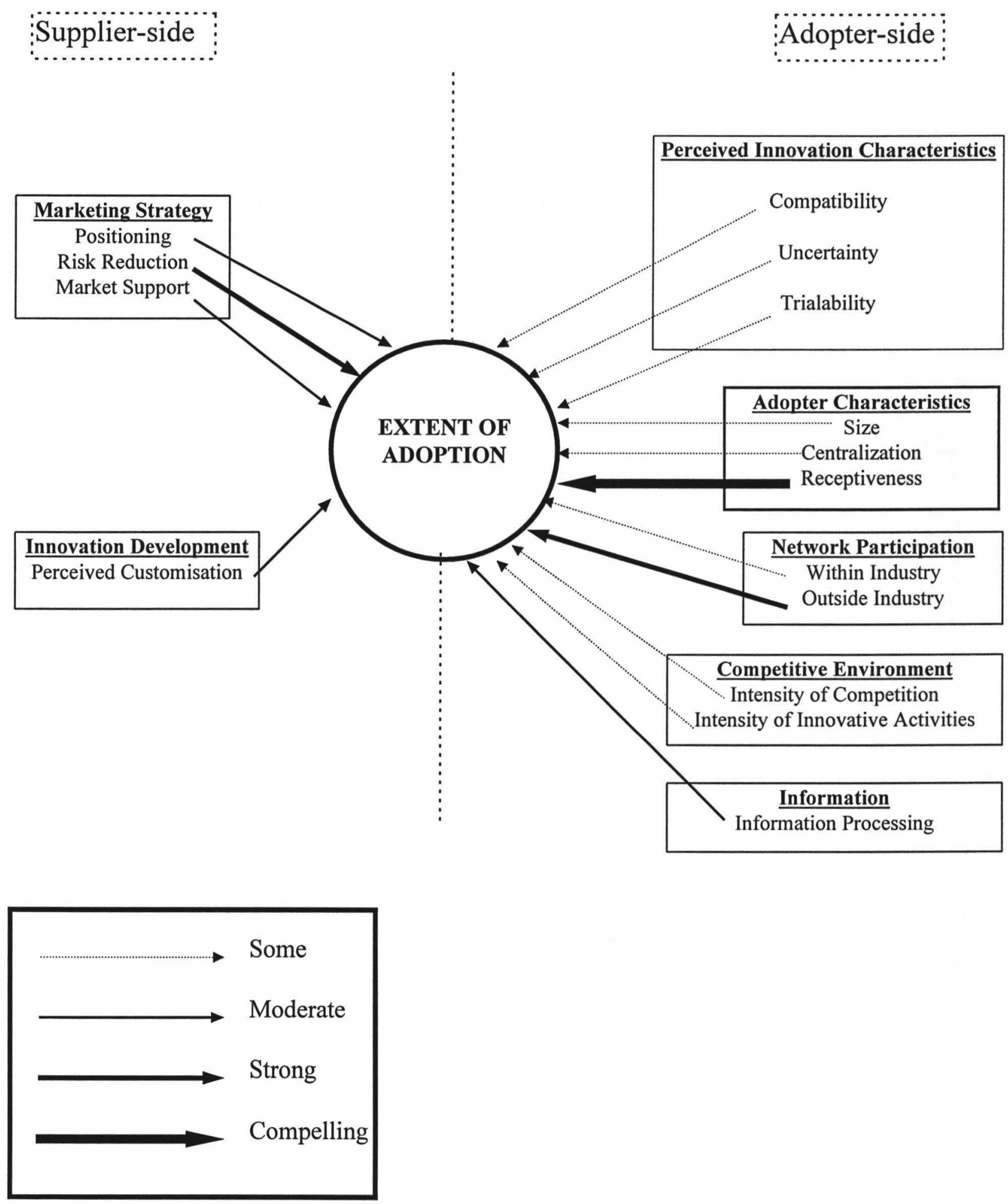
Figure 17: Model Two: Time of Adoption Model
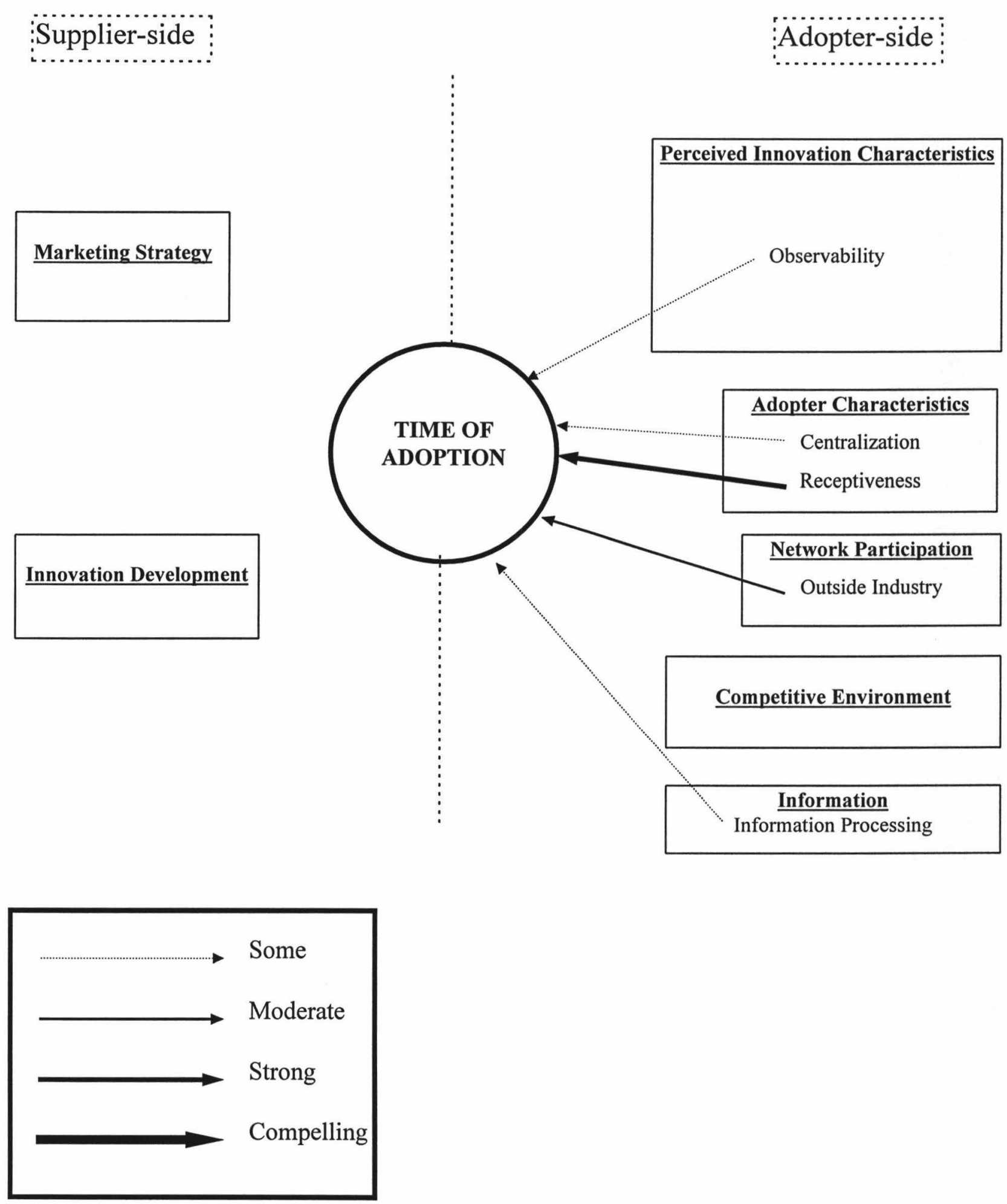
Figure 18: Integrated Model of Adoption of Digital Technology in the Motion Picture Industry

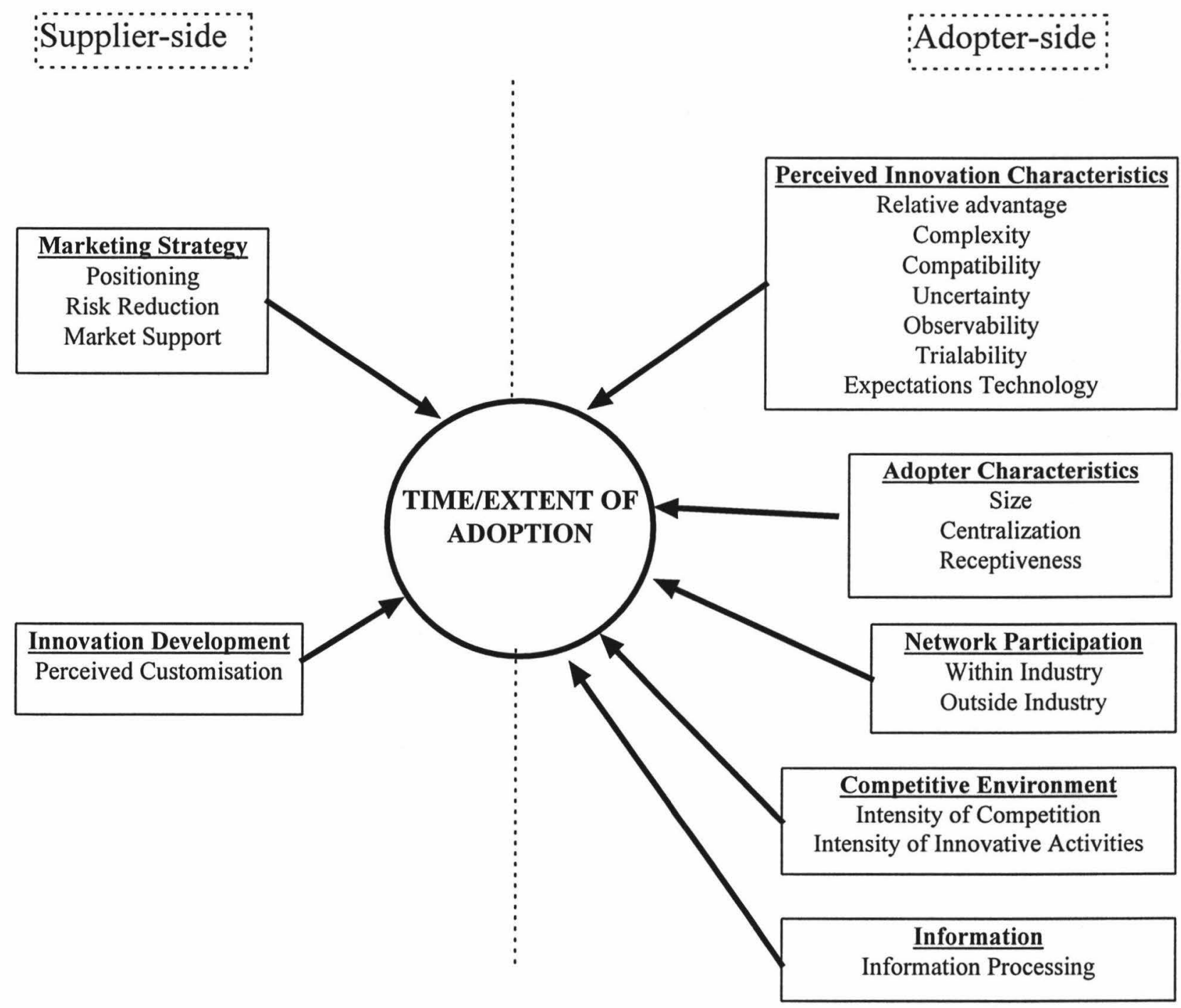

Source: Adapted from Frambach et al 1996 


\subsection{LIMITATIONS OF THE RESEARCH}

Key limitations of this research include:

- Frambach's model is reasonably new (1993) and has been empirically tested only once (on electronic banking in the Netherlands);

- The nature of the motion picture industry makes it very difficult to research. For example, often the majority of an organisation's staff are part-time, making industry statistics difficult to gather;

- The time and extent of adoption are very difficult variables to measure, especially when considering a group of innovations, as opposed to one particular innovation with a very clear and visible adoption time, such as EFTPOS (Electronic Funds Transfer Point of Sale);

- The small size of the NZ motion picture industry limited the amount of data that could be gathered for statistical analysis;

- The mail out survey considers one snap shot at one point in time and does not reveal the nature of dynamic innovation processes over time;

- Time of adoption questions rely heavily on the respondent's ability to recall the date and details of adoption;

- Bonferroni probabilities were not calculated to allow for multiple tests in hypothesis testing;

- This research may have encountered bias through obtaining information from only one person per organisation.

\subsection{SUMMARY OF RESEARCH}

The NZ motion picture industry is one hundred years old. Today there are several key organisations involved in the NZ motion picture industry: The Broadcasting Standards Authority; The Film Commission; TVNZ and more. The NZ motion picture industry is largely unresearched. However this decade Tradenz, among others, has carried out several studies which aimed to provide a greater understanding of the structure, dynamics and capabilities of this rapidly expanded industry. Such research indicates 
the NZ motion picture industry to be buoyant and rapidly expanding. NZ has several competitive advantages as a location for filming. These include counter seasonality, local talent, the exchange rate, facilities and the natural beauty of the scenery. None of the past studies considered what is a central issue to this industry, the role of technological innovation.

From its beginnings, the motion picture industry has depended on technology. Many innovations have been instrumental in producing the motion picture industry we know today: the invention of photography in 1826; the Kinetoscope in 1890; television in the 1920s; the electronic stored program computer in 1946; wide-screen was introduced in the mid 1950; and more recently video.

In the last few decades a revolution has occurred in the motion picture industry. This is the large paradigm shift from analog to digital technology. Digital technology was first introduced in the form of the motion control camera, which was used in 1977 for the production of Star Wars. Since 1977 there has been a rapid increase in the use of digital technology, such that by 1995, fifty percent of movies released employed digital visuals of some sort. This revolution has changed many things about the industry from cost of production, to increased competition and the need for advanced training. Thus, technological innovation lies at the heart of motion picture industry and this thesis casts light on a core-process - the adoption process.

The adoption and diffusion literature is extremely large (around 4000 publications in 1995). The adoption process is central to the diffusion of technological innovations. Adoption involves a decision making unit gaining knowledge about an innovation, deciding whether to purchase and implementing the decision. Traditionally diffusion research has taken an adopter-side perspective; more recently the supply-side variables have started to gain researchers' interest. Diffusion research is carried out in two key ways, through variance research or process research. This thesis used the variance research approach modelled off the work of Frambach et al (1996). However, this research extended this work and considered the time and extent of 
adoption, against the supply-side and adopter-side variables postulated by Frambach et al.

Criticisms of the variance research approach were addressed in several ways. Firstly, through focusing on the outcome of the decision making process in terms of the time and extent of adoption. Secondly, the respondents' recall problems were overcome through selecting a technology that was salient to adopters and recently diffused. Recall was also overcome by asking respondents their perceptions of their time of adoption. Recall was not a problem for the extent variables as here the research is trying to isolate the extent of use in the present. The recall problem is also dealt with through very careful pretesting. Another double check used was to use several questionnaire items to try and isolated time and extent.

Data collection involved two key phases. The first was exploratory which consisted of informal interviews with key industry players. The aim was to develop an understanding of the industry, to narrow down the topic and clearly define the population. The second phase was quantitative. This second stage involved contacting many organisations to establish which organisations fitted the population. Data was then gathered through mail out surveys. The questionnaire was designed heavily around Frambach et al's 1996 questionnaire. Questions were modified, added, or deleted to fit the NZ motion picture industry. The dependent variables were the time and extent of adoption and the independent variables were in two key areas, namely, the adopter-side variables and the supply-side variables. Extra questions were added to test several hypotheses relating to issues such as the success of the NZ motion picture industry. A pilot test was carried out to improve the survey instrument. The pilot was sent to a group from the population and a panel of 'experts'.

The data was analysed using Microsoft Excel and a statistical package SYSTAT 6.0. Each hypothesis relating to the time and extent of adoption was tested through four measures of association, namely Pearson's correlation, Spearman's correlation, chi- 
square test and the Biserial correlation. Additional hypotheses were tested through Wilcoxon's signed pairs rank sum test.

The key findings from the descriptive statistics were:

- The population size is estimated to be 73 organisations;

- Key adjectives used to describe the industry were 'creative' and 'competitive';

- The combined sales revenue of organisations with over one FTE working with digital technology for the use in editing and effects in the NZ motion picture industry was $\$ 160$ million dollars;

- Most responding organisations had around seven FTE staff members;

- The main purpose of most responding organisations fell under post-production activities;

- The main tasks carried out by responding organisations were 'editing and special effects' and 'complete post-production';

- By far the majority of sales were for television and were local;

- $93 \%$ of respondents were male and aged between 36-45 years;

- The most common job title of respondents was 'Managing Director';

- Suppliers were many and varied.

Cronbach's alpha values were used to test the reliability of the data gathered. The lowest Cronbach's alpha values were for the dependent variables 'size' (of adopter) and 'network participation - outside the industry' (of adopter) and the dependent variable time of adoption.

Testing of the hypothesis, showed all of the (predicted) supply-side and all but four of the adopter-side independent variables to influence the extent of adoption. The time of adoption, however, is influenced by no supply-side variables and only five of the possible 15 adopter-side variables.

Other findings included: competition in the NZ motion picture industry is not seen as significantly different to competition overseas; the NZ motion picture industry is perceived to be successful overseas; NZ editing and special effects firms are not seen as successful or unsuccessful overseas; brands of digital technology are not perceived 
to affect the amount of work received; and more money is spent by NZ firms marketing (products and services) in NZ than overseas.

\subsection{MANAGERIAL IMPLICATIONS}

The results of this research have perhaps the largest impact on the suppliers of digital technology: Amber; Film Facilities; Silicon Graphics; Sony NZ and more. This research indicates that if these firms' marketing strategies and innovation development activities are perceived as aggressive by adopters of digital technology, then these adopters will adopt to a higher extent, where extent is measured through money spent and number of items of technology all well as by the adopters' perceptions of their extent of adoption. However such aggressive marketing activities by suppliers is not likely to encourage adopters to adopt sooner. Although the research has focused on the adopters' perceptions of suppliers' activity, there is an assumed connection between a firm's actual activities and the perception of these activities by their customers.

It would appear obvious that a supplier's marketing strategies would have an influence on the adoption of the given technology. However, as mentioned several times throughout the present work "in explaining individual adoption decisions (e.g. individuals or firms) diffusion theory in general and diffusion research in marketing in particular, have taken an adopter-side perspective, mostly ignoring the influence of the supplier of the innovation on the adoption process." (Frambach, 1993:22)

This research is useful to suppliers of digital technology not only in that it highlights the importance of supply-side variables, but that it indicates which particular aspects of the suppliers' behaviour affect which particular aspects of adoption. Notably, active positioning, risk reduction, winning market support and perceived customisation increase the extent of adoption. 
This research is also highly useful to the 'adopters' of digital technology who were surveyed. In order for organisations to gain and maintain competitive advantage, it is crucial for them to remain at least abreast of what competitors and the industry at large is up to. "A Company can outperform rivals only if it can establish a difference that it can preserve" (Porter, 1996). Industry knowledge is vital to establishing and maintaining this 'difference'. Hence the demographics obtained in this research will aid in the continued success of adopting firms. These demographics include: the population size; industry sales; staff numbers; purpose and tasks of organisations; distribution of sales; and perception of the industry overseas.

This research makes clear that the success of an innovation in the market place is influenced by a large number of factors. Suppliers should be aware of their many possible impacts on the adoption process. This understanding may be enhanced through the integrated model of adoption of innovations proposed in this thesis.

As competitive advantage in this industry relies heavily upon the digital technology in question, it is also useful for adopters to understand what factors about themselves, the industry and the suppliers influence their (the adopters') time and extent of adoption.

\subsection{RECOMMENDATIONS FOR FUTURE RESEARCH}

One of the key aims of this research was to contribute to theory and findings on innovation adoption, by considering both supply-side and adopter-side variables in relation to the time and extent of adoption. Something that has become clear is that the time and extent of adoption are difficult to measure. Future research could begin by trying to find effective measures of the time and extent of adoption.

The sheer complexity of the number of dependent and independent variables, and elements to measure them, made analysis very difficult, in particular, having each hypothesis tested through multiple individual tests. Future research could consider 
reducing the number of variables. This could mean using only one dependent variable or testing independent variables through a smaller number of questions.

Some other points for future research include:

- Bonferonni probabilities could be used to correct for multiple tests;

- Consider studying organisations' adoption behaviour over time, instead of ane point in time (i.e. process research);

- Consider multivariate analysis, in order to understand clearer associations between all the variables involved.

In summary, this research has identified the characteristics affecting the time and extent of adoption of digital technology in the NZ motion picture industry. The findings have the potential to both extend the theory and findings on innovation adoption and enable suppliers and adopters of digital technology to build and maintain competitive advantage here and overseas. 


\section{REFERENCES}

Abrahamson, E. (1991). Managerial Fads and Fashions: The Diffusion and Rejection of Innovations. Academy of Management Review 61(3): 586.

Alreck, P. L. \& Settle, R. B. (1985). The Survey Research Handbook. Richard D. Irwin, Inc.

Anonymous (1992). Big Three Square up for Technology Shoot-out. Ad/media August: 31.

Anonymous (1992). New Toys for the Boys. Ad/media August 1992: 34.

Anonymous (1995). The Virtual Studio: Computers Come to Tinseltown. The Economist, December 24, 1995: 87.

Augarten, S. (1984). Bit by Bit. New York, Ticknor \& Fields.

Avgerakis, G. (1995). Digital Video Technology: Getting Your Money's Worth. Videography 20(12): 100.

Bamborough, P. (1996). Near Futures. Videograpy 21(4): 163.

Berger, P. (1993). Progress Report, Television. SMPTE Journal 103(4): 216.

Bibby, D. (1996). All systems go for further IT progress. The Dominion Tuesday April 9: IT 19.

Boyd-Bell, R. (1985). New Zealand Television The First 25 Years. Auckland, Reed Methuen Publishers Ltd.

Brown, L. A. (1981). Innovation Diffusion. London/New York, Methuen \& Co.

Brown, S. (1996). Conference Address - PRINZ Conference 1996.

http://www.prinz.org.nz/brown.html Dec 15

Colmar Brunton Research (1996). Production Survey of Film and Television Industry. Wellington, Colmar Brunton Research.

Daniel, W. D. (1977). Introductory Statistics with Applications. Houghton Mifflin Company.

Department of Statistics (1992). A Guide to Good Survey Design. Wellington, Department of Statistics.

Estes, G. (1994). Computers in post-production :possibilities and challenges. SMPTE Journal, 103(3): 157. 
Evanston, K. (1992). Statistics. SYSTAT Inc.

FaEM (1996). Analysis of a Survey Conducted by the Film and Electronic Media Industry Training Organisation. Wellington, FaEM.

Ferster, B. (1995). Making Video Digital. Videography 20(12): 96.

Frambach, R. T. et al. (1996). Adoption of a Service Innovation in the Business Market: an empirical test of supply side variables. University of Ghent, Working Paper.

Frambach, R. T. (1993). An Integrated Model of Organizational Adoption and Diffusion of Innovations. European Journal of Marketing 27(5): 22.

Gatignon, H. \& Robertson, T. (1989). Technology Diffusion: an Empirical Test of Competitive Effects. Journal of Marketing 53: 35.

Hagedorn, J. (1989). The Dynamic Analysis of Innovation and Diffusion: A Study in Process Control. London, Printer Publishers Ltd.

Karshenas, M. \& Stoneman, P. L. (1993). Rank, Stock, Order, and Epidemic Effects in the Diffusion of New Process Technologies: an empirical model. RAND Journal of Economics 24(4): 503.

Kessler, J. A. (1995). Virtual News. Forbes, 155(12): 164.

Lane, R. (1996). The Magician. Forbes, 157(5): 122.

Liebman, S. (1995). Prisa Networks Empowers Workgroup Production. Videography 20(12): 116.

Liebman, S. (1996). Video Networks Transform the Teleproduction Industry. Videography 21(4): 90.

Mast, G. (1986). A Short History of the Movies. New York, Macmillian Publishing.

Metcalfe, S. J. (1988). The Diffusion of Innovation an Interpretative Study. Technical Change and Economic Theory. London, Printer Publishers.

Microsoft Corporation Limited. (1993). Microsoft Excel Help.

Miles, J. \& Fuller, G. (1993). A Strategic Audit of the NZ Film, Television, Commercial and Video Industry. Wellington, Tradenz.

NZ On Air (1995/96). Annual Report. NZ On Air.

Onfilm (1996). The Databook. 
Pank, B. (1996). The Digital Fact Book. 8th Edition. Quantel Limited.

Pierce, R. B. (1996). Cooperative Competition. Videography 21(4): 30.

Pope, A. (1711). An Essay on Criticism. Part II

Porter, M. E. (1996). What is Strategy. Harvard Business Review, 174(6):61

Ricotta, F. J. (1994). Progress Report, Motion Pictures. SMPTE Journal, 103(4): 211.

Rogers, E. \& Agarwala-Rogers, R. (1976). Communication in Organisations. New York, The Free Press : 26.

Rogers, E. M. (1983). Diffusion of innovations. New York, The Free Press.

Rogers, E. M. (1995). Diffusion of Innovations. New York, The Free Press.

Sekaran (1984). Research Methods for Managers: a skill building approach. New York, Wiley.

Shurkin, J. (1984). Engines of the Mind: a History of the Computer. Toronto, J McLeod Limited.

Singley, S. (1990). The Cinema in NZ a Short Survey.

Smith, Peter. (1997). Personal Communication. Director of the Institute for Statistical and Operations Research, Internal Consulting Service, Victoria University of Wellington.

Sowry, C. (1980). Film Making in NZ. Wellington, NZ Film Archive.

SPSS Inc. (1996). Systat Manual. Chicago, SPSS, Inc.

Statistics New Zealand (1996). New Zealand Official Year Book. Wellington, Govt. Printer.

Stephens, R. J. (1984). Public Policy and the NZ Feature Film Industry: an economic appraisal. Wellington, NZ Film Commission.

Stoneman, P. \& Ireland, N. (1983). The Role of Supply Factors in the Diffusion of New Process Technology. Economic Journal 93.

Suydam, M. (1995). Teleproduction Training in the Digital Age. Videography 20(12): 64.

Swain, B. (1992). Not a lot of people know that .... New Scientist December 1992: 44. 
Thomas, W. I. \& Znaniecki (1927). The Polish Peasant in Europe and Amercia. New York, Knopf

Thorne, R. (1996). Professional Vision and Sound Expo 1996 Exhibition Programme. Media Resources Ltd, Southern Exposure Ltd.

Tradenz (1990). The US Market for New Zealand Film, Television and Commercial Production Services. Wellington, Tradenz.

Tradenz (1993/94). Stretching for Growth - Building an Export Strategy for NZ. Wellington, Tradenz.

Tradenz (1994/95). Stretching for Growth - Two Years Into an Eight Year Journey. Wellington, Tradenz.

Tradenz (1995). Tradenz Annual Report. Wellington, Tradenz.

Walker, P. (Ed.) (1991). Chambers Science and Technology Dictionary. W and R Chambers Ltd.

Wyer, J. (1989). The Moving Image: An International History of Film, Television and Video. Oxford, Basil Blackwell Ltd.

Zorpette, G. (1994). An Eye-popping Summer. IEEE Spectrum October 1994: 19. 


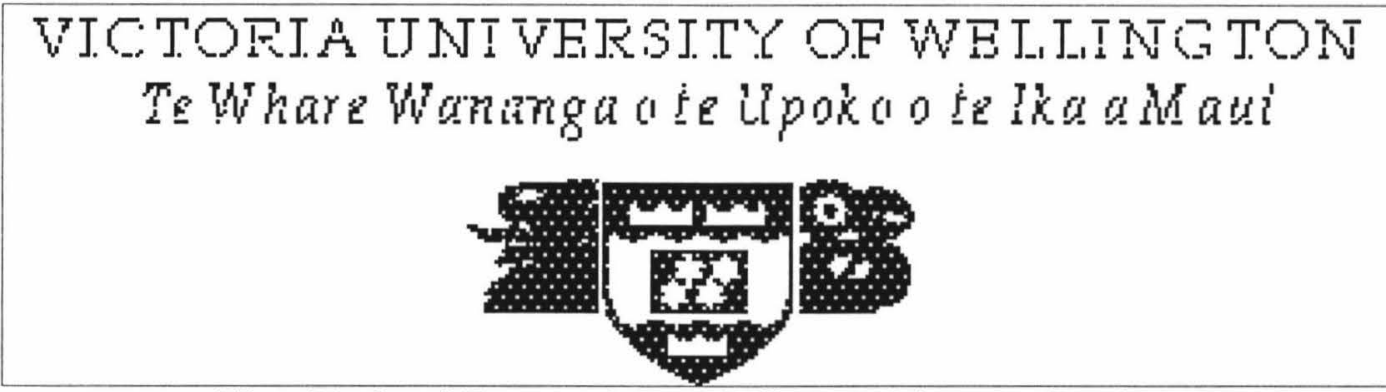

New Zealand Innovation and Competitiveness Project Adoption of digital technology in the NZ motion picture industry

Name

Organisation

Address

Address

$8^{\text {th }}$ August 96

Dear Participant,

In the near future we will start a ground-breaking study of forces relating to the adoption of digital technology in film, television and video in New Zealand.

The New Zealand industry has gained international acceptance as a leading edge exponent of digital technology and special effects. This project will attempt to find out why we take up new technology at the rate we do and then use it to build competitive advantage against much bigger players overseas?

The research team is made up of Rachel McInnes, field researcher, Dr Dai Gilbertson, director of the project and Dr Bob Cavana, research associate.

Rachel has attached a one page statement of the aims of the project and a 'Confidential Response Sheet' that we ask you to return by fax or by fast mail. We will need approximately thirty minutes of your time to complete the research instrument that is currently being tested.

We undertake to ensure complete confidentiality and will send you a report of the findings and recommendations as soon as the analysis is complete. Any confidential data will be destroyed as soon as the data has been entered on the computer and there will be no means of identifying individual responses. You may withdraw from the project at any time.

We do hope that you will become involved in this intriguing study and look forward to receiving your faxed agreement. Please contact me on 044955145 if you have any questions or concerns.

Yours sincerely,

Associate Professor Dai Gilbertson PhD, JP 


\title{
New Zealand Innovation and Competitiveness Project
}

\section{Adoption of digital technology in the NZ motion picture industry}

\section{THE PROJECT IN BRIEF}

The New Zealand film industry is perceived to be highly innovative and competitive, especially in the areas of editing and special effects using digital technology.

This research project seeks to investigate five significant research questions:

What are the characteristics of these highly innovative firms?

How competitive is the motion picture industry?

What affects the rate at which the industry uptakes new technology?

What marketing strategies are used by suppliers of digital technology?

What is your evaluation of digital technology?

Responses to these research questions will be analysed and a report published with the summarised results. This report will be distributed to participants in this project to assist them in thinking through how to maintain competitive advantage.

\section{THE VICTORIA UNIVERSITY PROJECT TEAM}

\author{
Ms Rachel McInnes \\ Dr Dai Gilbertson \\ Dr Bob Cavana
}




\section{NEW ZEALAND INNOVATION AND COMPETITIVENESS PROJECT CONFIDENTIAL RESPONSE SHEET}

\section{CRITERIA TO BE INCLUDED IN THIS STUDY}

There must be at least one full time equivalent person in your firm editing or producing special effects using digital technology for film, television or video.

Please circle ONE response:

- YES we fit the above criteria and will participate

- YES we fit the above criteria but will not participate

- NO we don't fit the above criteria

Signed

Date / /96

Please alter the label if the name and address is incorrect :

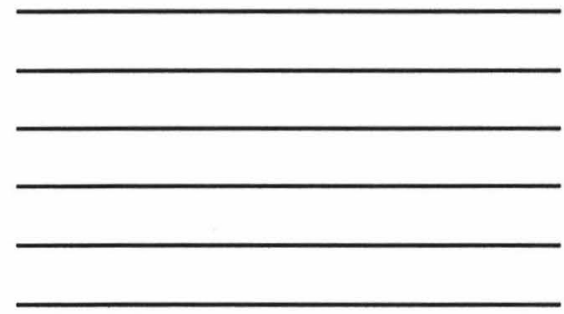

PLEASE SEND THIS FAX RESPONSE SHEET BACK TODAY TO Rachel McInnes

044955253

or by fastest mail to Rachel McInnes

c/o Dr Dai Gilbertson

Management Group

Victoria University

P. O. Box 600 Wellington 


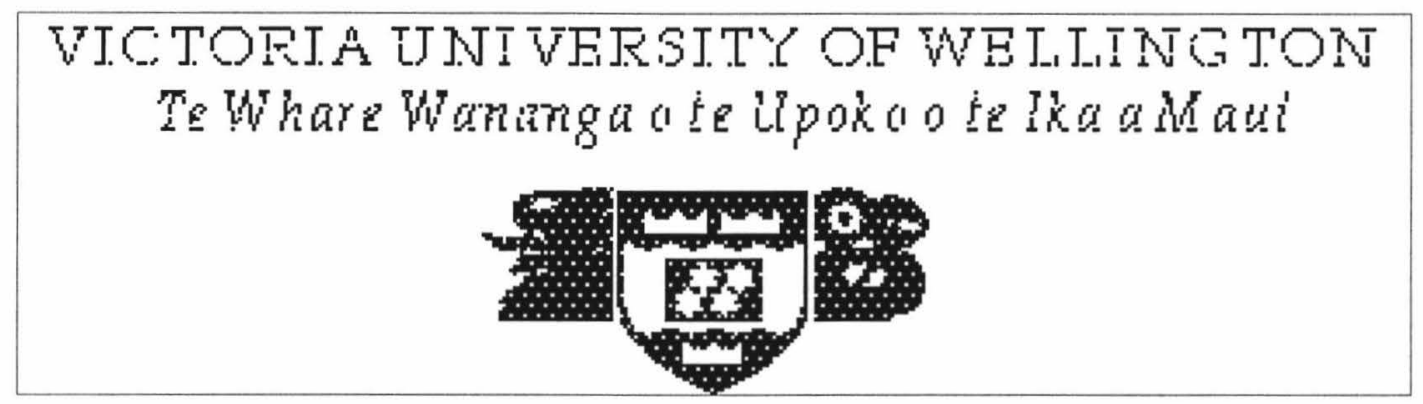

\section{NZ Innovation and Competitiveness Project Adoption of digital technology in the NZ motion picture industry}

Name

Organisation

Address

Address

18th September 1996

Dear Participant,

Thank you for agreeing to participate in this research. Your organisation has been selected to complete a pilot test. The purpose of this pilot test is to correct any problems that may exist with the structure and content of the survey. This should only take around twenty minutes of your time.

Please sign the consent form on the following page before proceeding with the survey. If you have any comments on the wording or content of the survey, feel free to write them on the questions themselves or on the backs of the pages.

Please complete the survey and return it by Friday 27th September in the post-paid addressed envelope enclosed.

We greatly appreciate your participation in this study.

Thanks again for your time.

Regards,

Rachel McInnes

Research Co-ordinator 


\section{VICTORIA UNIVERSITY OF WELLINGTON CONSENT TO PARTICIPATE IN RESEARCH}

\section{NZ Innovation and Competitiveness Project Adoption of digital technology in the NZ motion picture industry}

I have been given and have understood an explanation of this research project. I have had an opportunity to ask questions and have them answered to my satisfaction. I understand that I may withdraw myself or any information I have provided from this project (before data collection is completed), without having to give reasons and without penalty of any sort.

I agree to take part in this research.

Signed.

Name of participants.

Organisation

Date

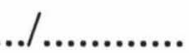


VICTORJ A UN NI VERSITY OF WE I T IING TON Te Whare Wonamga tí ilpoka te Ika a Mau

NZ Innovation and Competitiveness Project Adoption of digital technology in the NZ motion picture industry

Name

Organisation

Address

Address

18th September 1996

Dear Expert,

Thank you for agreeing to look over the pilot survey for this research on the adoption of digital technology in the New Zealand motion picture industry.

Please find the survey enclosed. Feel free to make any comments concerning the wording or content of the survey. Please make these comments on the questions or on the backs of the pages.

When you have looked over the survey please return it to me by Friday 27th September in the post paid return envelope enclosed.

Your help with this research is greatly appreciated.

Regards,

Rachel McInnes

Research Co-ordinator 


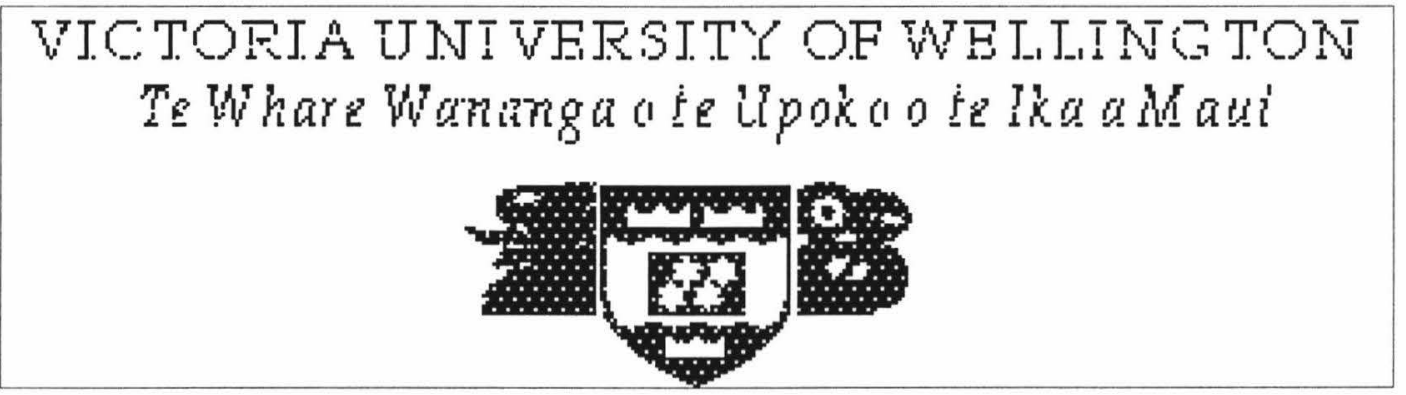

\section{NZ Innovation and Competitiveness Project Adoption of digital technology in the NZ motion picture industry}

Name

Organisation

Address

Address

$8^{\text {th }}$ November 1996

Dear Participant,

Thank you for agreeing to participate in this exciting study of Adoption of Digital Technology in the New Zealand Motion Picture Industry. We genuinely appreciate your valuable assistance. Your honest impressions and opinions are vital to ensure the effective completion of this research.

We remind you the research team will undertake to ensure complete confidentiality. Any confidential data will be destroyed when the data has been entered on the computer and there will be no means of identifying individual responses.

Please complete the attached survey and consent form and return it in the postpaid return envelope provided by Friday 15th November.

Again thank you for your help.

Regards,

Rachel McInnes

Research Coordinator 


\section{Adoption of Digital Technology in the NZ Motion Picture Industry}

\section{IMPORTANT DEFINITIONS PLEASE READ BEFORE PROCEEDING}

\section{Digital technology}

The phrase digital technology is used throughout this survey. Please take it to mean digital technology for the use in editing or special effects for film, television or video. This does not include sound. Also please limit your answers to digital hardware not software. Digital technology includes systems that are internally digital with analog inputs and outputs.

Organisation.

Please take your or our organisation to mean you if you are self employed.

\section{ABOUT YOUR INDUSTRY}

1. Which off the following adjectives would you use to describe your industry? [PLEASE TICK AS MANY ADJECTIVES AS YOU LIKE]
$\square$ Creative
$\square$ Conservative
$\square$ Cooperative
$\square$ Enterprising
$\square$ Competitive
$\square$ Innovative

$\square$ Fickle
$\square$ Developing
$\square$ Advanced
$\square$ Secretive
$\square$ Unique
$\square$ Other................

What do you think of the following statements? [PLEASE CIRCLE ONE OPTION FOR EACH STATEMENT]

2. The management of our organisation often has contact with managers of other organisations in our industry.

$\begin{array}{llllllll}\text { Strongly Agree } & 1 & 2 & 3 & 4 & 5 & \text { Strongly Disagree }\end{array}$

3. In our industry there is a lively network of informal relations between employees of the different firms.
Strongly Agree 1 2 3 4 $5 \quad$ Strongly Disagree

4. To what extent has your organisation discussed the use of digital technology in your industry with organisations outside your industry?
Very High Extent
12
3
$4 \quad 5$
Very Low Extent

5. How would you rate the degree of competition in your industry in New Zealand?
Very High
1
2
45
Very Low

6. How would you rate the degree of competition in your industry overseas? 

Very High
1
2
$3 \quad 4 \quad 5$
Very Low

7. Has the intensity of competition within your industry in_New Zealand increased or decreased during the last 2 years?
Strongly Increased 1
$\begin{array}{llll}2 & 3 & 4 & 5\end{array}$
Strongly Decreased

8. Has the intensity of competition within your industry overseas increased or decreased during the last 2 years?
Strongly Increased 1
2
3
$4 \quad 5$
Strongly Decreased

9. How successful is the New Zealand motion picture industry overseas?
Very Successful
$1 \quad 2$
34
5
Not At All Successful

10. Please comment on Q9.

11. How successful are New Zealand editing and special effects firms overseas?
Very Successful
1
2
34
$5 \quad$ Not At All Successful

12. Please comment on Q11.

13. How many times has your organisation asked for advice from external consultants (ie outside your industry) in the last year?.

\section{ABOUT YOUR MOST RECENT PIECE OF DIGITAL TECHNOLOGY}

When answering questions 14-20 please think specifically of the most recent significant (i.e. with a value greater than $\$ 30,000$ ) item of digital technology your organisation has obtained.

14. Briefly explain the technology and its use.

15. Was this technology leased or purchased?
$\square$ Leased
$\square$ Purchased
$\square$ Other, please specify.

16. What did this digital technology cost (if it was leased what would it have cost to buy)? 
17. When was it obtained? Year. Month.

18. When was this digital technology first available to be obtained by your organisation? Year...... Month.

19. What company was it obtained from?

20. Which of the following categories does this digital technology fit into? [Please tick both if applicable] $\square$ Technology to complete new tasks which in the past did not exist.

$\square$ Technology to complete tasks which in the past were done with different technology.

\section{ABOUT DIGITAL TECHNOLOGY IN GENERAL}

PLEASE now shift your thoughts to a more general discussion of a range of digital technologies for use in editing or special effects for film television or video. To what extent do you agree or disagree with the following statements [PLEASE CIRCLE OR TICK ONE OPTION FOR EACH STATEMENT]

21. Digital technology

Strongly

Agree
Strongly

Disagree

...is better than the technology it superseded (leave if not relevant)

...increased the quality of our on screen output.

...removed limits to the full realisation of our artistic creativity.

...lowered our maintenance costs.

...lowered our operating costs.

...changed the way we work.

...allowed us to expand our business capabilities.

...is simple to use.

...integrated well with existing technologies at our organisation.

...is consistent with our organisation's existing values.

...requires very specific knowledge to be handled well.

...meets our needs

22. Our organisation already had sufficient knowledge to handle digital technology well.

$\begin{array}{llllllll}\text { Strongly Agree } & 1 & 2 & 3 & 4 & 5 & \text { Strongly Disagree }\end{array}$

23. In our organisation people were uncertain about the costs of purchase and use of digital technology.
Strongly Agree
12
$3 \quad 4 \quad 5$
Strongly Disagree

24. In our organisation people were uncertain as to whether digital technology would work well.

$\begin{array}{llllllll}\text { Strongly Agree } & 1 & 2 & 3 & 4 & 5 & \text { Strongly Disagree }\end{array}$

25. It was questionable whether digital technology would be accepted by employees of our organisation.
Strongly Agree
1
2
345
Strongly Disagree 
26. The use of the latest and greatest digital technology projects a positive image to our customers.

$\begin{array}{llllllll}\text { Strongly Agree } & 1 & 2 & 3 & 4 & 5 & \text { Strongly Disagree }\end{array}$

27. The brands of digital technology we use affect the amount of work we receive.
Strongly Agree
12
$\begin{array}{lll}3 & 4 & 5\end{array}$
Strongly Disagree

28. It is possible to have digital technology on trial for a certain period.
Strongly Agree
$1 \quad 2$
3
$4 \quad 5$
Strongly Disagree

29. The fact that technologies in this field change very rapidly makes us hesitant to purchase digital technology for fear the next technological advance would very soon make the purchase redundant.
Strongly Agree
$\begin{array}{lllll}1 & 2 & 3 & 4 & 5\end{array}$
Strongly Disagree

\section{ABOUT COMPANIES MARKETING DIGITAL TECHNOLOGY}

30. Was your organisation approached by company(s) selling digital technology before they marketed the technology?
$\square$ Yes
$\square$ No

31. Has your organisation been approached personally by a representative of a company selling digital technology on the subject of digital technology?
$\square$ Yes
$\square$ No

32. Has a company selling digital technology sent your organisation brochures or any other information on digital technology without an explicit request on behalf of your organisation?
$\square$ Yes
$\square$ No

33. Have employees of your organisation been invited by companies selling digital technology to attend trade exhibitions, conferences or seminars where digital technology would be discussed?

$\square$ Yes $\quad \square$ No

34. Have companies selling digital technology pointed out specific product features of the technology to your organisation?
$\square$ Yes
$\square$ No

35. Has a company selling digital technology pointed out the price of digital technology to your organisation?<smiles>[Mg][Mg]</smiles>

36. Has a company selling digital technology offered your organisation the opportunity to have any digital technology on trial for a certain period?
$\square$ Yes
$\square$ No

37. Have any companies selling digital technology stressed their distinctive capabilities in digital technology to your organisation?
$\square$ Yes
$\square$ No 
38. Have any companies selling digital technology stressed their distinctive international capabilities to your organisation?
$\square$ Yes
$\square$ No

39. Have any companies selling digital technology stressed to your organisation their distinctive capabilities specifically relevant to companies editing or producing special effects for film, television, or video?

$\square$ Yes $\quad \square$ No

40. Have companies selling digital technology pointed out to your organisation other organisations which have purchased this technology?
$\square$ Yes
$\square$ No

To what extent do you agree or disagree with the following statements?[PLEASE CIRCLE ONE OPTION ONLY]

41. Marketers of digital technology have effectively taken into account the needs and wants of our industry in the development of digital technology
Strongly Agree
1
$\begin{array}{lll}3 & 4 & 5\end{array}$
Strongly Disagree

42. The digital technology marketed to our organisation is sophisticated.

$\begin{array}{lllllll}\text { Strongly Agree } & 1 & 2 & 3 & 4 & 5 & \text { Strongly Disagree }\end{array}$

\section{ABOUT YOUR ORGANISATION}

43. Please tell us what is the main purpose or mission of your organisation?

44. What main tasks does your organisation do in the area of editing and special effects?

45. What percentage of your total output of editing and special effects using digital technology is in the following categories? [Please ensure responses add up to 100\%]

$\begin{array}{lll}\text { Film? } & \ldots \ldots \ldots . . . \% & \\ \text { Television } ? & \ldots \ldots \ldots . . . \% & \\ \text { Video? } & \ldots \ldots \ldots . . . \% & \\ \text { Other? } & \ldots \ldots \ldots . . \% & \text { Please Specify. }\end{array}$

46. When did your organisation adopt your first item of digital technology? Year. Month

47. When was this digital technology first available to be obtained by your organisation? Year....... Month. 
48. Which of the following categories did this digital technology fit into? [Please tick both if applicable]

$\square$ Technology to complete a new task which in the past did not exist.

$\square$ Technology to complete tasks which in the past were done with different technology.

49. Compared to other companies in your industry would you consider your organisation high end or low end, in terms of the technology you use?
High End
1
2
$3 \quad 4 \quad 5$
Low End

50. How fast do you feel your organisation adopts digital technology compared to your competitors?
Much Faster

1
2
$3 \quad 4 \quad 5$
Much Slower

51. Please comment on Q50.

52. How many dollars (excluding GST) has your organisation spent on digital technology in the last two years (if leased what would it have cost to buy)?

53. How many items of digital technology has your organisation purchased in the last two years?

54. How many full time equivalent staff members (including yourself if applicable) does your organisation employ?.

55. How many full time equivalent staff members (including yourself if applicable) working with digital technology does your organisation employ?.....

56. What was the total sales revenue of your organisation (excluding GST) in the last financial year?

57. When did your organisation commence business? Year. Month.

58. When did your organisation begin editing or producing special effects? Year. ... Month.

59. In general how long after a new piece of digital technology is introduced to the market does your organisation obtain it? [Tick one option only]
$\square$ 0-3 Months
4- 6 Months
-7-12 Months
$\square 13$ Months - 2 Years
DOver 2 Years

60. In general does your organisation adopt digital technology to a high or low extent?
Very High Extent
1
2
$\begin{array}{lll}3 & 4 & 5\end{array}$
Very Low Extent

What do you think of the following statements? Please leave questions 61 to 63 blank if they are not applicable. [CIRCLE ONE OPTION FOR EACH STATEMENT]

61. In our organisation employees have a high degree of freedom to adjust their activities from one situation to another
Strongly Agree
12
3
$4 \quad 5$
Strongly Disagree 
62. Low levels of management in our organisation have a high degree of freedom to make their own decisions $\begin{array}{lllllll}\text { Strongly Agree } & 1 & 2 & 3 & 4 & 5 & \text { Strongly Disagree }\end{array}$

63. In our organisation important decisions are made only after consultation with employees.
Strongly Agree
$\begin{array}{lllll}1 & 2 & 3 & 4 & 5\end{array}$
Strongly Disagree

64. This organisation is most often ahead of others in buying new digital technology
Strongly Agree
$1 \quad 2$
$\begin{array}{lll}3 & 4 & 5\end{array}$
Strongly Disagree

65. This organisation is eager to purchase or upgrade digital technology on a regular basis.
Strongly Agree
$1 \quad 2 \quad 3$
45
Strongly Disagree

66. Does your organisation normally contact marketers of digital technology before they contact you?

$\square$ Yes $\quad \square$ No

67. To what extent does your organisation invest in the development of new products or services?
Very High Extent
12
$\begin{array}{lll}3 & 4 & 5\end{array}$
Very Low Extent

68. To what extent does your organisation invest in the marketing of new products or services in New Zealand?
Very High Extent
$\begin{array}{llll}2 & 3 & 4 & 5\end{array}$
Very Low Extent

1

69. To what extent does your organisation invest in the marketing of new products or services overseas?
Very High Extent
$\begin{array}{llllll}1 & 2 & 3 & 4 & 5\end{array}$
Very Low Extent

70. What percent of your organisations sales are distributed in the following categories? [Please ensure responses add up to $100 \%]$

Local (ie your city/town)
Rest of New Zealand
Overseas

71. How successful is your organisation in_New Zealand?
Not at all successful
1
2
345
Very successful

72. How successful is your organisation overseas?
Not at all successful
1
2

3
$4 \quad 5$
Very successful

73. How many meetings did your organisation have with marketers of digital technology in which digital technology was discussed in the last year?

74. How many brochures have you read on digital technology in the last year?.....

75. How many trade exhibitions, conferences or seminars on digital technology has your organisation attended in the last year? 


\section{ABOUT YOU}
76. Are you
$\square$ Male $\square$ Female

77. What is your age? $\square$ Under $25 \quad \square 26-35 \quad \square 36-45 \quad \square 45-55 \quad \square$ Over 55

78. What is your job title?

79. How many years have you been with this organisation?

80. Would you like a copy of the summarised results of this research?
$\square$ Yes
$\square$ No

Please add any extra information you feel is relevant to this research. 


\begin{tabular}{|c|c|c|c|c|c|c|c|}
\hline & Item No. & n & mean & stdev & $\min$ & $\max$ & Ptv end \\
\hline \multicolumn{8}{|l|}{ MARKETING STRATEGY } \\
\hline & & & & & & & \\
\hline \multicolumn{8}{|l|}{ Positioning } \\
\hline Pre-announcement & 30 & 37 & 1.57 & 0.50 & 1 & 2 & 1 \\
\hline Personal selling & 31 & 36 & 1.22 & 0.42 & 1 & 2 & 1 \\
\hline Direct mail & 32 & 38 & 1.05 & 0.23 & 1 & 2 & 1 \\
\hline Trade exhibitions & 33 & 37 & 1.00 & 0.00 & 1 & 1 & 1 \\
\hline Communication product features & 34 & 37 & 1.08 & 0.28 & 1 & 2 & 1 \\
\hline Communication price & 35 & 38 & 1.24 & 0.43 & 1 & 2 & 1 \\
\hline \multicolumn{8}{|l|}{ Risk Reduction } \\
\hline Trail period & 36 & 37 & 1.46 & 0.51 & 1 & 2 & 1 \\
\hline \multicolumn{8}{|l|}{ Market Support } \\
\hline Reputation market leader & 37 & 37 & 1.19 & 0.40 & 1 & 2 & 1 \\
\hline Reputation international & 38 & 37 & 1.38 & 0.49 & 1 & 2 & 1 \\
\hline Reputation editing \& FX firms in mpi & 39 & 39 & 1.15 & 0.37 & 1 & 2 & 1 \\
\hline Pointing out users & 40 & 38 & 1.18 & 0.39 & 1 & 2 & 1 \\
\hline \multicolumn{8}{|l|}{ INNOVATION DEVELOPEMENT } \\
\hline \multicolumn{8}{|l|}{ Perceived Customisation } \\
\hline Taking account of needs & 41 & 37 & 2.57 & 1.07 & 1 & 5 & 1 \\
\hline Sophisticated product & 42 & 37 & 1.89 & 0.99 & 1 & 5 & 1 \\
\hline \multicolumn{8}{|c|}{ PERCEIVED INNOVATION CHARACTERISTICS } \\
\hline \multirow{2}{*}{\multicolumn{8}{|c|}{ Relative Advantage }} \\
\hline & & & & & & & \\
\hline Better than previous & $21 a$ & 37 & 1.49 & 0.73 & 1 & 4 & 1 \\
\hline Improved on-screen output & $21 b$ & 39 & 2.00 & 1.05 & 1 & 5 & 1 \\
\hline Removed limits to creativity & $21 \mathrm{c}$ & 39 & 2.10 & 0.85 & 1 & 4 & 1 \\
\hline Lowered costs - maintenance & $21 d$ & 35 & 2.91 & 1.22 & 1 & 5 & 1 \\
\hline Lowered costs - operating & $21 \mathrm{e}$ & 35 & 2.89 & 1.18 & 1 & 5 & 1 \\
\hline Changed work & $21 f$ & 38 & 1.66 & 0.71 & 1 & 3 & 1 \\
\hline Expand business capabilities & $21 \mathrm{~g}$ & 38 & 1.97 & 0.68 & 1 & 3 & 1 \\
\hline \multicolumn{8}{|l|}{ Complexity } \\
\hline Ease of use & $21 \mathrm{~h}$ & 39 & 2.64 & 0.93 & 1 & 5 & 5 \\
\hline Knowledge required & $21 \mathrm{k}$ & 38 & 1.89 & 0.95 & 1 & 4 & 1 \\
\hline \multicolumn{8}{|l|}{ Compatibility } \\
\hline Availibility of equipment & $21 \mathrm{i}$ & 38 & 2.21 & 0.91 & 1 & 4 & 1 \\
\hline Consistent with goals & $21 \mathrm{j}$ & 38 & 1.76 & 0.82 & 1 & 3 & 1 \\
\hline Match with needs & 211 & 39 & 1.67 & 0.74 & 1 & 3 & 1 \\
\hline Availability of knowledge & 22 & 39 & 2.10 & 1.02 & 1 & 5 & 1 \\
\hline \multicolumn{8}{|l|}{ Uncertainty } \\
\hline Costs & 23 & 38 & 3.26 & 1.22 & 1 & 5 & 1 \\
\hline
\end{tabular}




\begin{tabular}{|c|c|c|c|c|c|c|c|}
\hline Operations & 24 & 39 & 3.82 & 1.23 & 1 & 5 & 1 \\
\hline Internal acceptance & 25 & 38 & 4.42 & 0.86 & 2 & 5 & 1 \\
\hline \multicolumn{8}{|l|}{ Observability } \\
\hline Image & 26 & 39 & 1.69 & 0.83 & 1 & 4 & 1 \\
\hline \multicolumn{8}{|l|}{ Trialability } \\
\hline Possibility trial period & 28 & 37 & 2.89 & 1.29 & 1 & 5 & 1 \\
\hline \multicolumn{8}{|l|}{ Expectations Technology } \\
\hline Asks outright & 29 & 38 & 2.58 & 1.29 & 1 & 5 & \\
\hline \multicolumn{8}{|l|}{ ADOPTER CHARACTERISTICS } \\
\hline \multicolumn{8}{|l|}{ Size } \\
\hline FTE & 54 & 39 & 46 & 180 & 0 & 1100 & MAX \\
\hline Sales & 56 & 26 & 9399286 & 39054143 & 0 & 200000000 & MAX \\
\hline \multicolumn{8}{|l|}{ Centralisation } \\
\hline Freedom in activities & 61 & 34 & 2.03 & 1.06 & 1 & 4 & 5 \\
\hline Autonomy lower management & 62 & 30 & 2.43 & 1.07 & 1 & 5 & 5 \\
\hline Joint decision making & 63 & 31 & 2.58 & 1.23 & 1 & 5 & 5 \\
\hline \multicolumn{8}{|l|}{ Receptiveness } \\
\hline early adopter & 64 & 35 & 2.89 & 0.96 & 1 & 5 & 1 \\
\hline eager adopter & 65 & 36 & 2.42 & 1.18 & 1 & 5 & 1 \\
\hline innovativeness & 66 & 37 & 1.43 & 0.50 & 1 & 2 & 1 \\
\hline \multicolumn{8}{|l|}{ NETWORK PARTICIPATION } \\
\hline \multicolumn{8}{|l|}{ Within industry } \\
\hline Contact between mangers & 2 & 39 & 2.97 & 1.25 & 1 & 5 & 1 \\
\hline Contact between employees & 3 & 38 & 2.82 & 1.06 & 1 & 5 & 1 \\
\hline \multicolumn{8}{|l|}{ Outside Industry } \\
\hline Discussion with other than colleagues & 4 & 39 & 2.92 & 1.42 & 1 & 5 & 1 \\
\hline Frequency external advice & 13 & 34 & 3.46 & 9.47 & 0 & 52 & MAX \\
\hline \multicolumn{8}{|l|}{ COMPETTIVE ENVIRONMENT } \\
\hline \multicolumn{8}{|l|}{ Intensity of Competition } \\
\hline Degree of competition - NZ & 5 & 39 & 1.74 & 0.88 & 1 & 5 & 1 \\
\hline Degree of competition - Overseas & 6 & 38 & 1.47 & 0.51 & 1 & 2 & 1 \\
\hline Dynamics of competition - NZ & 7 & 39 & 2.05 & 0.79 & 1 & 4 & 1 \\
\hline Dynamics of competition - overseas & 8 & 37 & 2.03 & 0.80 & 1 & 4 & 1 \\
\hline \multicolumn{8}{|l|}{ Intensity of Innovative activities } \\
\hline R\&D & 67 & 39 & 3.13 & 1.24 & 1 & 5 & 1 \\
\hline Marketing - NZ & 68 & 39 & 3.69 & 1.15 & 1 & 5 & 1 \\
\hline Marketing - overseas & 69 & 39 & 4.18 & 1.10 & 1 & 5 & 1 \\
\hline Distribution of sales - Local & 70 & 36 & 67.92 & 34.02 & 0 & 100 & $?$ \\
\hline Distribution of sales - Rest of NZ & 70 & 36 & 21.44 & 24.61 & 0 & 80 & $?$ \\
\hline
\end{tabular}




\begin{tabular}{|l|l|l|l|l|l|l|l|}
\hline Distribution of sales - Overseas & 70 & 36 & 7.58 & 14.96 & 0 & 70 & $?$ \\
\hline & & & & & & & \\
\hline INFORMATION & & & & & & & \\
\hline & & & & & & & \\
\hline Information & & & & & & & \\
\hline Number of meetings & 73 & 35 & 6.09 & 7.42 & 0 & 35 & MAX \\
\hline Number of brochures & 74 & 29 & 32.33 & 31.86 & 2 & 100 & MAX \\
\hline Number of exhibitions & 75 & 39 & 2.88 & 2.68 & 0 & 10 & MAX \\
\hline & & & & & & & \\
\hline MY HYPOTHESES & & & & & & & \\
\hline & & & & & & \\
\hline Success of NZMPI overseas & 9 & 39 & 2.59 & 0.72 & 1 & 4 & \\
\hline Success of NZ editing and effects firms overseas & 11 & 37 & 2.92 & 0.80 & 2 & 5 & \\
\hline Branding & 27 & 38 & 2.71 & 1.06 & 1 & 5 & \\
\hline Marketing in NZ & 68 & 39 & 3.69 & 1.15 & 1 & 5 & \\
\hline Marketing overseas & 69 & 39 & 4.18 & 1.10 & 1 & 5 & \\
\hline & & & & & & & \\
\hline DEMOGRAPHICS & & & & & & & \\
\hline Film (output) & & & & & & & \\
\hline Television (output) & $45 a$ & 39 & 9.54 & 23.65 & 0 & 100 & \\
\hline Video (output) & $45 \mathrm{~b}$ & 39 & 64.56 & 36.56 & 0 & 100 & \\
\hline Other (output) & $45 \mathrm{c}$ & 39 & 21.56 & 29.65 & 0 & 100 & \\
\hline Success of respondents org - NZ & $45 \mathrm{~d}$ & 39 & 1.54 & 6.50 & 0 & 40 & \\
\hline Success of respondents org - overseas & 71 & 39 & 3.69 & 0.86 & 1 & 5 & \\
\hline Sex of respondent & 72 & 33 & 2.24 & 1.25 & 1 & 5 & \\
\hline Age of respondent & 76 & 39 & 1.10 & 0.31 & 1 & 2 & \\
\hline Years with organisation & 77 & 39 & 2.87 & 0.73 & 2 & 4 & \\
\hline
\end{tabular}

\section{Note on coding:}

For yes/no question; $1=$ Yes and $2=$ No.

For sex; $1=$ Male and $2=$ Female

Ranked questions are coded 1 to 5 . These numbers correspond directly to the number circled in the survey instrument by the responds. For answers which contained tick boxes 1 is the left most box and 5 the right most.

The column entitled "ptv end", shows which value makes the item being investigated true. That is, if we consider Trialability, for which the 'positive end' is 1 , this means the respondent who select yes (which is coded as ' 1 ') feels Trialability exists. 


\begin{tabular}{|c|c|c|c|c|c|c|c|}
\hline & Item No. & n & mean & stdev & $\min$ & $\max$ & Ptv end \\
\hline \multicolumn{8}{|l|}{ MARKETING STRATEGY } \\
\hline & & & & & & & \\
\hline \multicolumn{8}{|l|}{ Positioning } \\
\hline Pre-announcement & 30 & 28 & 1.54 & 0.51 & 1 & 2 & 1 \\
\hline Personal selling & 31 & 27 & 1.22 & 0.42 & 1 & 2 & 1 \\
\hline Direct mail & 32 & 29 & 1.07 & 0.26 & 1 & 2 & 1 \\
\hline Trade exhibitions & 33 & 28 & 1.00 & 0.00 & 1 & 1 & 1 \\
\hline Communication product features & 34 & 28 & 1.04 & 0.19 & 1 & 2 & 1 \\
\hline Communication price & 35 & 29 & 1.21 & 0.41 & 1 & 2 & 1 \\
\hline \multicolumn{8}{|l|}{ Risk Reduction } \\
\hline Trail period & 36 & 28 & 1.46 & 0.51 & 1 & 2 & 1 \\
\hline \multicolumn{8}{|l|}{ Market Support } \\
\hline Reputation market leader & 37 & 28 & 1.14 & 0.36 & 1 & 2 & 1 \\
\hline Reputation international & 38 & 28 & 1.36 & 0.49 & 1 & 2 & 1 \\
\hline Reputation editing \& FX firms in mpi & 39 & 30 & 1.13 & 0.35 & 1 & 2 & 1 \\
\hline Pointing out users & 40 & 29 & 1.17 & 0.38 & 1 & 2 & 1 \\
\hline \multicolumn{8}{|l|}{ INNOVATION DEVELOPMENT } \\
\hline \multicolumn{8}{|l|}{ Perceived Customisation } \\
\hline Taking account of needs & 41 & 28 & 2.57 & 1.10 & 1 & 5 & 1 \\
\hline Sophisticated product & 42 & 28 & 1.86 & 1.04 & 1 & 5 & 1 \\
\hline \multicolumn{8}{|c|}{ PERCEIVED INNOVATION CHARACTERISTICS } \\
\hline \multicolumn{8}{|l|}{ Relative Advantage } \\
\hline Better than previous & $21 a$ & 28 & 1.50 & 0.75 & 1 & 4 & 1 \\
\hline Improved on-screen output & $21 \mathrm{~b}$ & 30 & 2.10 & 1.12 & 1 & 5 & 1 \\
\hline Removed limits to creativity & $21 \mathrm{c}$ & 30 & 2.00 & 0.87 & 1 & 4 & 1 \\
\hline Lowered costs - maintenance & 21d & 28 & 2.82 & 1.31 & 1 & 5 & 1 \\
\hline Lowered costs - operating & $21 \mathrm{e}$ & 27 & 2.78 & 1.19 & 1 & 5 & 1 \\
\hline Changed work & $21 f$ & 29 & 1.62 & 0.68 & 1 & 3 & 1 \\
\hline Expand business capabilities & $21 \mathrm{~g}$ & 30 & 1.93 & 0.69 & 1 & 3 & 1 \\
\hline \multicolumn{8}{|l|}{ Complexity } \\
\hline Ease of use & $21 \mathrm{~h}$ & 30 & 2.63 & 0.96 & 1 & 5 & 5 \\
\hline Knowledge required & $21 \mathrm{k}$ & 29 & 1.97 & 1.02 & 1 & 4 & 1 \\
\hline \multicolumn{8}{|l|}{ Compatibility } \\
\hline Availability of equipment & $21 \mathrm{i}$ & 30 & 2.17 & 0.87 & 1 & 4 & 1 \\
\hline Consistent with goals & $21 j$ & 29 & 1.69 & 0.81 & 1 & 3 & 1 \\
\hline Match with needs & 211 & 30 & 1.70 & 0.75 & 1 & 3 & 1 \\
\hline Availability of knowledge & 22 & 30 & 2.10 & 1.06 & 1 & 5 & 1 \\
\hline \multicolumn{8}{|l|}{ Uncertainty } \\
\hline Costs & 23 & 30 & 3.17 & 1.21 & 1 & 5 & 1 \\
\hline
\end{tabular}




\begin{tabular}{|c|c|c|c|c|c|c|c|}
\hline Operations & 24 & 30 & 3.73 & 1.28 & 1 & 5 & 1 \\
\hline Internal acceptance & 25 & 29 & 4.34 & 0.81 & 2 & 5 & 1 \\
\hline \multicolumn{8}{|l|}{ Observability } \\
\hline Image & 26 & 30 & 1.63 & 0.85 & 1 & 4 & 1 \\
\hline \multicolumn{8}{|l|}{ Trialability } \\
\hline Possibility trial period & 28 & 29 & 3.10 & 1.35 & 1 & 5 & 1 \\
\hline \multicolumn{8}{|l|}{ Expectations Technology } \\
\hline Asks outright & 29 & 29 & 2.66 & 1.37 & 1 & 5 & 1 \\
\hline \multicolumn{8}{|l|}{ ADOPTER CHARACTERISTIC CS } \\
\hline \multicolumn{7}{|l|}{ Size } & \\
\hline FTE & 54 & 30 & 58 & 204 & 0 & 1100 & MAX \\
\hline Sales & 56 & 20 & 2188752 & 4178503 & 0 & 15000000 & MAX \\
\hline \multicolumn{8}{|l|}{ Centralisation } \\
\hline Freedom in activities & 61 & 26 & 2.15 & 1.01 & 1 & 4 & \\
\hline Autonomy lower management & 62 & 25 & 2.40 & 1.08 & 1 & 5 & \\
\hline Joint decision making & 63 & 26 & 2.54 & 1.21 & 1 & 5 & \\
\hline \multicolumn{8}{|l|}{ Receptiveness } \\
\hline early adopter & 64 & 30 & 2.80 & 1.00 & 1 & 5 & 1 \\
\hline eager adopter & 65 & 30 & 2.40 & 1.16 & 1 & 5 & 1 \\
\hline innovativeness & 66 & 28 & 1.36 & 0.49 & 1 & 2 & 1 \\
\hline \multicolumn{8}{|l|}{ NETWORK PARTICIPATION } \\
\hline \multicolumn{8}{|l|}{ Within industry } \\
\hline Contact between mangers & 2 & 30 & 2.97 & 1.30 & 1 & 5 & 1 \\
\hline Contact between employees & 3 & 29 & 2.97 & 1.02 & 1 & 5 & 1 \\
\hline \multicolumn{8}{|l|}{ Outside Industry } \\
\hline Discussion with other than colleagues & 4 & 30 & 2.97 & 1.43 & 1 & 5 & 1 \\
\hline Frequency external advice & 13 & 25 & 3.82 & 10.40 & 0 & 52 & MAX \\
\hline \multicolumn{8}{|l|}{ COMPETITIVE ENVIRONMENT } \\
\hline \multicolumn{8}{|l|}{ Intensity of Competition } \\
\hline Degree of competition - NZ & 5 & 30 & 1.70 & 0.95 & 1 & 5 & 1 \\
\hline Degree of competition - Overseas & 6 & 30 & 1.40 & 0.50 & 1 & 2 & 1 \\
\hline Dynamics of competition - NZ & 7 & 30 & 2.03 & 0.85 & 1 & 4 & 1 \\
\hline Dynamics of competition - overseas & 8 & 29 & 2.03 & 0.87 & 1 & 4 & 1 \\
\hline \multicolumn{8}{|l|}{ Intensity of Innovative activities } \\
\hline$R \& D$ & 67 & 30 & 2.97 & 1.25 & 1 & 5 & 1 \\
\hline Marketing - NZ & 68 & 30 & 3.70 & 1.06 & 2 & 5 & 1 \\
\hline Marketing - overseas & 69 & 30 & 4.13 & 1.14 & 1 & 5 & 1 \\
\hline Distribution of sales - Local & 70 & 27 & 70.74 & 31.31 & 0 & 100 & \\
\hline Distribution of sales - Rest of NZ & 70 & 27 & 20.44 & 22.76 & 0 & 70 & \\
\hline
\end{tabular}




\begin{tabular}{|l|l|l|l|l|l|l|l|}
\hline Distribution of sales - Overseas & 70 & 27 & 8.44 & 16.35 & 0 & 70 & \\
\hline & & & & & & & \\
\hline INFORMATION & & & & & & & \\
\hline & & & & & & & \\
\hline Information & & & & & & & \\
\hline Number of meetings & 73 & 26 & 6.385 & 7.850 & 0 & 35 & MAX \\
\hline Number of brochures & 74 & 23 & 74.174 & 204.263 & 2 & 1000 & MAX \\
\hline Number of exhibitions & 75 & 30 & 2.783 & 2.504 & 0 & 10 & MAX \\
\hline & & & & & & & \\
\hline MY HYPOTHESES & & & & & & & \\
\hline & & & & & & & \\
\hline Success of NZMPI overseas & 9 & 30 & 2.53 & 0.73 & 1 & 4 & \\
\hline Success of NZ editing and effects firms overseas & 11 & 28 & 2.82 & 0.67 & 2 & 4 & \\
\hline Branding & 27 & 29 & 2.72 & 1.16 & 1 & 5 & \\
\hline Marketing in NZ & 68 & 30 & 3.70 & 1.06 & 2 & 5 & \\
\hline Marketing overseas & 69 & 30 & 4.13 & 1.14 & 1 & 5 & \\
\hline & & & & & & & \\
\hline DEMOGRAPHICS & & & & & & & \\
\hline & & & & & & & \\
\hline Film (output) & $45 a$ & 30 & 10.57 & 26.48 & 0 & 100 & \\
\hline Television (output) & $45 \mathrm{~b}$ & 29 & 64.83 & 36.97 & 0 & 100 & \\
\hline Video (output) & $45 \mathrm{c}$ & 30 & 19.20 & 27.98 & 0 & 100 & \\
\hline Other (output) & $45 \mathrm{~d}$ & 30 & 1.83 & 7.37 & 0 & 40 & \\
\hline Success of respondents org - NZ & 71 & 30 & 3.83 & 0.79 & 2 & 5 & \\
\hline Success of respondents org - overseas & 72 & 27 & 2.30 & 1.32 & 1 & 5 & \\
\hline Sex of respondent & 76 & 30 & 1.07 & 0.25 & 1 & 2 & \\
\hline Age of respondent & 77 & 30 & 2.83 & 0.75 & 2 & 4 & \\
\hline Years with organisation & 79 & 30 & 6.00 & 4.91 & 0 & 20 & \\
\hline
\end{tabular}

\section{Note on coding:}

For yes/no question; $1=$ Yes and $2=$ No.

For sex; $1=$ Male and $2=$ Female

Ranked questions are coded 1 to 5 . These numbers correspond directly to the number circled in the survey instrument by the responds. For answers which contained tick boxes 1 is the left most box and 5 the right most.

The column entitled "ptv end", shows which value makes the item being investigated true. That is, if we consider Trialability, for which the 'positive end' is 1 , this means the respondent who select yes (which is coded as ' 1 ') feels Trialability exists. 


\section{Spending On Digital Technology}

As discussed in Chapter 4 (Section 4.4.1) Nine respondents are to be removed before the hypotheses will be tested. However descriptive statistics are given with (Appendix I) and without (Appendix J) the said nine respondents.

On comparing Appendix I and $\mathrm{J}$, it becomes evident that, excluding size characteristics, most means and standard deviations are the same to one or two significant figures.

Table 1: Demographics for Sample Size of 30

\begin{tabular}{|l|c|c|c|c|}
\hline & Respondents & Mean & Total & $\begin{array}{c}\text { Population } \\
\text { estimation }\end{array}$ \\
\hline Dollars spent on digital technology & 26 & $\$ 246,981$ & $\$ 6,421,500$ & $\$ 18,029,613$ \\
No of items of digital technology & 26 & 2.9 & 74 & 212 \\
FTE staff members & 30 & 58.0 & 1741 & 4,236 \\
FTE working with digital technology & 29 & 5.7 & 165.5 & 416 \\
Sales revenue of organisation & 20 & $\$ 2,188,751$ & $\$ 43,775,020$ & $\$ 159,778,823$ \\
\hline
\end{tabular}

Table 2: Demograhpics for Sample Size of 39

\begin{tabular}{|l|c|c|c|c|}
\hline & Respondents & Mean & Total & $\begin{array}{c}\text { Population } \\
\text { estimation }\end{array}$ \\
\hline Dollars spent on digital technology & 29 & $\$ 222,655$ & $\$ 6,456,995$ & $\$ 16,253,815$ \\
Number of items of digital technology & 30 & 2.6 & 78 & 190 \\
FTE staff members & 39 & 45.9 & $1,789.30$ & 3,349 \\
FTE working with digital technology & 37 & 4.8 & 176.55 & 348 \\
Sales revenue of organisation & 26 & $\$ 9,399,286$ & $\$ 244,381,433$ & $\$ 686,147,878$ \\
\hline
\end{tabular}

Table 1 and Table 2 show demographics for; spending on digital technology, items of digital technology, full time equivalent (FTE) staff members, FTE staff members working with digital technology, and sales revenue. The first column in Table 1 and Table 2 show the number of respondents who answered the question. The last column shows a population estimation. Estimations are based on a population size of 73 organisations.

The difference between Table 1 and Table 2 is due to the nine firms who do not hire or purchase their equipment but instead contract their staff to other organisations. Hence there would appear to be an anomaly in the number of respondents for the dollars spent question, in that three of the non purchasers have answered this question. 
It is likely they are answering for what they would have spent or what the firm they are contracting to has spent.

The dollars spent per annum on digital technology by these firms in NZ appears fairly robust at around $\$ 17$ million. The number of items appears robust at around 200 . Notice the estimates for the larger sample size is smaller, this is due to the total being lowered by the nine non purchasers. The estimate of the number of staff employed by the population varies a little between the tables, the non-purchasers tend to be smaller companies (mostly 1 or 2 full time equivalents). Similarly with the FTE working with digital technology.

However note the inclusion of the nine smaller firms does not lower the industry sales revenue in fact it somewhat raises it to $\$ 686$ million. This anomaly is because by far the largest earning respondent, does not own any digital technology but was in fact in the process of purchasing at the time of the research. 


\section{Pearsons and Spearmans}

The numeric and ordinal independent variables were investigated through Pearson's and Spearman's correlations. Spearman's correlation coefficients were calculated through ranking the data and running a Pearsons correlation. This produces the same results as running a Spearmans correlation and is more efficient when many correlation's are required. The statistical package used (SYSTAT) produces twotailed tests. In most cases hypothesis testing required one tailed tests, hence p-values were halved. Results for these tests are shown in Chapter 5.

\section{Chi-square test}

Pearsons chi-square test of independence was carried out for all ordinal dependents and binary independents. The binary data was "yes"/ "no" data.

Larger contingency tables should not have any expected values less than one and more than $20 \%$ of the expected values should be greater than five. This was not the case with any of the tests. Hence all results produced a warning than more than one fifth of the fitted cells were 'sparse'. The only way to remedy this is to combine or omit categories. The first step was to look at the p-values to see which tables indicated any sort of relationship. All tables with p-values less than $10 \%$ where selected and categories were combined to produce a two-way table.

There were four tables with p-values less than $10 \%$. Of these, one had only one respondent under "no". It was deemed not relevant to look any closer at this table as even on combining categories the data would still be 'sparse'. Categories where combined for the remaining three tables to produce two by two tables. The chi-square test is only an approximation and does not work well for small samples. In these cases Fisher's exact test is more appropriate. The Fisher's exact test counts all possible outcomes exactly. Fisher's exact tests were carried out using SYSTAT on the three tables in question. To double check probabilities for Pearsons chi-square and Yates corrected chi-square were also calculated. Yates corrected chi-square is an attempt to adjust the Pearsons chi-square statistic for smaller samples. All probabilities for all three tables were well in excess of ten percent. However much of 
this was due to the effect of combining cells and collapsing the table to a two-way two, hence losing some of the relationships that exist.

The statistical package S-PLUS, is capable of fishers exact tests on tables larger than two way. The three tables with p-values less than ten percent (Pearsons chi-square) where run on S-PLUS. As shown in Table 1, two of the p-values were less than $10 \%$ and one less than 5\%. All three independent variables are the same variable positioning and the same number question, ie 35 .

Table 1: Chi-square associations

\begin{tabular}{|l|l|l|l|}
\hline Independent variable (question number) & 35 & 35 & 35 \\
\hline Independent Variable & Positioning & Positioning & Positioning \\
\hline Dependent variable & T3 & T5 & E5 \\
\hline Pearson Chi-square p-value (SYSTAT) & 0.033 & 0.06 & 0.034 \\
\hline Pearson chi-square value & 8.728 & 9.041 & 8.95 \\
\hline Fishers Exact p-value (SYSTAT) & 0.646 & 0.633 & 1 \\
\hline Fishers Exact p-value (S-PLUS) & 0.0968 & 0.124 & 0.023 \\
\hline Number of observations & 29 & 29 & 29 \\
\hline Cramers V & 0.548 & 0.558 & 0.556 \\
\hline
\end{tabular}

The association could be not tested for question 33, which asked how many trade exhibition respondents had been invited to attend. This was testing the market strategy variable - positioning. This variable could not have its association with time and extend tested as all respondents answered 'yes'.

\section{$\underline{\text { Biserial Correlations }}$}

Associations between the ratio and binary combinations were tested through the Biserial correlation. Question 33, which tests positioning could not be tested for any of the dependent variables as all the respondents answered 'yes'. In two other instances the correlation could not be tested as once the incomplete cases where removed all respondents remaining respondents answered 'yes'. These instances were E4 with question 32 and T1 with question 34. 
There were five associations for which p-values could not be calculated as the correlation coefficient was larger than one. These were E3 with questions 30, 31, 37, 66 and E4 with question 39. 


\begin{tabular}{|c|c|c|c|c|c|c|c|c|c|c|c|}
\hline & Q NO & T1 & T2 & T3 & T4 & T5 & E1 & E2 & E3 & E4 & E5 \\
\hline INNOVATION DEVELOPEMENT & & & & & & & & & & & \\
\hline Perceived Customisation & & & & & & & & & & & \\
\hline Taking account of needs & 41 & + & + & + & + & + & + & - & - & - & + \\
\hline Sophisticated product & 42 & + & + & + & + & + & + & - & - & - & + \\
\hline $\begin{array}{l}\text { PERCIEVED INNOVATION } \\
\text { CHARACTERISTICS }\end{array}$ & & & & & & & & & & & \\
\hline Relative Advantage & & & & & & & & & & & \\
\hline Better than previous & $21 a$ & + & + & + & + & + & + & - & - & - & + \\
\hline Improved on-screen output & $21 b$ & + & + & + & + & + & + & - & - & - & + \\
\hline Removed limits to creativity & $21 \mathrm{c}$ & + & + & + & + & + & + & - & - & - & + \\
\hline Lowered costs - maintenance & $21 d$ & + & + & + & + & + & + & - & - & - & + \\
\hline Lowered costs - operating & $21 e$ & + & + & + & + & + & + & - & - & - & + \\
\hline Changed work & $21 f$ & + & + & + & + & + & + & - & - & - & + \\
\hline Expand business capabilities & $21 \mathrm{~g}$ & + & + & + & + & + & + & - & - & - & + \\
\hline Complexity & & & & & & & & & & & \\
\hline Ease of use & $21 \mathrm{~h}$ & + & + & + & + & + & + & - & - & - & + \\
\hline Knowledge required & $21 \mathrm{k}$ & - & - & - & - & - & - & + & + & + & - \\
\hline Compatibility & & & & & & & & & & & \\
\hline Availability of equipment & $21 \mathrm{i}$ & + & + & + & + & + & + & - & - & - & + \\
\hline Consistent with goals & $21 \mathrm{j}$ & + & + & + & + & + & + & - & - & - & + \\
\hline Match with needs & 211 & + & + & + & + & + & + & - & - & - & + \\
\hline Availability of knowledge & 22 & + & + & + & + & + & + & - & - & - & + \\
\hline Uncertainty & & & & & & & & & & & \\
\hline Costs & 23 & - & - & - & - & - & - & + & + & + & - \\
\hline Operations & 24 & - & - & - & - & - & - & + & + & + & - \\
\hline Internal acceptance & 25 & - & - & - & - & - & - & + & + & + & - \\
\hline Observability & & & & & & & & & & & \\
\hline Image & 26 & + & + & + & + & + & + & - & - & - & + \\
\hline Trialability & & & & & & & & & & & \\
\hline Possibility trial period & 28 & + & + & + & + & + & + & - & - & - & + \\
\hline ADOPTER CHARACTERISTI CS & & & & & & & & & & & \\
\hline Size & & & & & & & & & & & \\
\hline FTE & 54 & - & - & - & - & - & - & + & + & + & - \\
\hline Sales & 56 & - & - & - & - & - & - & + & + & + & - \\
\hline Centralisation & & & & & & & & & & & \\
\hline Freedom in activities & 61 & + & + & + & + & + & + & - & - & - & + \\
\hline Autonomy lower management & 62 & + & + & + & + & + & + & - & - & - & + \\
\hline Joint decision making & 63 & + & + & + & + & + & + & - & - & - & + \\
\hline
\end{tabular}




\begin{tabular}{|c|c|c|c|c|c|c|c|c|c|c|c|}
\hline & Q No. & T1 & T2 & T3 & T4 & T5 & E1 & E2 & E3 & E3 & E4 \\
\hline Receptiveness & & & & & & & & & & & \\
\hline early adopter & 64 & + & + & + & + & + & + & - & - & - & + \\
\hline eager adopter & 65 & + & + & + & + & + & + & - & - & - & + \\
\hline innovativeness & 66 & & & & & & & & & & \\
\hline NETWORK PARTICIPATION & & & & & & & & & & & \\
\hline Within industry & & & & & & & & & & & \\
\hline Contact between managers & 2 & + & + & + & + & + & + & - & - & - & + \\
\hline Contact between employees & 3 & + & + & + & + & + & + & - & - & - & + \\
\hline Outside Industry & & & & & & & & & & & \\
\hline Discussion with other than colleagues & 4 & + & + & + & + & + & + & - & - & - & + \\
\hline Frequency external advice & 13 & - & - & - & - & - & - & + & + & + & - \\
\hline COMPETTIVE ENVIRONMENT & & & & & & & & & & & \\
\hline Intensity of Competition & & & & & & & & & & & \\
\hline Degree of competition - NZ & 5 & + & + & + & + & + & + & - & - & - & + \\
\hline Degree of competition - Overseas & 6 & + & + & + & + & + & + & - & - & - & + \\
\hline Dynamics of competition - NZ & 7 & + & + & + & + & + & + & - & - & - & + \\
\hline Dynamics of competition - overseas & 8 & + & + & + & + & + & + & - & - & - & + \\
\hline Intensity of Innovative activities & & & & & & & & & & & \\
\hline R\&D & 67 & + & + & + & + & + & + & - & - & - & + \\
\hline Marketing - NZ & 68 & + & + & + & + & + & + & - & - & - & + \\
\hline Marketing - overseas & 69 & + & + & + & + & + & + & - & - & - & + \\
\hline Distribution of sales & 70 & & & & & & & & & & \\
\hline INFORMATION & & & & & & & & & & & \\
\hline Information & & & & & & & & & & & \\
\hline Number of meetings & 73 & - & - & - & - & - & - & + & + & + & - \\
\hline Number of brochures & 74 & - & - & - & - & - & - & + & + & + & - \\
\hline Number of exhibitions & 75 & - & - & - & - & - & - & + & + & + & - \\
\hline
\end{tabular}

